\title{
Beaupréau (Maine-et-Loire), la Tufferie - Un atelier de tuilier médiéval dans les Mauges
}

Beaupréau (Maine-et-Loire), la Tufferie - A workshop of medieval tile in the Mauges

Beaupréau (Maine-et-Loire), la Tufferie. Eine mittelalterliche Ziegelwerkstatt im Bereich der Mauges (Maine-et-Loire, Frankreich)

Jean-François Nauleau, Teddy Veron, Xavier Dubillot et Roland Le Guevellou

\section{OpenEdition}

\section{Journals}

Édition électronique

URL : https://journals.openedition.org/rao/3493

DOI : $10.4000 /$ rao.3493

ISSN : $1775-3732$

\section{Éditeur}

Presses universitaires de Rennes

Édition imprimée

Date de publication : 31 décembre 2016

Pagination : 277-310

ISBN : 978-2-7535-5683-6

ISSN : 0767-709X

\section{Référence électronique}

Jean-François Nauleau, Teddy Veron, Xavier Dubillot et Roland Le Guevellou, « Beaupréau (Maine-etLoire), la Tufferie - Un atelier de tuilier médiéval dans les Mauges », Revue archéologique de l'Ouest [En ligne], 33 | 2016, mis en ligne le 31 juillet 2019, consulté le 22 août 2022. URL : http:// journals.openedition.org/rao/3493; DOI : https://doi.org/10.4000/rao.3493 


\title{
Beaupréau (Maine-et-Loire), la Tufferie Un atelier de tuilier médiéval dans les Mauges
}

\author{
Beaupréau (Maine-et-Loire), La Tufferie \\ A Workshop of Medieval Tile in the Mauges
}

\author{
Jean-François Nauleau ${ }^{a}$ et Teddy VERON ${ }^{b}$, \\ avec la collaboration de Patrick Bellanger ${ }^{a}$, Xavier Dubillot ${ }^{a}$ \\ et Roland Le Guevellou ${ }^{\mathrm{a}}$
}

\begin{abstract}
Résumé : L'atelier médiéval de tuilier de la Tufferie a été découvert dans le cadre d'une opération de diagnostic menée sur le territoire de la commune de Beaupréau dans les Mauges (Maine-et-Loire). Il est caractérisé par un enclos annulaire ovoïde d'une vingtaine de mètres de diamètre, dans lequel ont été repérés des impacts de poteau à partir desquels on peut restituer un ou plusieurs bâtiments. Une structure excavée profonde de plus de 2,50 mètres a été en partie dégagée dans ce même périmètre. Dans cette probable cave, a été découverte une motte d'argile crue prête au façonnage des matériaux. À l'extérieur de l'enclos, des fosses profondes de formes variées creusées dans les altérites argileuses pourraient correspondre à des fosses d'extraction. Le caractère limité des investigations n'a pas permis d'identifier le ou les fours de cuisson; néanmoins, de nombreux fragments de parois rubéfiées ont été découverts dans les comblements des fosses externes à l'enclos, permettant de situer approximativement sa position. Concernant l'organisation générale des vestiges repérés, des analogies avec des sites d'habitat contemporains laissent penser

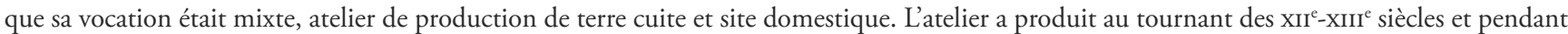
un laps de temps semblant assez bref, des tuiles de différentes natures, dont un dérivé de tegula inattendu dans ce contexte et quelques briques. Des éléments décoratifs remarquables, probablement destinés à un chantier de construction au statut privilégié, ont également été découverts. Seul un commanditaire appartenant à l'élite civile ou religieuse a pu susciter, au travers d'un projet de construction, la production de matériaux en terre cuite très rares à cette époque et recruter des artisans capables de la réaliser. Un travail mené sur le cartulaire de l'abbaye de Saint-Serge et Saint-Bach a permis d'identifier divers groupes sociaux pouvant jouer le rôle de maître d'ouvrage à cette époque. Il a aussi révélé l'existence de plusieurs édifices contemporains de l'atelier, susceptibles d'avoir bénéficié des matériaux qui y ont été produits. Un travail de prospection mené sur ces différents sites, permettra peut-être à l'avenir de collecter d'éventuels restes de ces matériaux.
\end{abstract}

Abstract: The Medieval tile workshop at the Tufferie was discovered during an archaeological evaluation carried out in the area of Beaupréau in the Manges (Maine-et-Loire). The site is characterised by an oval enclosure measuring $20 \mathrm{~m}$ across, which contains postholes that mark out one or several buildings. A 2,5 $m$ deep excavated feature was also found within the same perimeter. A clay motte destined to be made into objects was found in this probable cellar. Outside of the enclosure, deep pits of varying forms had been dug into the clay alterite layers and could be extraction pits. The limited investigations were not able to discover a furnace, but the many fragments of rubified clay construction elements found in the fill of the external pits indicated its approximate position. The general organisation of the features and analogies made with other settlement sites of the same date indicate that the site was not only a terracotta workshop but also a settlement site. The workshop dates to the 12-13 th century and during a short period different tiles, including an unexpected derivative of the tegula and some bricks were produced. Remarkable decorative elements probably destined for the construction site of a privileged dwelling were also discovered. Only a sponsor belonging to the civil or religious upper classes overseeing a large building project could have ordered the production of such rare terracotta objects and employ the craftsman capable of making then. A study of the cartulary of the Saint-Serge and Saint-Bach abbey has enabled the identification of several social groups that could have played the role of the contracting authority at this time. It also revealed the existence of several edifices built at the time of the running of the workshop that could have benefitted from the materials that were produced there. Further prospection on other sites could provide the opportunity for collecting fragments of these materials.

Mots clés : Moyen Âge, enclos annulaire, matériaux de construction, terre cuite architecturale, atelier, production, tuilerie, tuile, brique, décor, poinçon.

Keywords: Middle Ages, enclosure, construction materials, architectural terracotta, workshop, production, tile workshop, tile, brick, decor, punch.

a Inrap, Responsable d'opération - Centre archéologique de Carquefou, 4 rue du Tertre, 44470 CARQUEFOU.

b Enseignant, Chercheur spécialisé dans l'histoire des Mauges. 


\section{INTRODUCTION}

\section{Beaupréau et les Mauges}

Les vestiges ont été mis au jour en 2013 dans le cadre d'un diagnostic réalisé par l'Inrap sur le territoire de la commune de Beaupréau (Le Guevellou, 2013). Celle-ci est située à une quarantaine de kilomètres au sud-ouest de la ville d'Angers dans la région des Mauges (Maine-et-Loire). Ce " pays " rural, situé aux confins de l'Anjou et de la Vendée, dont Beaupréau constitue l'agglomération principale, est un pays de bocage constitué de plateaux peu élevés (environ $100 \mathrm{~m}$ NGF), incisés par des cours d'eau appartenant au bassin versant de la Loire (fig. 1). Ces pénéplaines sont, dans la plupart des cas, recouvertes par d'épais manteaux argileux provenant de l'altération du socle. Cette configuration géomorphologique, propre au développement vendéen et sudligérien du Massif armoricain, a favorisé le développement d'un grand nombre d'activités artisanales liées à la production de terres cuites, tant potières que tuilières et briquetières. Aujourd'hui encore, ces productions perdurent, au stade artisanal (village potier du Fuilet, Maine-et-Loire) ou industriel (groupe Bouyer-Leroux, La Séguinière, Maine-etLoire, leader français de la brique).

\section{Contexte de découverte}

Le diagnostic archéologique, préalable à l'implantation d'un parc d'activités, a été mené sur une emprise de 24,5 hectares de prairies situées à environ 2,5 kilomètres au nord du bourg (fig. 2). Peu de vestiges témoignant d'une occupation humaine ont été repérés sur ce vaste espace ${ }^{1}$, à l'exception de trois entités rattachées à la période médiévale. Un vaste enclos matérialisé par un modeste fossé est probablement à lier à une modeste occupation du haut Moyen Âge, tandis qu'à l'extrême sud-est de la zone investiguée, plusieurs enclos ont été datés de la seconde moitié du Xvi ${ }^{\mathrm{e}}$ ou du début du XvII ${ }^{\mathrm{e}}$ siècle.

Mais les vestiges qui concernent la contribution présentée ici sont apparus à l'extrême ouest de l'emprise près de la ferme de la Tufferie. Sur une surface d'environ 2500 mètres carrés ont été dégagés des structures diverses, à l'intérieur et autour d'un enclos fossoyé annulaire (fig. 4).

De nombreux indices, tenant aussi bien aux vestiges immobiliers qu'aux restes mobiliers, attestent une activité de production de matériaux en terre cuite. En effet, même si aucune structure de combustion n'a été identifiée, de nombreux fragments de parois rubéfiées ont été découverts

1. Un diagnostic réalisé en 2007 et portant sur les trente hectares de la première tranche d'aménagement avait montré la très faible occupation de ce territoire, toutes époques confondues (Dubillot, 2008). dans les comblements des structures fossoyées, associés à de grandes quantités de matériaux en terre cuite.

Compte tenu du devenir du site ${ }^{2}$, et malgré la nature de l'intervention archéologique limitée au seul diagnostic, il a paru nécessaire de présenter ces vestiges dans la mesure où aucun site de production de matériaux en terre cuite médiéval ou moderne n'a jamais été découvert ${ }^{3}$ dans la région des Pays de la Loire.

\section{Contexte archéologique}

Les connaissances archéologiques relatives au territoire communal et aux environs proches sont assez faibles ${ }^{4}$. Les périodes préhistoriques et protohistoriques anciennes sont peu documentées. En revanche, un important oppidum gaulois est attesté au lieu-dit la Ségourie (fig. 2) sur la commune du Fief-Sauvin à environ quatre kilomètres à l'ouest du site de la Tufferie.

L'occupation romaine est elle-même bien avérée avec le développement d'une importante agglomération galloromaine autour de l'oppidum, à la faveur de sa situation sur l'axe majeur Poitiers-Rezé. L'existence d'un cheminement du Fief-Sauvin, à Angers/Juliomagus semble confirmée par les informations tirées de la carte de Peutinger.

Pour l'époque médiévale, aucun vestige n'est attesté sur la commune, même si un certain nombre d'édifices présents dans le bourg ancien ou dans des hameaux peuvent se rapporter au moins à la fin de cette époque. C'est le cas notamment du château de Beaupréau et de plusieurs édifices religieux dont certains ont été détruits, par exemple dans le quartier Saint-Martin (cf. \$6. Les commanditaires potentiels...).

Plus globalement, il est certain que la présence de gisements auriferes sur le territoire communal et à proximité a eu un impact important sur son attractivité. Si l'extraction n'est pas avérée pour l'époque gauloise, elle l'est en revanche pour la période romaine et le haut Moyen Âge sur la commune proche de Saint-Pierre-Montlimart.

2. Une prescription de fouille a été émise par le service régional de l'Archéologie des Pays de la Loire sur une surface de 2500 mètres carrés. Le projet d'aménagement a été modifié afin de le maintenir hors de la zone concernée par la contrainte archéologique (information J.-P. Bouvet, conservateur en chef adjoint, service régional de l'Archéologie des Pays de la Loire).

3. La carte archéologique des Pays de la Loire ne contient aucune entité archéologique renseignée avec des vestiges de ce type. Le site de production potière de la Hardelière à Laval (Mayenne) a livré quelques fragments de tuiles creuses à crochet (Naveau, 1984), mais compte tenu du faible nombre de restes, il n'est pas impossible qu'il s'agisse plutôt de matériaux utilisés dans la structure même du four.

4. Synthèse archéologique réalisée par le service régional de l'Archéologie des Pays de la Loire (J.-P. Bouvet) dans le cadre du projet d'AVAP (Aire de mise en valeur de l'Architecture et du Patrimoine) de la commune de Beaupréau. 


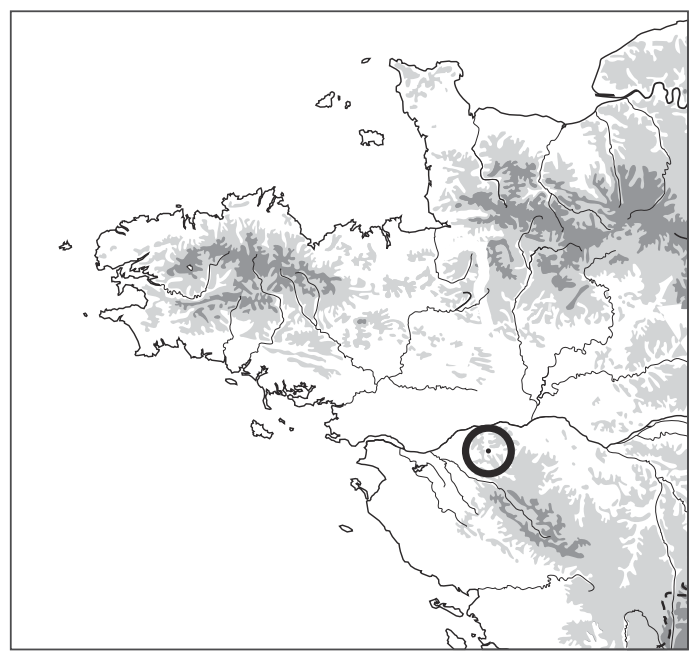

Extension du diocèse d'Angers (Mauges)

Diocèse d'Angers avant le $\mathrm{XI}^{\mathrm{e}}$ siècle

Diocèse de Nantes

Diocèse de Poitiers

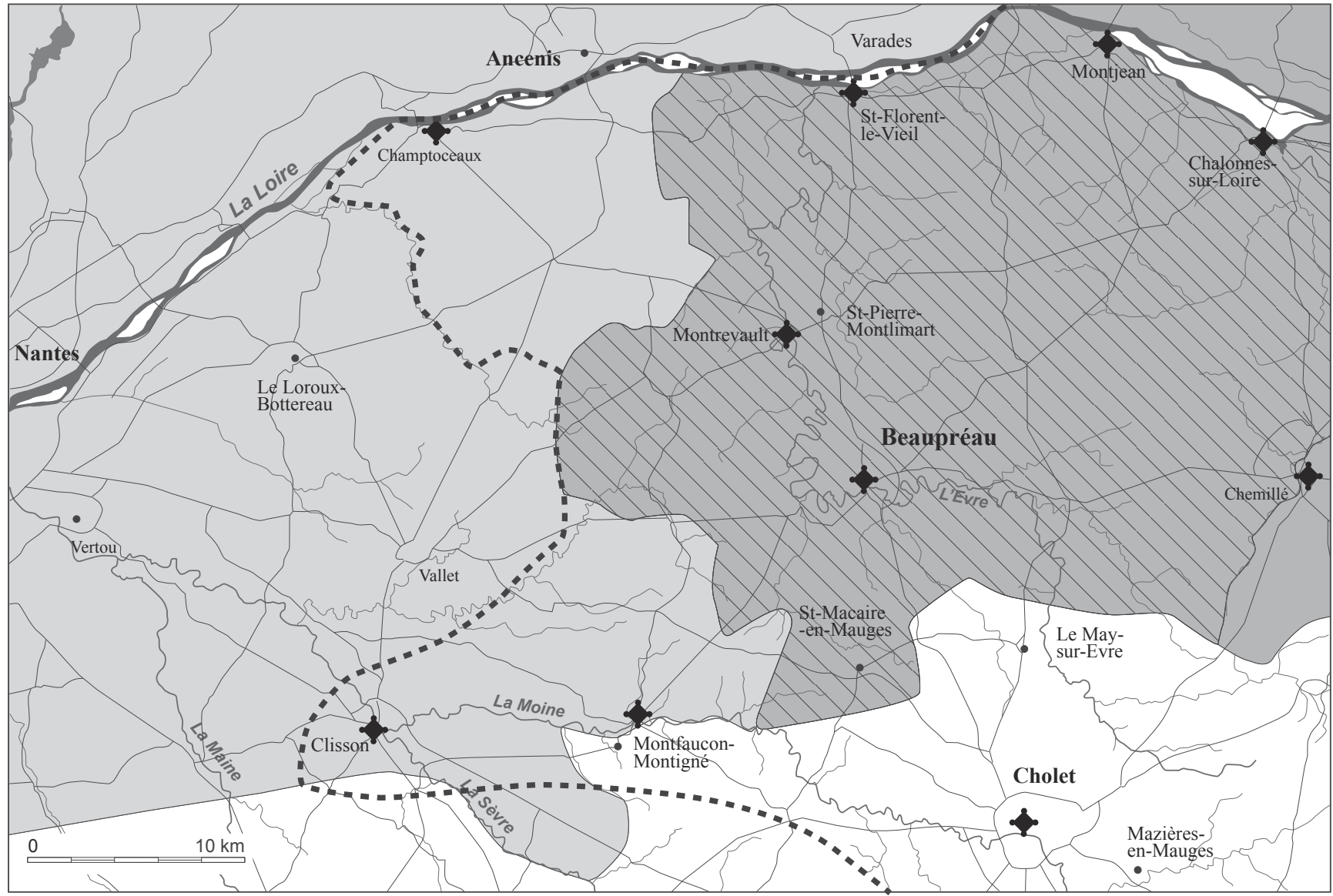

Figure 1 : Les Mauges et les limites territoriales aux XI ${ }^{\mathrm{e}}$ et XII ${ }^{\mathrm{e}}$ siècles (dessin J.-F. Nauleau/T. Veron). Figure 1: Les Mauges and its borders during the 11-12 th century (drawing J.-F. Nauleau/T. Veron). 


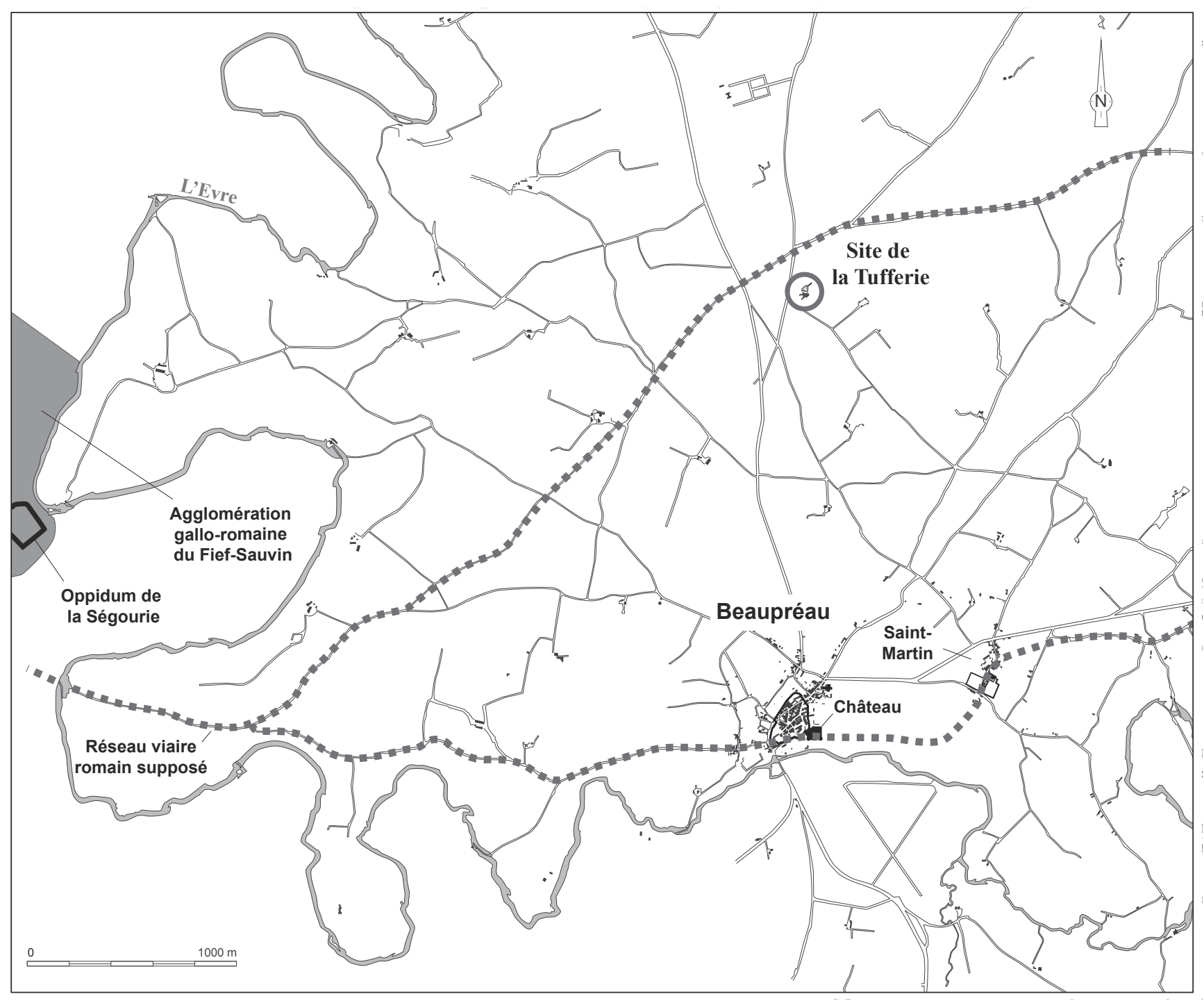

Figure 2 : L'environnement archéologique (dessin J.-F. Nauleau /J.-P. Bouvet).

Figure 2: The archaeological environment (drawing J.-F. Nauleau /J.-P. Bouvet).

\section{Contexte historique régional entre le $\mathrm{X}^{\mathrm{e}}$ et le $\mathrm{XII}^{\mathrm{e}}$ siècle}

Au $\mathrm{X}^{\mathrm{e}}$ siècle, tandis que les incursions normandes se font de plus en plus rares, le petit pagus des Mauges est tiraillé entre le Poitou, sa région d'origine, et le Nantais. Mais c'est finalement le puissant comte d'Anjou Foulques Nerra qui l'annexe dans les premières années du XI ${ }^{\mathrm{e}}$ siècle grâce à une stratégie habile qui mêle ruse et démonstration de force. Prudemment, les Angevins y font construire plusieurs forteresses (Montrevault, Beaupréau, Montfaucon, Montjean, Saint-Florent-le-Vieil, fig. 1) dans lesquelles s'installent des chevaliers parmi les plus fidèles au comte Foulques et à ses descendants, afin d'enraciner la conquête (Véron, 2007).
À partir de ce moment, le destin politique des Mauges est étroitement lié à celui du comté d'Anjou, devenu au cours du XII esiècle le cœur de l'" Empire Plantagenêt ". Objet d'un affrontement à grande échelle avec le royaume de France, l'Anjou est confisqué par Philippe Auguste en 1204 et devient, dix ans plus tard, le théâtre de la bataille de La Roche-aux-Moines (près d'Angers) à l'issue de laquelle le roi d'Angleterre Jean sans Terre perdit définitivement ce comté. L'Anjou échoit dès lors définitivement dans le giron des rois de France et de leur administration qui s'empressent d'ériger à Angers une forteresse.

Même si l'occupation humaine était déjà probablement assez dense dès le $\mathrm{x}^{\mathrm{e}}$ siècle, quelques mentions de défrichements et de fondations nouvelles sont attestées au cours des 
$\mathrm{XI}^{\mathrm{e}}$ et XII ${ }^{\mathrm{e}}$ siècles, en particulier dans le nord-est des Mauges, aux dépens de l'antique forêt du Lattay qui matérialisait la frontière entre Poitou et Anjou, mais aussi en plein cœur du pagus, à Villeneuve, sur la commune du Fief-Sauvin, par exemple. Cet effort pour accroître l'anthropisation est à mettre au crédit des établissements religieux angevins qui ont été assez généreusement lotis dans les Mauges aux XI ${ }^{\mathrm{e}}$ et $\mathrm{XII}^{\mathrm{e}}$ siècles. Il s'agit en particulier des moines de Saint-Serge d'Angers, de Saint-Florent de Saumur, de Marmoutier, près de Tours, et des moniales du Ronceray, qui établissent des prieurés auprès de certaines de leurs possessions, et parfois aussi des bourgs, afin d'attirer des colons et de mettre en valeur les terres qu'ils ont reçues.

C'est grâce à la présence de ces religieux que des actes écrits nous sont parvenus, et notamment les cartulaires de l'abbaye Saint-Serge et Saint-Bach d'Angers ( $\mathrm{XI}^{\mathrm{e}}$ et $\mathrm{XII}^{\mathrm{e}}$ siècles) édités et analysés par Yves Chauvin (Chauvin, 1997).

\section{Cadre géomorphologique local}

Les vestiges sont situés sur un plateau culminant à 117 m NGF dans le secteur d'étude (fig. 3) et représentant la paléosurface d'érosion constituée au début du Cénozoïque. Ce plateau est fortement entaillé par la vallée de l'Èvre, laquelle coule à une altitude de cinquante-cinq mètres au sud-est de Beaupréau et à environ vingt-cinq mètres au nord-est du FiefSauvin. Cette incision principale est relayée vers le plateau par de courts thalwegs alimentés par de petites sources.

Sur le territoire communal, le substrat est constitué d'un massif de micaschiste qui laisse la place, dans la partie sud-ouest, à un ensemble de métabasaltes et de métagabbros, roches métamorphiques d'origine volcanique (Wyns et al., 1998).

Ce substrat métamorphique a été fortement altéré sous climat tropical humide pendant le Cénozoïque, ce qui a généré une importante couverture argileuse recouvrant initialement l'ensemble du massif. Avec le substrat sous-jacent, elle a été ensuite fortement incisée pendant le Quaternaire, au gré des fluctuations du niveau marin se répercutant par érosion régressive en Loire, puis dans la vallée de l'Èvre. Cette couverture ne subsiste plus que sur les plateaux, mais sur les versants nord et est du plateau de Beaupréau, ces argiles ont largement colluvionné, notamment par l'intermédiaire de coulées de solifluxion. Et si, à proximité de Beaupréau, la surface de base de cette couverture est située aux alentours de la cote 100 m NGF, elle peut être localement beaucoup plus basse, vers $50 \mathrm{~m}$ NGF sur ses versants.

Cette couverture argileuse est imperméable et l'eau est stockée en de petites mares disséminées sur le plateau.

Ces argiles sont épaisses de plusieurs mètres. À la base la structuration du schiste est encore souvent visible, tandis qu'en surface l'argilisation est plus poussée. Les minéraux argi- leux présents sont la kaolinite, l'illite et la chlorite avec augmentation de la kaolinite vers la surface. Des blocs de quartz cariés sont souvent rencontrés dans les argiles, soit épars, soit organisés en bandes verticales ou obliques, en remplissage de faille encore en place dans les séries argileuses, attestant alors que cette couverture n'a pas été déplacée latéralement.

Ces altérites argileuses sont fréquemment mélangées avec des limons éoliens déposés au moment des optima glaciaires et avec des résidus de dépôts éocènes, constitués de sables, de graviers et de cailloutis de quartz, qui recouvrent stratigraphiquement la couverture argileuse.

Elles ont été abondamment exploitées par l'industrie briquetière et tuilière à partir de 1850. Dans les communes limitrophes de Beaupréau, celles du Fief-Sauvin, de La Salleet-Chapelle-Aubry et de La Jubaudière ont été concernées.

Le contexte géologique rencontré ici est le même que celui qui caractérise l'important centre potier et tuilier du Fuilet situé à environ onze kilomètres au nord-ouest. Il s'étend sur plusieurs communes, principalement Le Puisé-Doré et Le Fuilet. Celui-ci a connu son apogée vers la fin du XIX ${ }^{e}$ siècle avec près de quarante-cinq fabricants dont quinze tuiliers stricts ${ }^{5}$.

\section{LE SITE : LES VESTIGES IMMOBILIERS}

Lélément structurant le plus marquant est un enclos annulaire dans lequel ont été repérés des trous de poteau, à partir desquels on peut restituer un ou plusieurs bâtiments (fig. 4). Une structure excavée profonde de plus de 2,50 mètres a été en partie dégagée dans ce même périmètre. À l'extérieur de l'enclos, des fosses profondes de formes variées complètent l'ensemble des vestiges.

\section{Des indices concordants orientant vers un site dédié à la production de terres cuites}

Pendant les investigations, plusieurs indices de nature variée ont permis d'orienter les recherches vers une activité de production de matériaux de construction en terre cuite et de reconsidérer l'intérêt du site ${ }^{6}$.

C'est tout d'abord la grande variabilité des matériaux rencontrés qui est inhabituelle si on se place dans le cadre

5. Au Fuilet, l'origine de la production est ancienne puisque, dès 1446, des potiers sont mentionnés au lieu-dit "Les Challonges " (Audouin, 2002, p. 22), et la production de tuiles est très probable dès cette époque. Mais, en l'absence de sources anciennes ou de quelconques investigations archéologiques, il est difficile de dire si on peut faire remonter cette activité de travail de la terre cuite au-delà du $\mathrm{Xv}^{\mathrm{e}}$ siècle.

6. Dans un premier temps, le site ne devait pas faire l'objet d'une prescription de fouille. La mise en évidence d'une activité de production de matériaux en terre cuite a permis de reconsidérer la question (Le Guevellou, 2013, p. 35). 


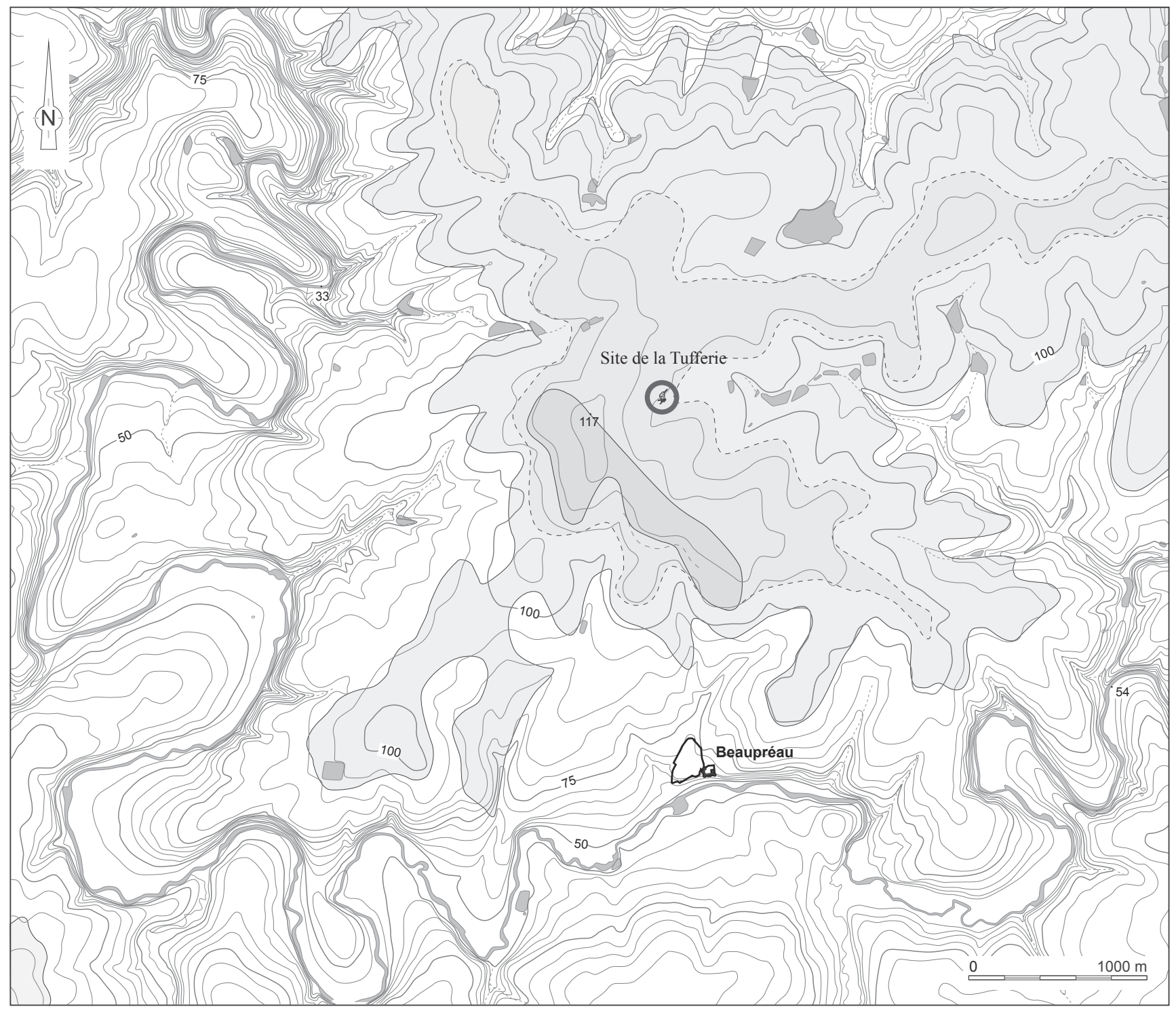

\begin{tabular}{|l|l}
\hline A & Altérites en place ou déplacées des plateaux et des versants : argiles et silts argileux micacés avec fragments et blocs de quartz \\
\hline e & Eocène probable : sables, graviers et cailloutis de quartz plus ou moins argileux, grès et conglomérats \\
\hline $\operatorname{Re}$ & Résiduels ou sous couverture d'altérites colluvionnées (niveau de base initial de l'Éocène)
\end{tabular}

Figure 3 : Contexte géomorphologique simplifié du secteur d'étude (dessin J.-F. Nauleau, d'après Wyns et al., 1998).

Figure 3: Simplified geomorphologic context of the study area (infography J.-F. Nauleau, after Wyns et al., 1998).

d'un site limité à une fonction d'habitat. En effet, pour la période considérée ici $\left(\mathrm{XI}^{\mathrm{e}}-\mathrm{XIII}^{\mathrm{e}}\right.$ siècle), si la présence de matériaux de construction en terre cuite est avérée régionalement (Nauleau, à paraître), celle-ci est timide et ne concerne alors que des édifices à statut privilégié. Dans le cas présent, la découverte de trois types de tuiles, de briques décorées et de tuyaux de canalisation, semble incompatible avec la modestie des vestiges immobiliers mis au jour par ailleurs.

Ensuite, c'est la présence, dans de nombreuses structures fossoyées situées hors de l'enclos, de fragments de terre cuite, parfois de grande taille, fortement altérés par la chaleur, qui retient l'attention : il s'agit à l'évidence de matériaux ayant été mis en œuvre dans une structure de combustion ayant atteint des degrés de température importants, aux alentours de mille degrés.

Enfin et surtout, c'est la découverte dans la structure excavée profonde F.229.2, d'une motte d'argile crue prête au façonnage et mise en réserve, qui atteste d'une activité de production de terre cuite. 


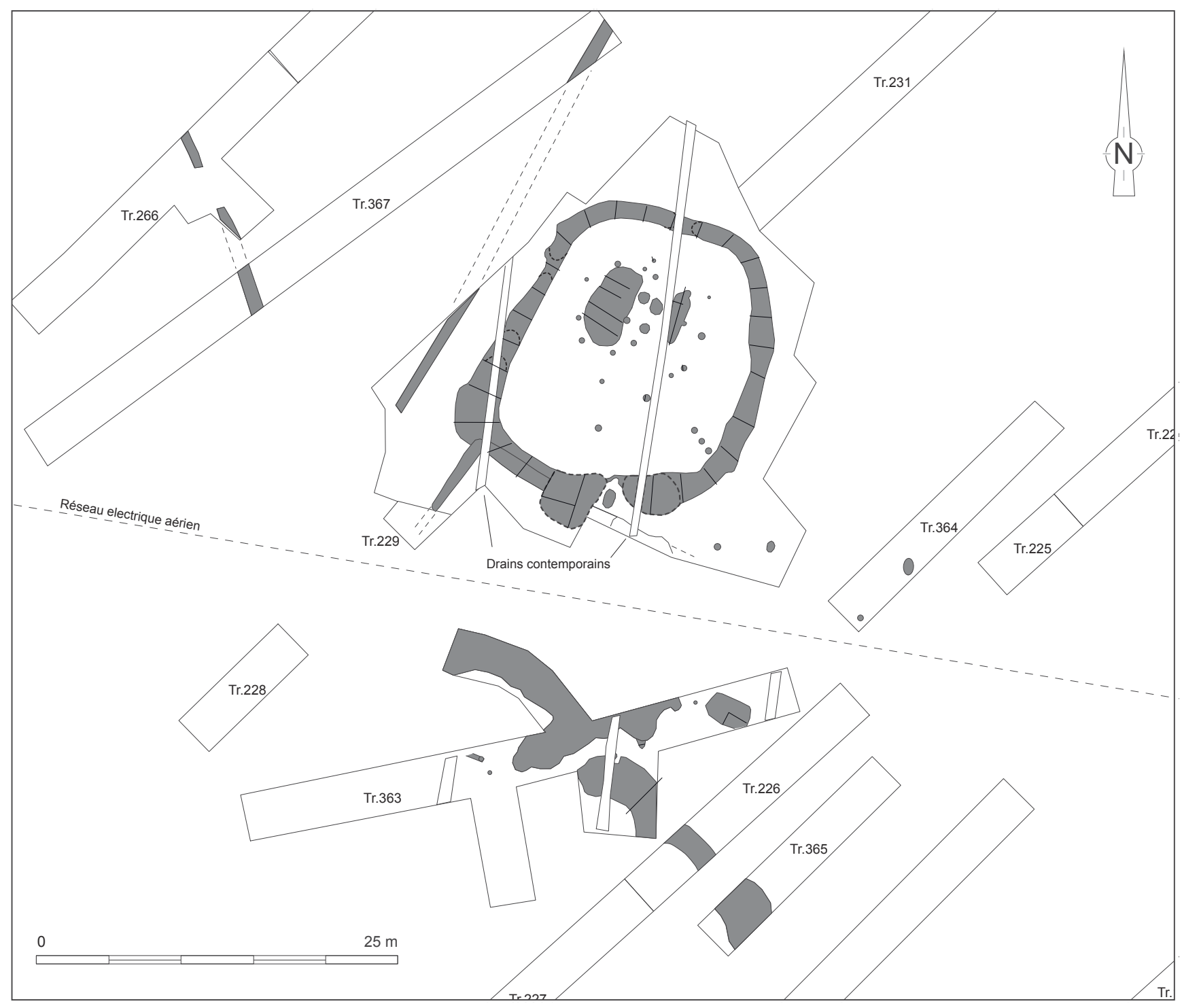

Figure 4 : Beaupréau, plan général des vestiges du site de la Tufferie (dessin D. Fillon, F. Melec, J.-F. Nauleau).

Figure 4: Beaupréau, site plan of the Tufferie (infography D. Fillon, F. Melec, J.-F. Nauleau).

\section{L'enclos annulaire}

Il s'agit d'un enclos ovoïde (F.229.29), d'environ vingt et un mètres de long pour dix-huit mètres de large (fig. 5). Le fossé le matérialisant est irrégulier dans son profil et son gabarit, mais il reste modeste puisqu'il ne dépasse jamais 0,60 mètre de profondeur ${ }^{7}$. Le creusement est quasi interrompu au sud entre les deux fosses F.229.32 et F.229.33 observées dans les sondages 121 et 122/123 : seul subsiste

7. Les profondeurs indiquées dans cet article le seront toujours, sauf mention contraire, par rapport au niveau de décapage. Environ 0,40 mètre de terre arable a été retirée. un petit creusement linéaire de 0,20 mètre de large ${ }^{8}$. Il est possible d'envisager malgré tout une entrée dans l'enclos au moyen d'une modeste passerelle en bois.

Les profondeurs enregistrées sur le tracé du fossé sont très variables, et la série de sondages effectués a révélé les brusques variations de profil de creusement. Ainsi, à deux reprises, entre les sondages 106 et 107 d'une part, et entre les sondages 111 et 112 de l'autre, des seuils ont été observés qui limitent la puissance du creusement à environ 0,20 mètre (fig. 5). Ils ne semblent pas constituer des aménagements spécifiques, mais témoignent plutôt des diffé-

8. Peut-être plus large initialement si on restitue le niveau de sol d'origine. 


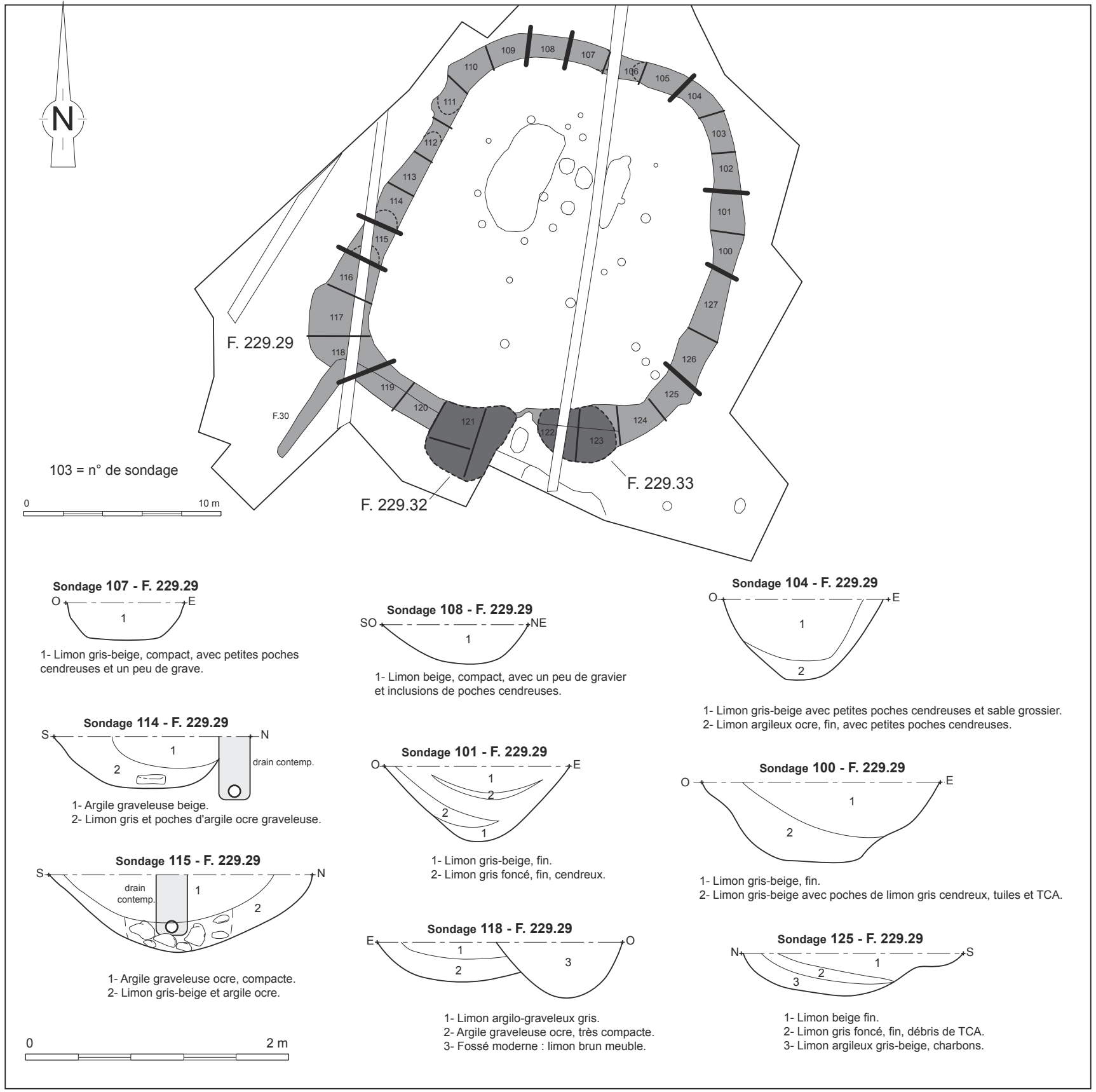

Figure 5 : Beaupréau, site de la Tufferie, coupes des comblements du fossé d'enclos F.229.29 (dessin J.-F. Nauleau).

Figure 5: Beaupréau, the Tufferie site, sections of the ditch fill F.229.29 (infography J.-F. Nauleau).

rentes « campagnes » de creusement. En tout état de cause, le fossé possède un gabarit très modeste.

Son comblement est homogène sur l'ensemble du tracé avec présence à la base d'un niveau argileux ocre-beige et en partie haute d'un dépôt limono-argileux gris-beige. Seul le tronçon nord-ouest entre les sondages 106 et 111 fait exception; le limon argileux beige de surface est remplacé par un sédiment nettement plus sombre. Les informations enregistrées dans le comblement du fossé sont en défini- tive maigres : la présence d'un niveau basal plus argileux est liée au phénomène de lessivage, classique dans ces terrains d'altérites argileuses. L'ensemble des comblements montre une histoire sédimentaire linéaire sans témoignage de remaniement manifeste ${ }^{\text {. }}$.

9. Mentionnons cependant dans la partie sud de l'enclos, entre les sondages 118 et 121, l'installation d'un petit fossé (F.229.30) daté de l'époque moderne. 


\section{Les fosses « puisards »}

Dans la partie sud de l'enclos, de part et d'autre de l'interruption, le fossé est en relation avec deux fosses nettement plus profondes (fig. 6 et 7 ).
À l'est, dans le sondage 123, la coupe réalisée dans la fosse F.229.33 a révélé les dimensions importantes du creusement : il s'agit d'une structure oblongue de 2,80 par 2,50 mètres et profonde de 1,60 mètre. Son comblement est à dominante argilo-sableuse dans les premières unités

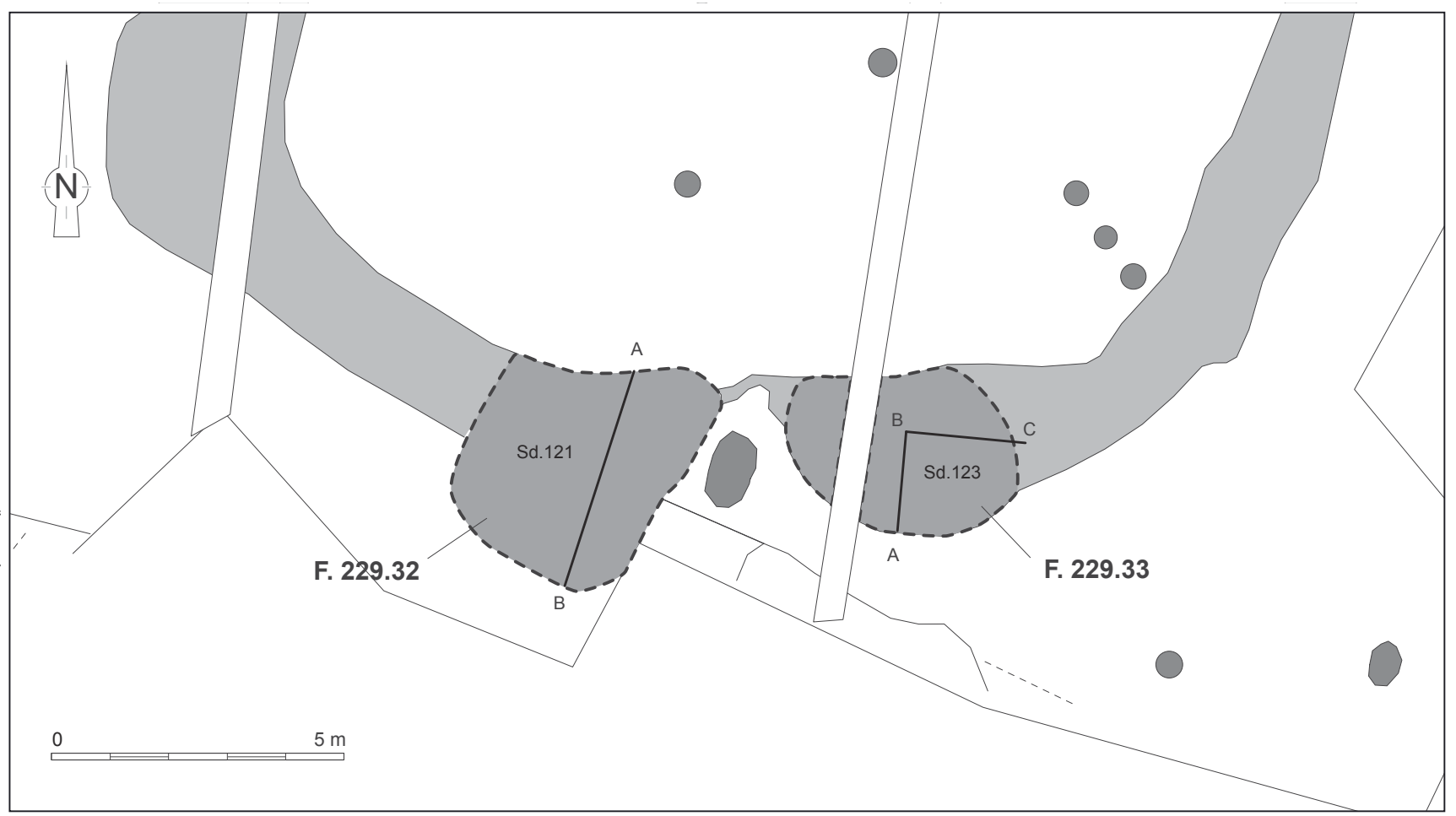

F. 229.33

A

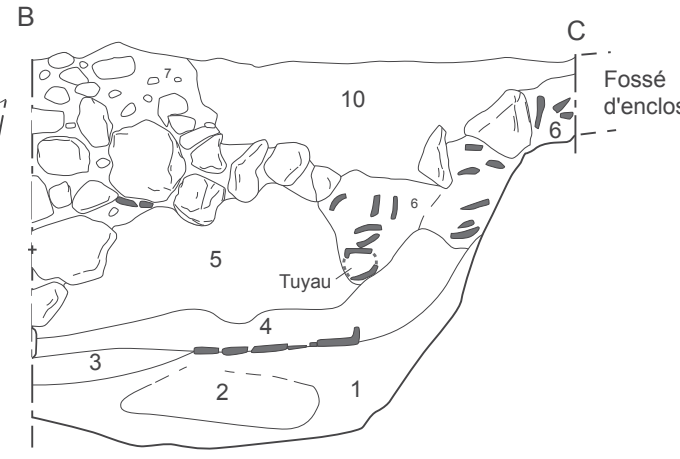

1- Sédiment sablo-argileux orange à rouge

2- Poches de sédiment sablo-argileux gris clair à gris foncé

3- Sédiment argileux et peu sableux + rares graviers de quartz

- Sédiment sablo-argileux hétérogène marron à gris

5- Sédiment argilo-sableux marron-jaune

6 - sédiment sableux marron-gris avec TCA

7- Blocs de quartz.

8- Sédiment sablo-argileux marron tacheté gris avec gravier

9- Isédiment sableux gris avec TCA

10- Sédiment sablo-argileux marron, homogène et compact.

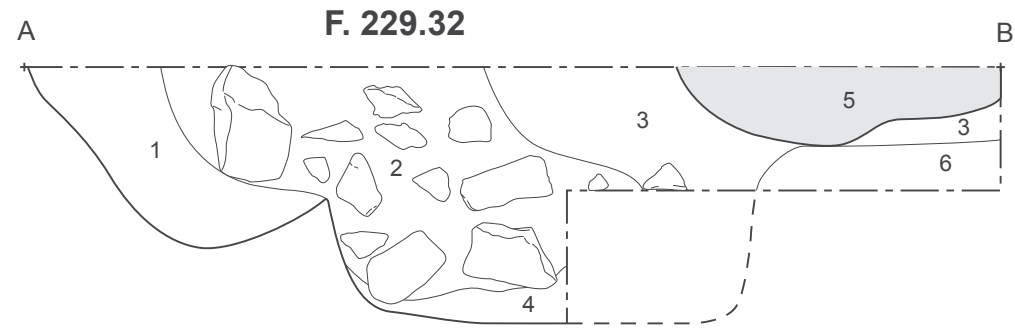

B

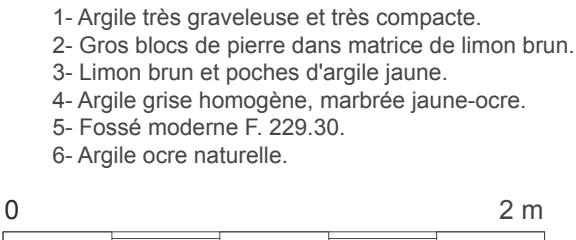

Figure 6 : Beaupréau, site de la Tufferie, coupes des fosses puisards situées aux extrémités de l'enclos annulaire (dessin J.-F. Nauleau). Figure 6: Beaupréau, the Tufferie site, sections of the sump pits located at both ends of the enclosure (infography J.-F. Nauleau). 


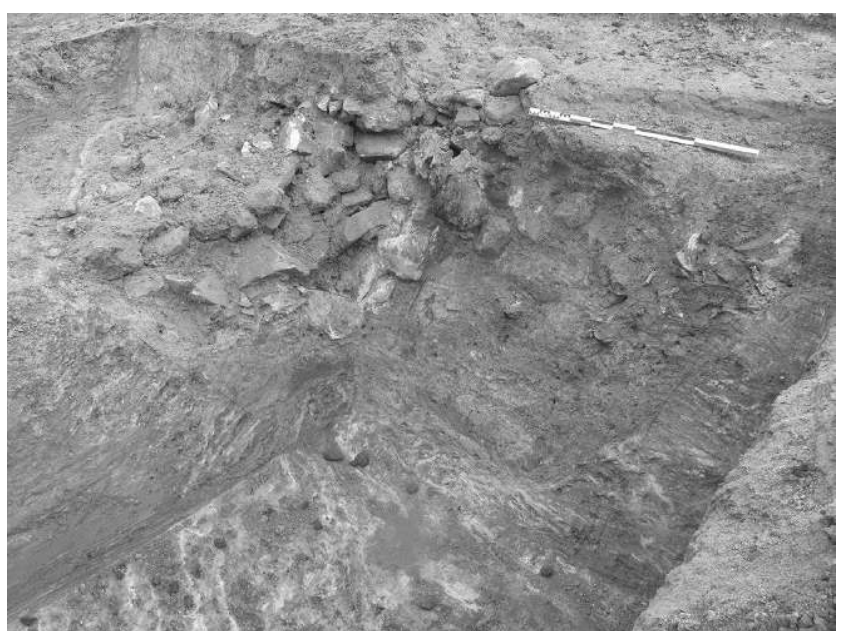

Figure 7 : (Voir planche couleur XXV) Beaupréau, site de la Tufferie, sondage 123, coupe de la fosse F.229.33 située à l'extrémité du fossé d'enclos F.229.29. (cliché R. Le Guevellou).

Figure 7: (Voir planche couleur XXV) Beaupréau, the Tufferie site, trench 123, section of the pit F.229.33 situated at the end of the ditch of the encosure F.229.29. (photo R. Le Guevellou).

stratigraphiques (US 1 à 4), tandis qu'en partie haute, de très nombreux blocs pluridécimétriques sont présents. Il s'agit de grès saccharoïde blanc fin et de conglomérats hétérogènes cimentés par des oxydes de fer et de manganèse. Ces deux roches, rencontrées dans les argiles, proviennent de la couverture Eocène-Pliocène surmontant les argiles altéritiques.

L'étude de la transition entre le fossé d'enclos et la fosse n’a pas révélé de rupture stratigraphique, la continuité des comblements semblant avérée. Les deux structures paraissent donc fonctionnellement liées et partagent une histoire commune.

À l'ouest, dans le sondage 121, la fosse F.229.32 présente un gabarit plus modeste, une longueur de trois mètres, une largeur de deux mètres, et une profondeur d'un mètre. Le log stratigraphique relevé dans les comblements est identique à celui de la première fosse, mais avec un niveau inférieur argilo-sableux gris moins épais. La zone de transition avec le fossé d'enclos n'a été étudiée que succinctement; malgré cela, une continuité stratigraphique avec le fossé a été observée.

Dans la première fosse F.229.33, de nombreux fragments de matériaux en terre cuite figurent dans les unités stratigraphiques situées à la base du creusement. Parmi ces restes, au moins deux tuyaux de canalisation ont été observés en coupe (et prélevés) dans la partie est du sondage. Leur disposition à l'horizontale et orientée vers le fossé d'enclos, laisse penser qu'ils étaient probablement en place et qu'ils assuraient le transfert des eaux de ruissellement entre le fossé et la fosse.
Dans ce même sondage, en partie ouest, la quantité et la disposition de certains blocs sont telles qu'il est possible d'envisager l'existence d'un parement grossier chemisant et protégeant le creusement.

La structuration générale serait donc celle de deux fosses assez profondes, grossièrement parementées et connectées au fossé, au moins dans un cas, par l'intermédiaire de tuyaux de canalisation en terre cuite posés au travers du parement à la base du creusement.

La position altimétrique du fond du creusement montre que ce fossé d'enclos est situé sur un plan très légèrement incliné du nord/nord-ouest vers le sud/sud-est. Cette pente est modeste puisqu'on passe de $106 \mathrm{~m}$ NGF au niveau du sondage 109 à 105,1 m NGF dans le secteur des sondages $121 / 123$.

Ces différents éléments montrent que le fossé, en dehors de sa fonction de délimitation, a joué un rôle de drainage et de captage des eaux de ruissellement. La déclivité constatée, même faible, permet un transfert en direction des deux puisards dans lesquels l'eau pouvait être stockée. Notons qu'un puisard identique connecté au fossé d'enclos a été observé sur le site d'habitat des Tardivières à Tiercé (Maine-et-Loire; Guérin, Pétorin, 2006).

Dans le cadre d'un artisanat de la terre cuite, le besoin en eau est important afin de régler au mieux la proportion en eau dans les terres à pétrir. Dans " l'Art du tuilier et du briquetier ", un petit fossé curviligne (alimenté par un puits) est décrit comme « rigole par laquelle l'eau se rend dans de petits bassins où les ouvriers la puisent " (Duhamel du Monceau, Fourcroy et Gallon, 1763. VI). Compte tenu de la saisonnalité de la production ( $\mathrm{cf}$. $\$ 6$. Le site et ses marqueurs fonctionnels...), la question de la ressource en eau est primordiale.

\section{Les structures internes}

\section{Une vaste fosse peu profonde (F.229.1)}

Dans la partie nord-ouest de l'enclos (fig. 4), a été dégagée une fosse longue de 5,40 mètres, large de 2,70 mètres et profonde au maximum de 0,50 mètre (fig. 8 ). Le sondage manuel réalisé dans sa partie nord a montré l'existence d'un petit massif de blocs de pierre, large d'environ 0,50 mètre, flanquant le bord est du creusement de la fosse; il n'a pas été retrouvé dans le sondage sud. Le comblement est constitué d'un limon argileux accompagné d'un cailloutis, qui ne donne pas d'indication particulière concernant son histoire.

Ce creusement est ceinturé par un ensemble d'une douzaine de trous de poteau de taille modeste. Une dizaine d'entre eux (F.3, F.4, F.5, F.6, F.7, F.14, F.10, F.11, F.18, F.13) pourrait constituer les poteaux porteurs d'un bâtiment 


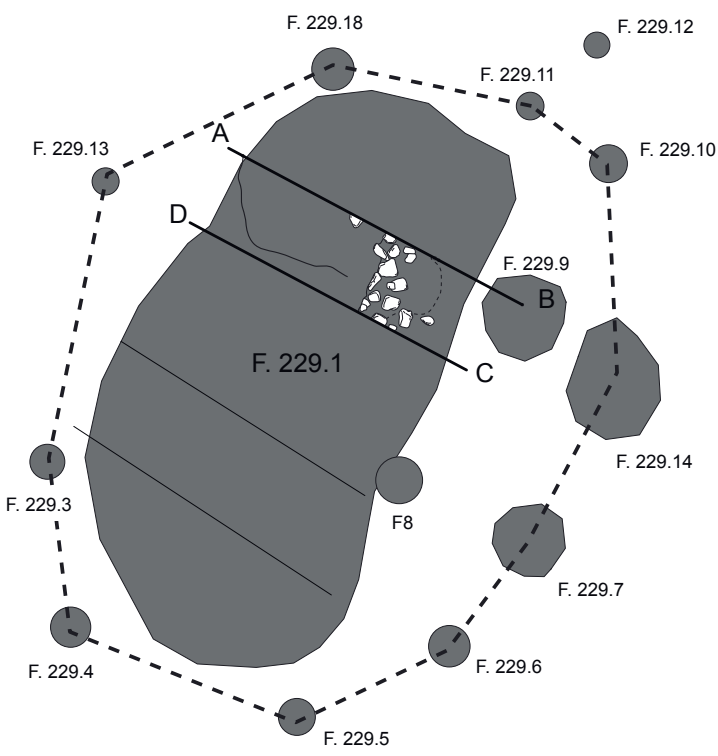

0
NO

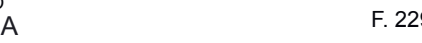

F. 229.1

SE

$\mathrm{B}$

$+$

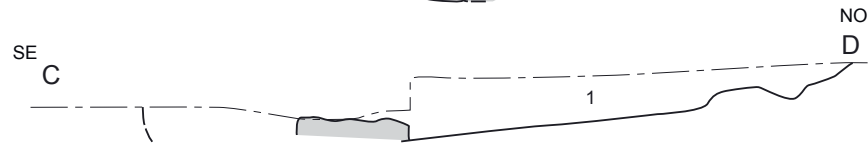

1- Sédiment sableux marron à brun, homogène et meuble avec un peu de gravier. 2- Sédiment sableux marron tacheté beige, homogène et meuble avec gros gravier.

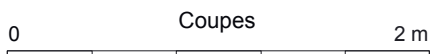

Figure 8 : Beaupréau, site de la Tufferie, la fosse F.229.1 et son cortège de poteaux périphériques (dessin J.-F. Nauleau). Figure 8: Beaupréau, the Tufferie site, pit F.229.1 and its peripheral posts (infography J.-F. Nauleau).

polygonal lié au creusement central. Cependant, leur disposition est telle que son architecture est difficile à restituer et que son existence même reste hypothétique.

Cette structure composée d'une partie excavée (environ quatorze mètres carrés) et d'un ensemble périphérique de poteaux (environ vingt-six mètres carrés) est difficile à comprendre. Ce type de vestige est assez bien connu pour l'époque médiévale et est interprété en général comme bâtiment excavé à structure sur poteau; mais ce genre de structure se rencontre plutôt dans une fourchette chronologique $\mathrm{VII}^{\mathrm{e}}-\mathrm{X}^{\mathrm{e}}$ siècles, et dans la région, aucune n'est pour l'heure connue après l'an Mil (Valais, 2012a, p. 95). Par ailleurs, dans tous les cas recensés, les poteaux sont situés dans l'emprise du creusement et non rejetés à l'extérieur. La présence d'un petit muret flanquant un des bords du creusement n'entre pas non plus dans le schéma habituel. Enfin, les plans "à pans coupés ", s'ils sont assez fréquents pour les périodes laténiennes et romaines, sont plus rares pour le Moyen Âge.

Dans le cadre d'une autre hypothèse fonctionnelle, ce type de fosse évoque, d'un point de vue morphologique, des bassins rencontrés à l'époque moderne dans les ateliers liés à la terre cuite, et dédiés au foulage de l'argile, comme à SoiransFouffrans (Côte-d'Or; Charlier, 1994) ou à Grisolles (Aisne; Galmiche et al., 2010). Dans les Mauges, ces « marchoirs » se rencontrent encore dans certains ateliers (Audouin, 2002, p. 24). Ils étaient utilisés durant la première étape de travail de l'argile et permettait l'homogénéisation de la terre, l'ajout éventuel d'eau et le retrait des éléments siliceux les plus gros ainsi que des éléments organiques (racines). L'énergie animale pouvait être utilisée au cours de cette phase.

Mais, compte tenu du caractère incomplet des investigations archéologiques, cette hypothèse ne peut être davantage étayée; celle d'un bâtiment reste malgré tout privilégiée, avec les réserves émises précédemment.

\section{Une structure excavée très profonde (F.229.2)}

En parallèle et à environ trois mètres à l'est de la fosse F. 29.1, se développe une structure étroite, longue de 3,90 mètres et large de 1,20 mètre (fig. 4 et 9). Une fouille manuelle a été engagée dans un premier temps, puis poursuivie avec des moyens mécaniques pour des raisons de sécurité, la fosse se développant en sape sur son flanc ouest (fig. 9 et 10). La fouille n'a pas atteint le fond de la structure, malgré un sondage atteignant 2,60 mètres.

La fouille de sa partie supérieure a mis en évidence, à deux mètres de profondeur, deux petits creusements ménagés dans le substrat argileux et situés en vis-à-vis dans les parois ouest et est de la structure. Ils étaient très probablement destinés à accueillir une pièce de bois horizontale. Profond 


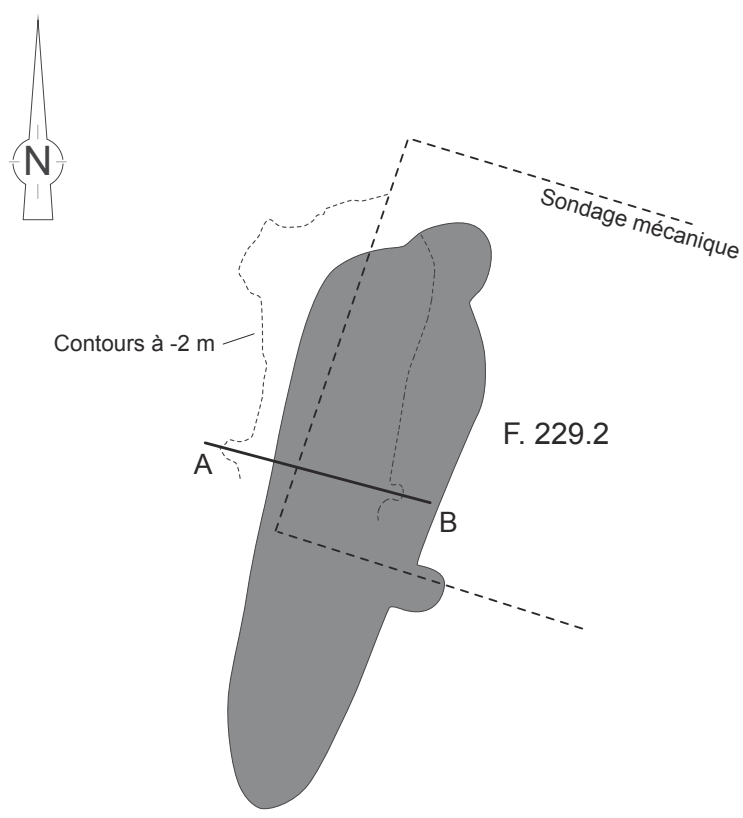

0 $5 \mathrm{~m}$

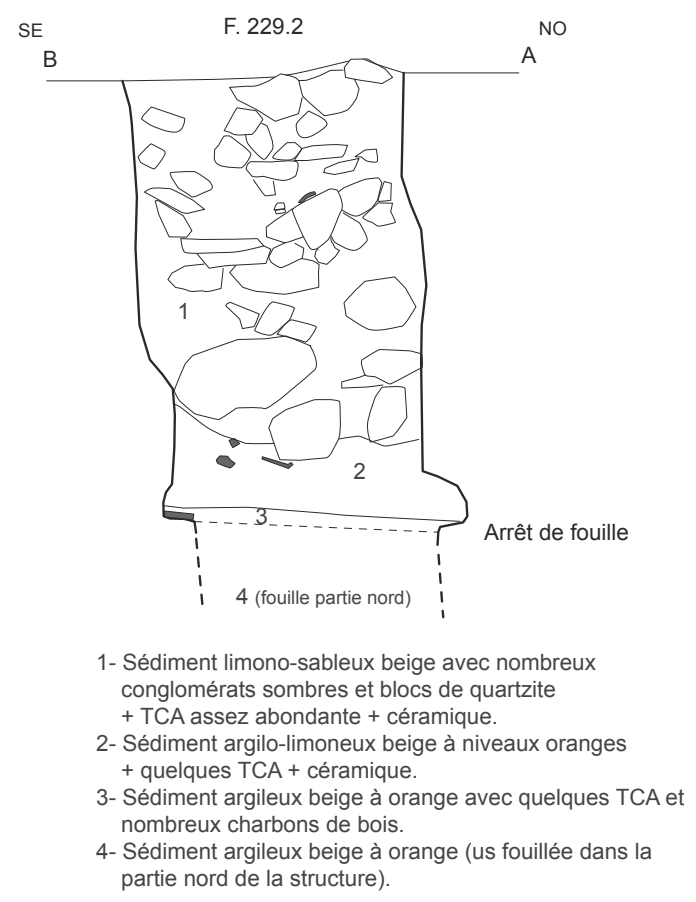

$2 \mathrm{~m}$

Figure 9 : Beaupréau, site de la Tufferie, la structure excavée F.229.2 (dessin J.-F. Nauleau).

Figure 9: Beaupréau, the Tufferie site, the excavated feature F.229.2 (infography J.-F. Nauleau).

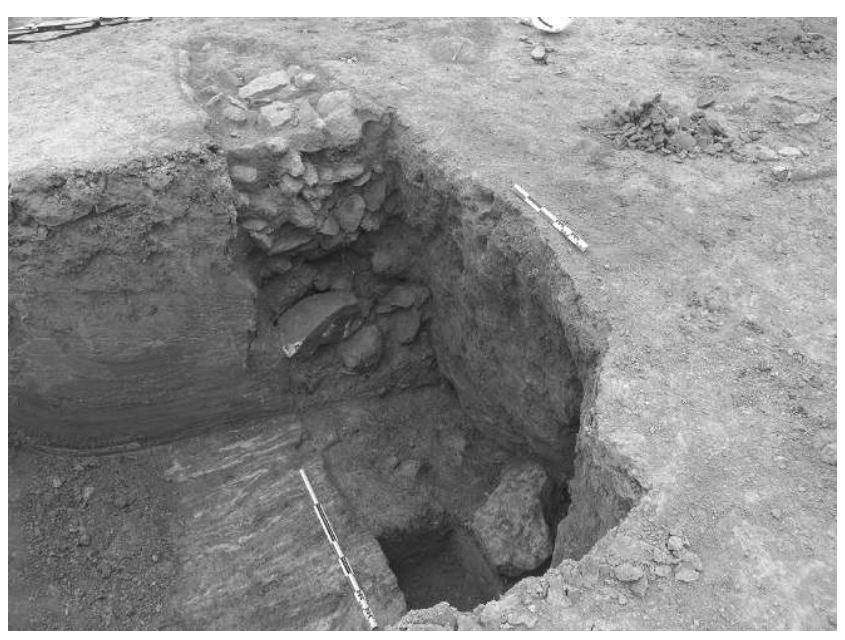

Figure 10 : (Voir planche couleur XXV) Beaupréau, site de la Tufferie, vue de la structure excavée F.229.2 vers le sud (cliché J.-F. Nauleau).

Figure 10: (See colour plate XXV) Beaupréau, the Tufferie site, view of the excavated feature F.229.2 towards the south (photo J.-F. Nauleau). d'une dizaine de centimètres, l'un d'eux accueille un fragment de tuile (fig. 11), vraisemblablement dans le but de régler l'aplomb de la pièce de bois et de renforcer la base du creusement.

La stratigraphie des comblements, même si elle n'a été vue que partiellement, est très contrastée. Dans les niveaux les plus profonds, le remplissage est constitué d'un sédiment argileux beige à orange (US 4) très proche des altérites argileuses dans lesquelles la structure a été creusée. Ce premier comblement est scellé par un niveau argileux beige épais de quelques centimètres très riche en charbons de bois ${ }^{10}$ (US 3), qui semble localisé dans la partie nord du creusement. Compte tenu de ces caractéristiques, il est probable qu'il corresponde à la dégradation d'un assemblage de pièces de bois de type plancher, escalier ou autre élément d'aménagement intérieur.

Immédiatement au-dessus de ce niveau, posée sur le lit de charbons de bois, a été dégagée une " motte " d'environ $0,55 \times 0,35 \times 0,25$ mètre constituée d'une argile plastique beige clair à rosé très homogène (fig. 11). Ce bloc était inclus

10. Un prélèvement a été réalisé dans le but d'effectuer une datation radiocarbone, cf. $\$ 5$. Datation $14 \mathrm{C}$. 


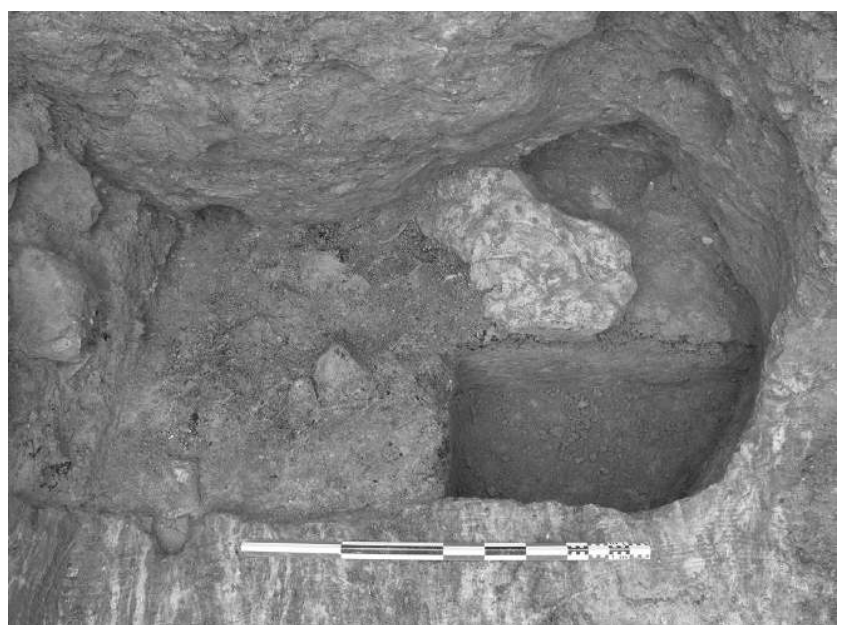

Figure 11 : (Voir planche couleur XXV) Beaupréau, site de la Tufferie, la structure excavée F.229.2, la motte d'argile sur le niveau de charbons de bois us 3 (cliché J.-F. Nauleau).

Figure 11: (Voir planche couleur XXV) Beaupréau, the Tufferie site, the excavated feature F.229.2, the clay motte on a layer of charcoal us 3 (photo J.-F. Nauleau).

dans un niveau argilo-limoneux beige (US 2). Cette unité stratigraphique, ainsi que la partie basale de l'US 1 a livré une série de briques décorées (cf. $\$ 4$. Les briques). Toute la partie sommitale du comblement, puissante de $1,75 \mathrm{~m}$ environ, est constituée d'un niveau limono-sableux beige avec de très nombreux blocs décimétriques de grès et de grave cimentée par des oxydes de fer et de manganèse identiques à ceux découverts dans les puisards. Ce niveau est particulièrement riche en matériaux en terre cuite, essentiellement des tuiles.

Il est difficile de comprendre la morphologie de cette structure profonde singulière. Les encoches pratiquées dans les parois de l'excavation montrent qu'une structure en bois a été installée dans la fosse; compte tenu de son format allongé et étroit $(3,90 \mathrm{~m} \times 1,20 \mathrm{~m})$, il pourrait s'agir d'un escalier ou d'une échelle fortement inclinée. L'absence d'une fouille intégrale ne permet pas de savoir de quelle nature est l'espace desservi par l'escalier. Il n'a été que partiellement observé en fond de fouille (fig. 10 et 11). L'hypothèse de l'existence d'un souterrain, tels qu'ils sont connus à cette époque, ne peut être écartée (cf. $\$ 6$. Le site et ses marqueurs fonctionnels...).

Le comblement de la structure, très riche en moellons, au moins dans sa partie sommitale, laisse penser qu'initialement, un aménagement lié à cette structure a existé en surface, mais dont il ne reste rien. Radier, mur-bahut, ou autre structure, aucune hypothèse ne peut être formulée concrètement; par ailleurs, quelques trous de poteau ont été dégagés autour de la fosse, mais rien ne permet de proposer un plan de bâtiment cohérent à partir de ces quelques creusements.
Pourtant, il est probable qu'un édifice couvert protégeait l'accès à cet espace excavé particulièrement vulnérable aux intempéries. La proximité avec la fosse F. 229.1 précédemment évoquée, permet d'ailleurs d'imaginer un bâtiment commun : un plan relativement cohérent pourrait se dessiner en associant les poteaux F.21/F.20 à l'est, F.19/F.5/F.4 au sud, F.3/F.13 à l'ouest et F.18/F.11/F.10/F.22 au nord (fig. 12). Le tout dessine un bâtiment quadrangulaire à "pans coupés " de près de quarante-huit mètres carrés, mais avec des trous de poteau peu marqués et mal répartis qui ne permettent pas de bien comprendre l'architecture de ce bâtiment éventuel. La présence d'une grande quantité de tuiles en surface du comblement de la cave (US 1), avec une part assez importante de ratés de cuisson témoignerait alors de l'adoption d'une couverture en tuiles sur cet édifice.

On peut poser la question de la fonction d'un tel espace au sein de l'atelier. À ce titre, la découverte de la motte d'argile au sein des comblements est un élément éclairant. On sait en effet que dans certains ateliers, la confection de mottes d'argiles malaxées et prêtes à l'emploi est une étape intermédiaire dans la chaîne de production. C'est notamment le cas dans le sud-est de la France où ces mottes sont appelées des pastons dans les ateliers produisant des tomettes (ateliers de Salernes, Var; Ulisse, 2008). Ces pastons sont stockés dans des espaces clos et humides afin de préserver leur hygrométrie et peuvent être préparés plusieurs mois auparavant. Dans le cas présent, on peut penser que l'espace excavé a pu avoir une fonction de même type.

\section{Les structures externes à l'enclos}

Peu de structures ont été détectées en dehors de l'enclos, à l'exception de quelques-unes repérées dans les tranchées 226, 363, 364 et 365, au sud de l'enclos à proximité de l'accès. Il s'agit de fosses de formes et de tailles variables et de rares trous de poteau (fig. 4 et 13).

\section{La fosse F.363.1}

Il s'agit d'une structure pseudo-quadrangulaire de $3,10 \mathrm{~m} \times 1,70 \mathrm{~m}$ creusée dans les altérites argileuses. Elle présente des parois sub-verticales et sa profondeur est supérieure à $0,70 \mathrm{~m}$ (fouillée manuellement, le fond n'a pas été atteint).

Le comblement est composé d'alternances de graves sabloargileuses et d'argile altéritique. Il résulte d'un mélange d'argiles encaissantes et de graves limoneuses rencontrées localement en surface. Le remblaiement final de la fosse est constitué d'un niveau d'une vingtaine de centimètres d'épaisseur, riche en fragments de tuiles (dont les trois fragments de tuiles creuses à crochet, cf. $\$ 4$. Les tuiles), d'un 


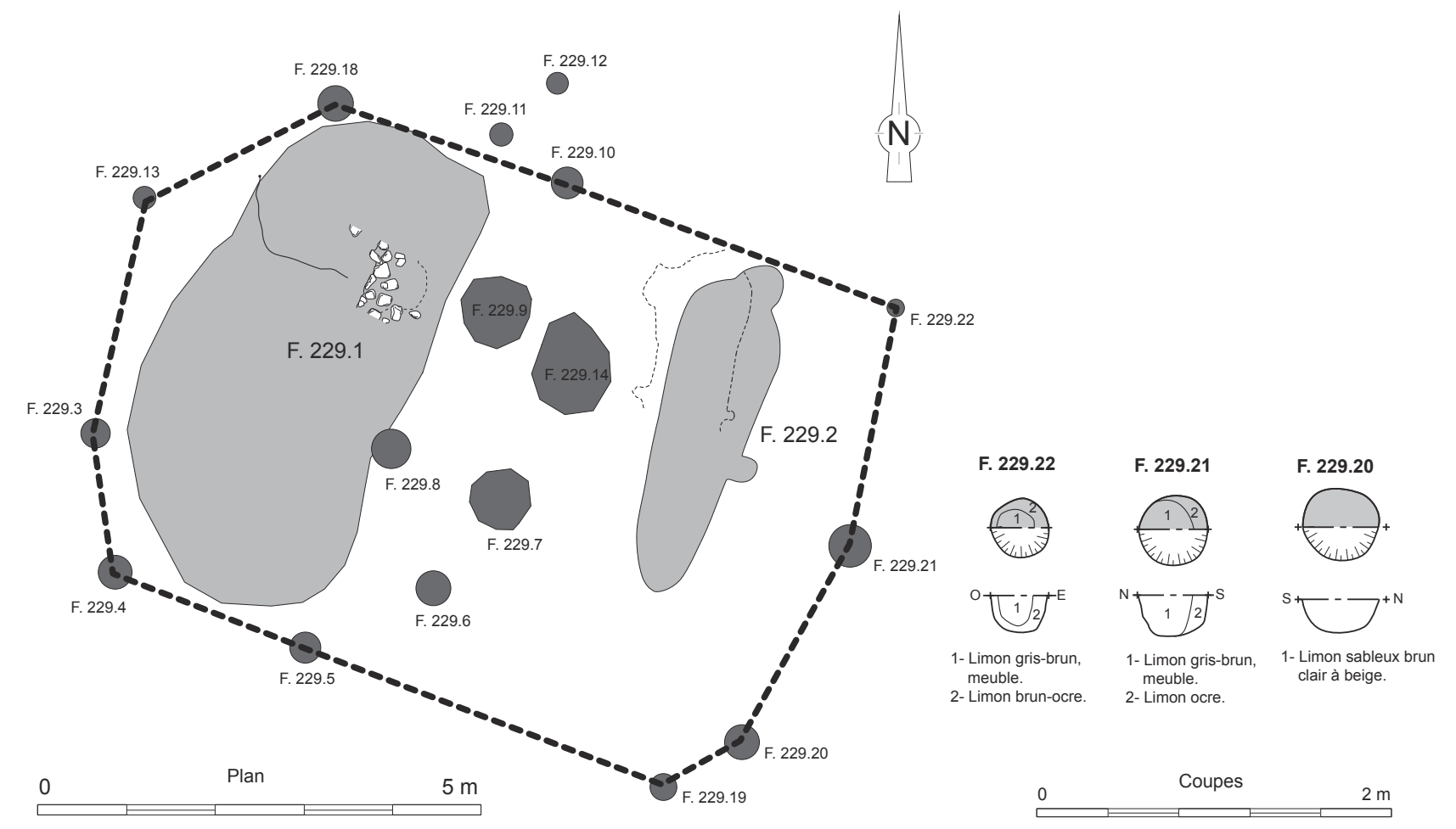

Figure 12 : Beaupréau, site de la Tufferie, un bâtiment potentiel autour des structures F.229.1 et F.229.2 (dessin J.-F. Nauleau). Figure 12: Beaupréau, the Tufferie site, a potential building around the features F.229.1 et F.229.2 (inforgraphy J.-F. Nauleau).

abondant mobilier céramique (80 restes, cf. $\$ 3$. Le mobilier céramique), et de restes de parois de four (fig. 14).

\section{La fosse F.363.3}

Cette fosse n'a été vue que partiellement dans la tranchée 363 et se développe vraisemblablement selon un tracé complexe. Un dégagement sommaire a été pratiqué dans sa partie est, laquelle montrait une concentration de matériaux divers, fragments de tuiles, parois de four, blocs de quartzite et mobilier céramique. Ce travail a mis en évidence la grande richesse de ce dernier niveau de comblement, qui présente des caractéristiques similaires à celui rencontré en F.363.1.

\section{La fosse F.363.2}

Elle a été observée dans les tranchées 363, 226 et 365 mais elle est absente dans la tranchée 366, ce qui limite son développement vers le sud-est. Elle prend la forme d'une structure linéaire d'une quinzaine de mètres de longueur, orientée selon un axe nord-ouest/sud-est (fig. 13). Au nordouest, elle s'interrompt mais trouve un prolongement dans la composante nord-ouest de la structure F.363.3 qui prend une orientation similaire. Sondée dans la tranchée 363, la structure révèle un creusement de 0,70 mètre de profondeur et affiche un profil largement évasé.

\section{Des fosses d'extraction d'argile?}

La plus vaste et la plus longue (F.363.2/3) de ces fosses semble être liée à la présence d'un niveau d'argile qui paraît avoir été exploité.

D'ampleur moindre, F.363.1 peut aussi appartenir à la même catégorie. Il peut s'agir d'une fosse exploratoire destinée à reconnaître les argiles sous-jacentes. Elle semble d'ailleurs avoir été rapidement comblée par des argiles altéritiques mais également par des graves qui constituent le niveau de stérile situé au-dessus des gisements exploitables.

Étant donné le maillage des tranchées exploratoires réalisées pendant le diagnostic, on peut estimer que les structures d'extraction sont limitées à ce secteur sud de l'enclos et, en dépit des incertitudes liées à l'absence de décapage intégral, que le volume d'argile extrait est relativement faible.

\section{LES VESTIGES MOBILIERS}

\section{Le mobilier céramique}

Le lot céramique recueilli comprend 191 restes dont la majeure partie est issue du fossé d'enclos F.229.29 et à l'intérieur de celui-ci des deux fosses F.229.1 et F.229.2, mais 

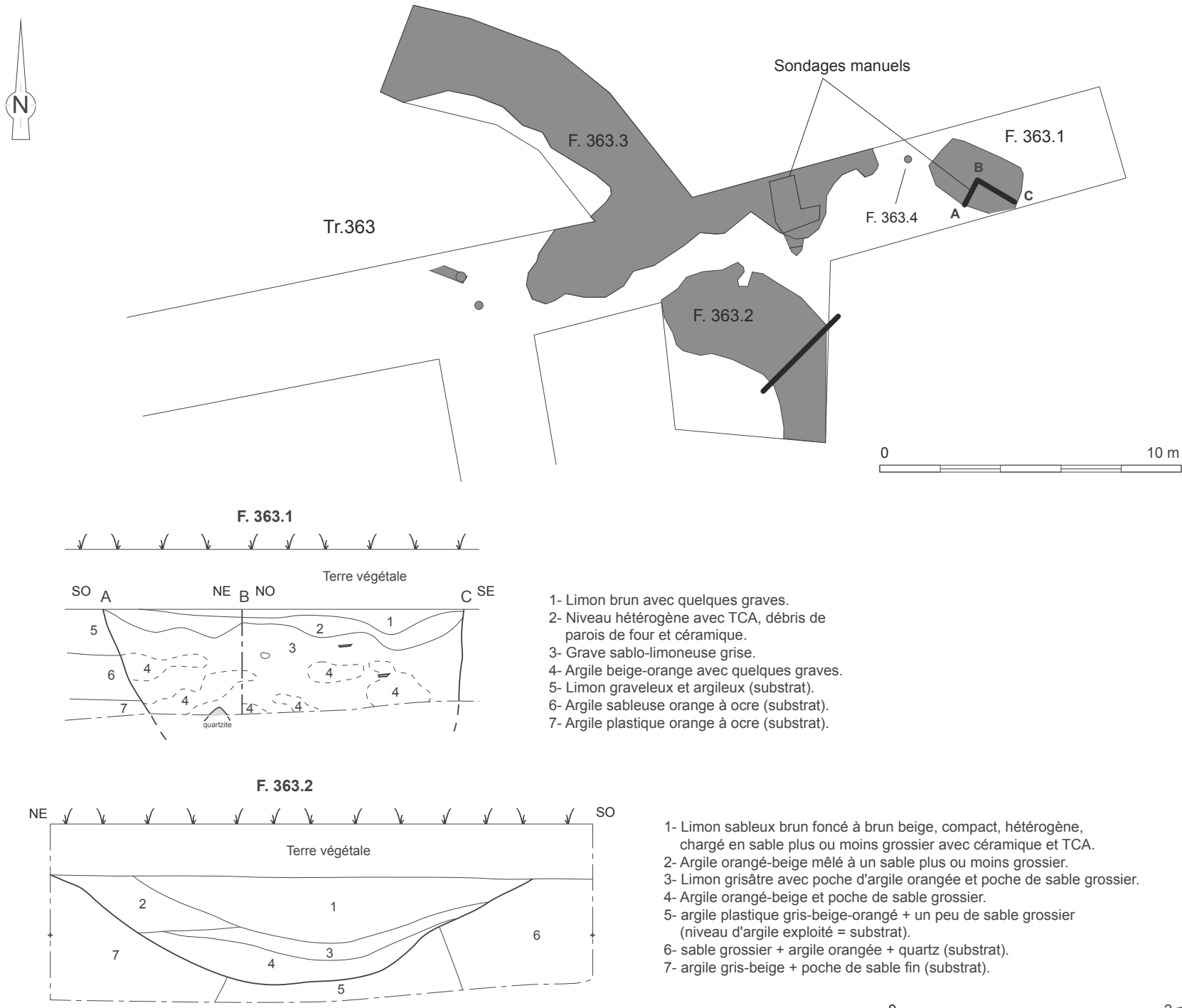

1- Limon sableux brun foncé à brun beige, compact, hétérogène, chargé en sable plus ou moins grossier avec céramique et TCA. 2- Argile orangé-beige mêlé à un sable plus ou moins grossier.

3- Limon grisâtre avec poche d'argile orangée et poche de sable grossier.

4- Argile orangé-beige et poche de sable grossier.

5- argile plastique gris-beige-orangé + un peu de sable grossier (niveau d'argile exploité $=$ substrat).

6- sable grossier + argile orangée + quartz (substrat).

7- argile gris-beige + poche de sable fin (substrat)

Figure 13 : Beaupréau, site de la Tufferie, les probables fosses d'extraction externes à l'enclos (dessin J.-F. Nauleau). Figure 13: Beaupréau, the Tufferie site, probable extraction pits outside of the enclosure (infography J.-F. Nauleau).

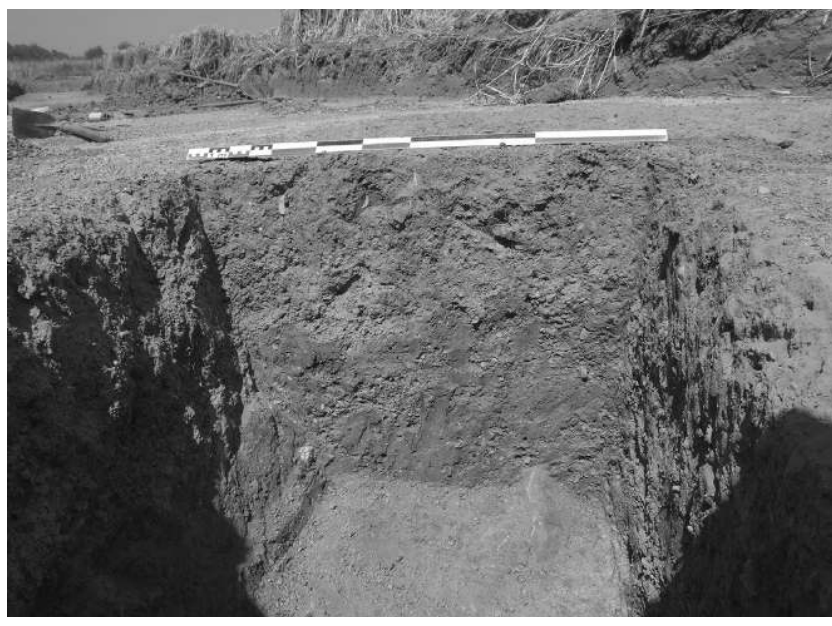

également des probables fosses d'extraction d'argile F.363.1 et F.363.3.

Dans cet ensemble, 167 éléments correspondent à des fragments de poteries façonnées au tour, parmi lesquels des bords ont permis d'identifier quatre formes fermées. Il s'agit de trois pots à cuire à lèvre en bandeau (lots 21, 23 et 24) et d'une cruche munie d'au moins une anse plate qui

Figure 14 : (Voir planche couleur XXV) Beaupréau, site de la Tufferie, coupe nord-ouest de la fosse F.363.1, avec son niveau supérieur riche en fragments de tuiles et probables parois de four (cliché J.-F. Nauleau).

Figure 14: (See colour plate XXV) Beaupréau, the Tufferie site, northwest section of the feature F.363.1 with its upper fill containing tile fragments and probable furnace wall fragments (photo J.-F. Nauleau). 

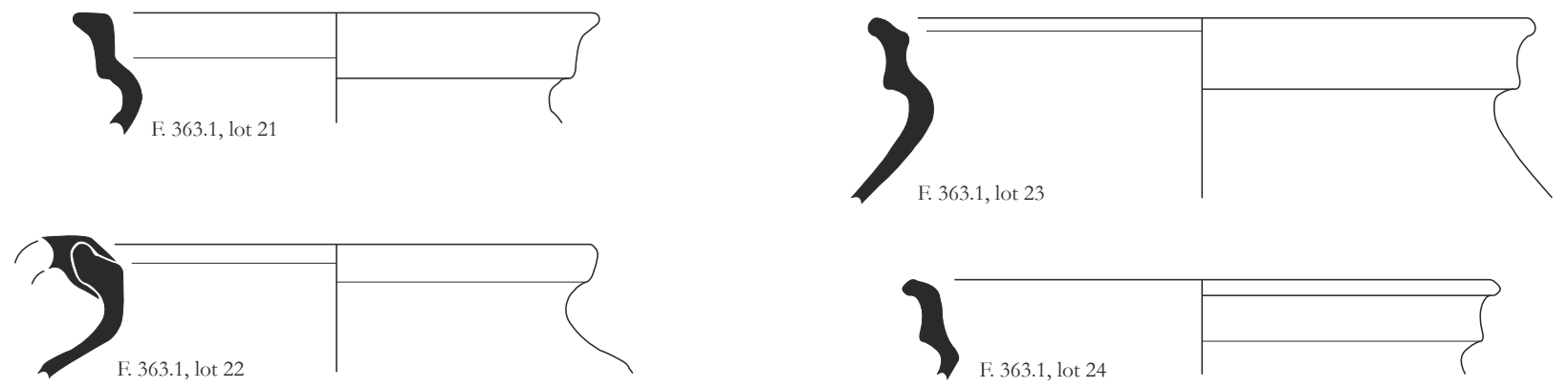

Céramique tournée
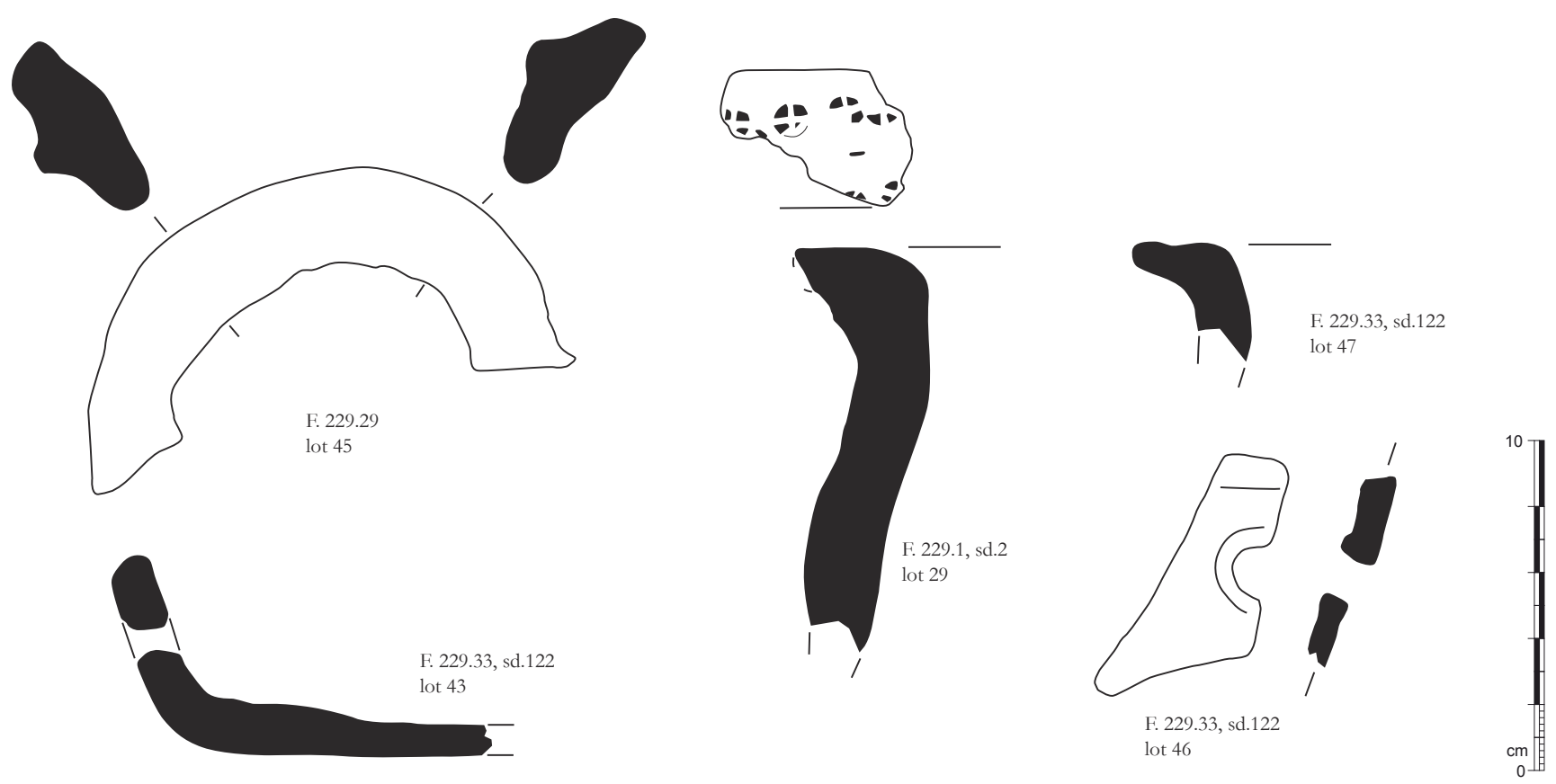

Céramique modelée

Figure 15 : Beaupréau, site de la Tufferie, le mobilier céramique (dessin P. Bellanger/J.-F. Nauleau).

Figure 15: Beaupréau, the Tufferie site, pottery (infography P. Bellanger/J.-F. Nauleau).

vient s'accrocher sur une lèvre éversée à légère gorge interne (lot 22). Ces quatre poteries de facture soignée présentent des caractéristiques techniques similaires, à savoir une pâte sableuse semi-fine à semi-grossière caractérisée par de nombreux grains siliceux (quartz et feldspath) ainsi qu'une teinte interne brun-orangé et des surfaces brun rougeâtre résultant d'une cuisson en atmosphère oxydante. Suivant la morphologie des lèvres en bandeau ${ }^{11}$ (parement courbe avec une extrémité en " visière ") et la hauteur de celles-ci, comprise entre 19 et $21 \mathrm{~mm}$, ce groupe de vases apparaît notamment

11. Voir le travail réalisé dans le cadre du bilan sur « L'habitat rural au Moyen Âge dans le nord-ouest de la France ", Moréra-Vinçotte, 2012, p. 197-203. comparable à celui de l'état de transition 1-2 sur l'occupation rurale de la Chapellière en Vendée, qui s'inscrit chronologiquement entre la seconde moitié du XII ${ }^{e}$ siècle et la première moitié du XIII ${ }^{\mathrm{e}}$ siècle (Dubillot, 2003, p. 140-141).

La fouille partielle des vestiges a par ailleurs permis de découvrir vingt-quatre restes d'un second type de production tout à fait spécifique à ce site. Ce sont des fragments de poteries modelées, à parois épaisses, avec une pâte semigrossière assez sableuse incluant quelques plus gros éléments siliceux épars de 3 à $18 \mathrm{~mm}$ de côté. Leur teinte varie légèrement du beige orangé au brun rougeâtre. Cette céramique de facture grossière, associée à des éléments de céramique tournée, provient du colmatage des structures F.229.1 et 
F.229.33. Deux bords de ce groupe, dotés d'une lèvre large légèrement en biseau (lots 29 et 47) pourraient correspondre à des fragments de bassins de forme ouverte. L'un des deux (lot 29) est orné sur le sommet plat de la lèvre d'une série de six décors cruciformes réalisés au poinçon circulaire. Un décor de ce type se retrouve également sur l'extrémité d'une anse épaisse quadrangulaire à bourrelet central, de facture particulièrement grossière (lot 45). Cet ensemble modelé comprend enfin deux formes basses à lèvre confondue avec la panse (lots 43 et 46) qui présente une perforation dans les deux cas, plus précisément à mi-hauteur pour le vase encore pourvu d'une partie de son fond plat (lot 43).

À la différence des formes tournées du site (oules et cruches), présentes régionalement sur pratiquement tous les habitats contemporains, les récipients modelés inédits, d'aspects technologiques similaires à ceux des terres cuites architecturales (tuiles, briques...), ont vraisemblablement été produits pour un usage limité à celui de l'atelier et à ses activités spécifiques ${ }^{12}$.

\section{Le mobilier de mouture}

Deux fragments de meules rotatives à bras ont été découverts dans l'US 1 de la structure profonde F.229.2, parmi les nombreux blocs de grès et de conglomérats à ciment ferrugineux et manganique.
Ils sont tous deux façonnés dans un grès fin à tendance saccharoïde dont la provenance semble locale (fig. 16). L'un des restes peut être identifié comme appartenant à une meule rotative, c'est-à-dire la partie supérieure du moulin. Il possède en effet un profil bitronconique caractéristique, avec trémie de chargement en partie supérieure et surface de travail en face inférieure. Mais celle-ci ne présente pas de traces de surface polie. L'épaisseur - incomplète - de l'élément est de $155 \mathrm{~mm}$ et est estimée à $170 \mathrm{~mm}$ environ. Le diamètre doit se situer aux alentours de $450 \mathrm{~mm}$. L'autre fragment est de grande taille, mais ces surfaces sont très altérées et il est impossible de préciser sa morphologie (il s'agit néanmoins probablement d'un second élément de meule dormante).

Par rapport aux restes répertoriés et étudiés dans la région (Nauleau, 2012), ces individus sont atypiques. Concernant la pétrographie tout d'abord, le faciès utilisé est caractérisé par un grain fin et homogène qui diffère des faciès meuliers médiévaux à granulométrie plus grossière ordinairement rencontrés (granite, grès micro-conglomératique et calcaire coquillier). Par sa morphologie ensuite, puisque l'individu présente une épaisseur nettement supérieure à la moyenne des meules rotatives étudiées, soit $56 \mathrm{~mm}$. La présence d'un ressaut bordier enfin, nettement visible autour de la trémie, est une des caractéristiques des moulins gallo-romains présents dans la région; aucune meule rotative médiévale possédant cette morphologie n'a été signalée.
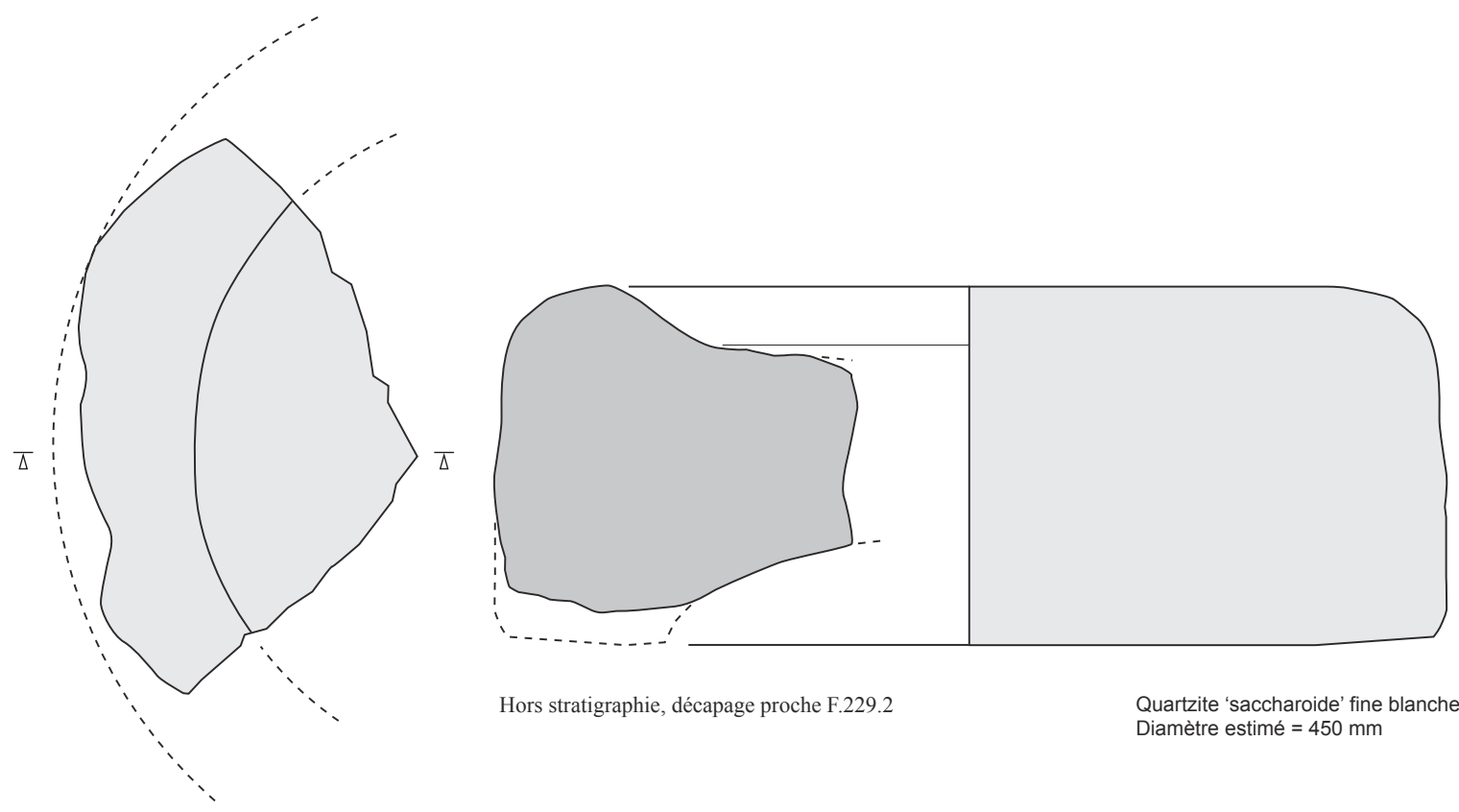

12. Il peut s'agir de récipients d'eau ou de sable fin utilisés pour les activités de moulage par exemple.
Figure 16 : Beaupréau, site de la Tufferie, le mobilier de mouture (dessin J.-F. Nauleau).

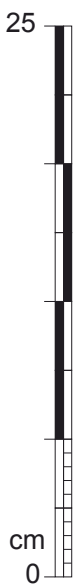

Figure 16: Beaupréau, the Tufferie site, grinding stones (infography J.-F. Nauleau). 
Ces fragments de meule sont difficiles à insérer dans le paysage des moulins rotatifs à bras médiévaux. S'agit-il d'éléments plus anciens remployés comme matériaux de construction? Ou sont-ils à corréler avec l'activité artisanale et à comprendre dans ce contexte? L'absence de chamotte dans les pâtes ou de dégraissant spécifique requérant un broyage, tend plutôt à écarter cette hypothèse.

\section{LeS MatériauX PRODUITS DANS L'ATELIER}

\section{Les différents types de matériaux}

\section{Les tuiles}

Trois types ont été observés : des tuiles creuses simples, des tuiles creuses à crochet et un type singulier : une tuile plate à rebords dérivée des tegulae antiques.

\section{Les tuiles creuses ( canal»)}

Seuls deux exemplaires provenant de la structure profonde F.229.2 sont archéologiquement complets (fig. 17 et 18). Le premier est long de $368 \mathrm{~mm}$, large de $130 \mathrm{~mm}$ à l'amont et $160 \mathrm{~mm}$ à l'aval. Le second est très déformé par une cuisson excessive, sa longueur étant de $367 \mathrm{~mm}$. Globalement au sein $\mathrm{du}$ lot, les épaisseurs sont très variables : elles s'échelonnent de 8 à $15 \mathrm{~mm}$, soit d'un côté des épaisseurs fines identiques à celles rencontrées sur des lots des XIII ${ }^{e}-$ XIV e siècles (Précigné, Sarthe; Nauleau, 2009 et Juignésur-Sarthe, Sarthe; Nauleau, 2013) et de l'autre des tuiles très robustes qui évoquent davantage des imbrices romaines (Nauleau, 2013, p. 228-229).

Le type de façonnage est assez classique avec des traces de sablage en face inférieure (permettant la non-adhérence de la plaque d'argile sur le moule). Les cuissons sont également inégales, certains individus pulvérulents semblent peu cuits tandis que d'autres montrent des couleurs bleu à brun témoignant de degrés de cuisson élevés.

\section{Les tuiles creuses à crochet}

Ce type de tuiles n'a été identifié que par l'intermédiaire de trois fragments de crochets, découverts dans le comblement supérieur de la structure d'extraction probable F.363.1.

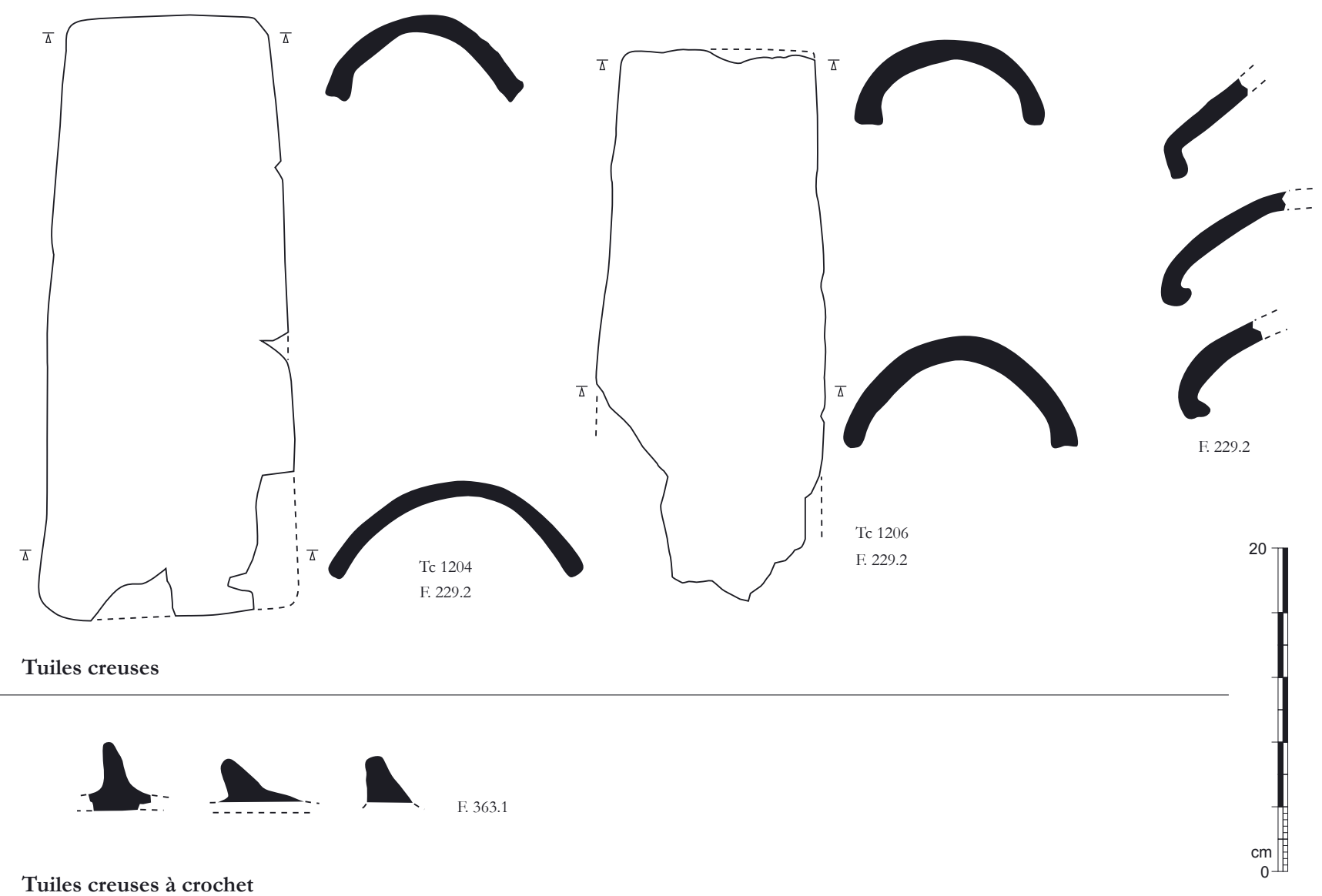

Figure 17 : Beaupréau, site de la Tufferie, les matériaux produits dans l'atelier : les tuiles creuses (dessin J.-F. Nauleau).

Figure 17: Beaupréau, the Tufferie site, the workshop's production: hollow tiles (infography J.-F. Nauleau). 


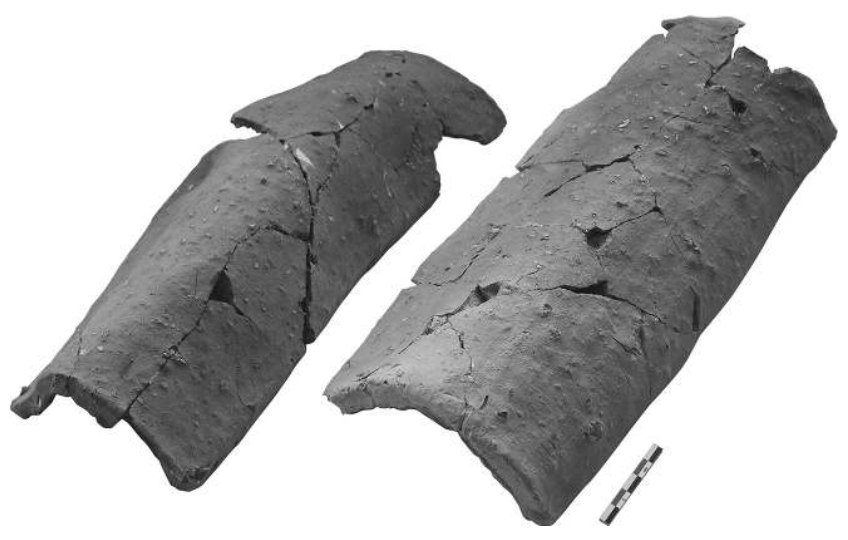

Figure 18 : (Voir planche couleur XXVI) Beaupréau, site de la Tufferie, exemples de tuiles creuses sans crochet produites dans l'atelier (cliché J.-F. Nauleau).

Figure 18: (See colour plate XXVI) Beaupréau, the Tufferie site, examples of hollow tiles without hooks produced in the workshop (infography J.-F. Nauleau).

Il s'agit d'un crochet de tuile couvrante et de deux de tuile courante. Ils sont hauts de 25 à $35 \mathrm{~mm}$, ce qui est conforme à ce qui a été vu à Précigné et Juigné-sur-Sarthe. Aucun fragment de tuile présentant un arrachement de crochet n'a été identifié parmi tous les restes observés.

\section{Une tuile singulière : un dérivé de tegula?}

Un individu archéologiquement complet d'un type de tuile singulier a été mis au jour dans le fossé d'enclos F.229.29, sondage 128. Un autre fragment de même type a été récolté dans la structure profonde F.229.2. L'exemplaire complet est une tuile plate légèrement trapézoïdale de $440 \mathrm{~mm}$ de long, large de $175 \mathrm{~mm}$ à l'aval et 190 à l'amont (fig. 19). Elle est munie d'un rebord haut de 15 à $18 \mathrm{~mm}$, décalé vers le centre de la tuile de $20 \mathrm{~mm}$ environ. Il existe un dispositif d'emboîtement qui se manifeste à l'aval par une petite découpe latérale oblique, longue de $62 \mathrm{~mm}$, diminuant la largeur de la tuile pour la ramener à $155 \mathrm{~mm}$. À l'amont, toute la partie centrale de la tuile est amincie, formant ainsi une réserve profonde de $15 \mathrm{~mm}$ environ et longue d'environ $60 \mathrm{~mm}$. Aucun système d'accroche (perforation, crochet) n'équipe la tuile en partie haute. Le façonnage est très grossier, il ne semble pas avoir été réalisé dans un moule. De nombreuses empreintes végétales en face inférieure montrent qu'elle a été façonnée sur un lit végétal évitant l'adhérence de l'argile sur le support.

Les caractéristiques de cette tuile sont très surprenantes : elle reprend la technique antique de la tuile plate à rebords, mais avec des modifications morphologiques importantes, à savoir un format allongé, un gabarit trapézoïdal facilitant l'emboîtement, un rebord ramené légèrement vers l'inté- rieur, et un système d'emboîtement " encastré " évitant les surépaisseurs. Notons un autre fragment d'une tuile de même type (Tc 1207, F.229.33), mais légèrement différente, avec un rebord non décalé vers le centre : la parenté avec une tegula antique est encore plus manifeste.

Ce type de tuile est très singulier. Il semble, en l'état actuel des travaux publiés, inédit. On peut évoquer les tuiles à rebords et à emboîtement en goulot découvertes à Metz (Moselle; Goutal, 1996) dans un contexte du XII siècle, mais elles sont sensiblement différentes en termes de technique de recouvrement.

Compte tenu du faible nombre d'éléments découverts, de leur absence totale jusqu'à nos jours sur les sites de consommation et de leur médiocre qualité de façonnage, on peut se poser la question de la production réelle de ces quelques individus : a-t-on réellement produit en série un tel type de tuile, ou ne s'agit-il que d'un prototype jamais réellement diffusé? À ce titre, la reconstitution théorique d'une toiture à partir de ce type de tuile montre que le système d'embồtement par encastrement n'est pas efficient, le recouvrement étant trop faible pour assurer l'étanchéité de la couverture.

En tout état de cause, au-delà du problème que soulèvent sa production réelle et sa diffusion, sa parenté avec la tegula romaine est source de questions. En effet, si le renouveau de la culture constructive antique est bien attesté à l'époque carolingienne, même s'il reste modeste régionalement, il est plus surprenant d'en établir le constat pour cette période plus tardive de la fin du XII ${ }^{\mathrm{e}}$ ou du début du XIII ${ }^{\mathrm{e}}$ siècle.

Quelles pouvaient être les sources de culture technique antique dans le contexte de cette époque? Elles ne sont probablement pas à chercher sur le territoire proche. Si une part des techniques constructives romaines a pu se transmettre jusqu'au cœur du Moyen Âge, c'est sans doute via des territoires où la culture antique a fortement imprégné les modes de vie (sud du territoire français, Italie, Espagne). Ces références exogènes ont-elles été apportées par les artisans tuiliers recrutés par le commanditaire? (cf. $\$ 6$. Le statut de l'atelier).

\section{Les briques}

Plusieurs structures ont livré des briques; il s'agit principalement de la structure profonde F.229.2 et de la citerne F.229.33. L'ensemble du lot est modeste avec seulement vingt restes avérés. La fragmentation des éléments est importante; aucune brique n'étant archéologiquement complète (aucune largeur n'est même intacte), cependant on peut noter un fragment assez long $(>175 \mathrm{~mm})$. Les épaisseurs quant à elles peuvent être importantes, jusqu'à $53 \mathrm{~mm}$.

Ces données semblent distinguer nettement le gabarit de ces briques de celles rencontrées dans la région à partir du XIII ${ }^{\mathrm{e}}$ siècle. En effet, les briques signalées sur les sites de 


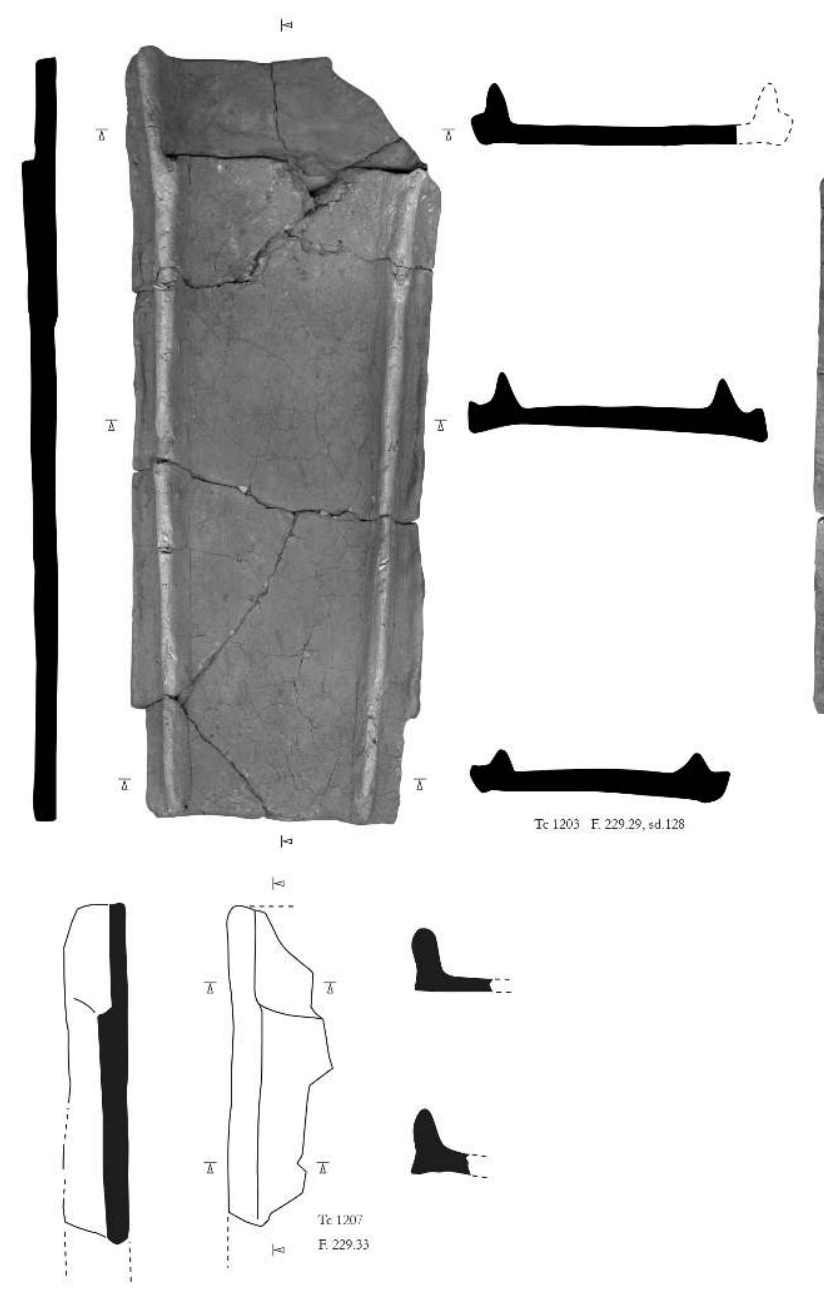

consommation sont peu épaisses ( 20 à $30 \mathrm{~mm}$ ) et de format déjà proche du format moderne, c'est-à-dire environ $210 \times 100 \mathrm{~mm}$. Compte tenu du petit nombre de restes avérés, on ne peut exclure l'hypothèse d'une production à usage interne, c'est-à-dire dévolue au four lui-même et en particulier à la sole. Elle est en effet difficile à concevoir sans recours à la terre cuite (cf. $\$ 4$. Les terres cuites provenant de la structure du [ou des] four[s]).

\section{Des restes remarquables : les briques décorées}

Plusieurs éléments provenant de la structure F.229.2 sont remarquables (fig. 20 et 21) : il s'agit de briques portant des empreintes de poinçons et d'estampilles (Tc 1200, Tc 1201 et Tc 1202) ${ }^{13}$.

Les poinçons sont des motifs cruciformes d'environ $10 \mathrm{~mm}$ de diamètre. Sur le fragment Tc 1200, vingt marques sont visibles sur une des faces, et quatre sur la tranche. Sur l'élément Tc 1201, une des faces porte trois marques, et

13. Les Tc 1200 et 1201 proviennent très vraisemblablement du même individu.
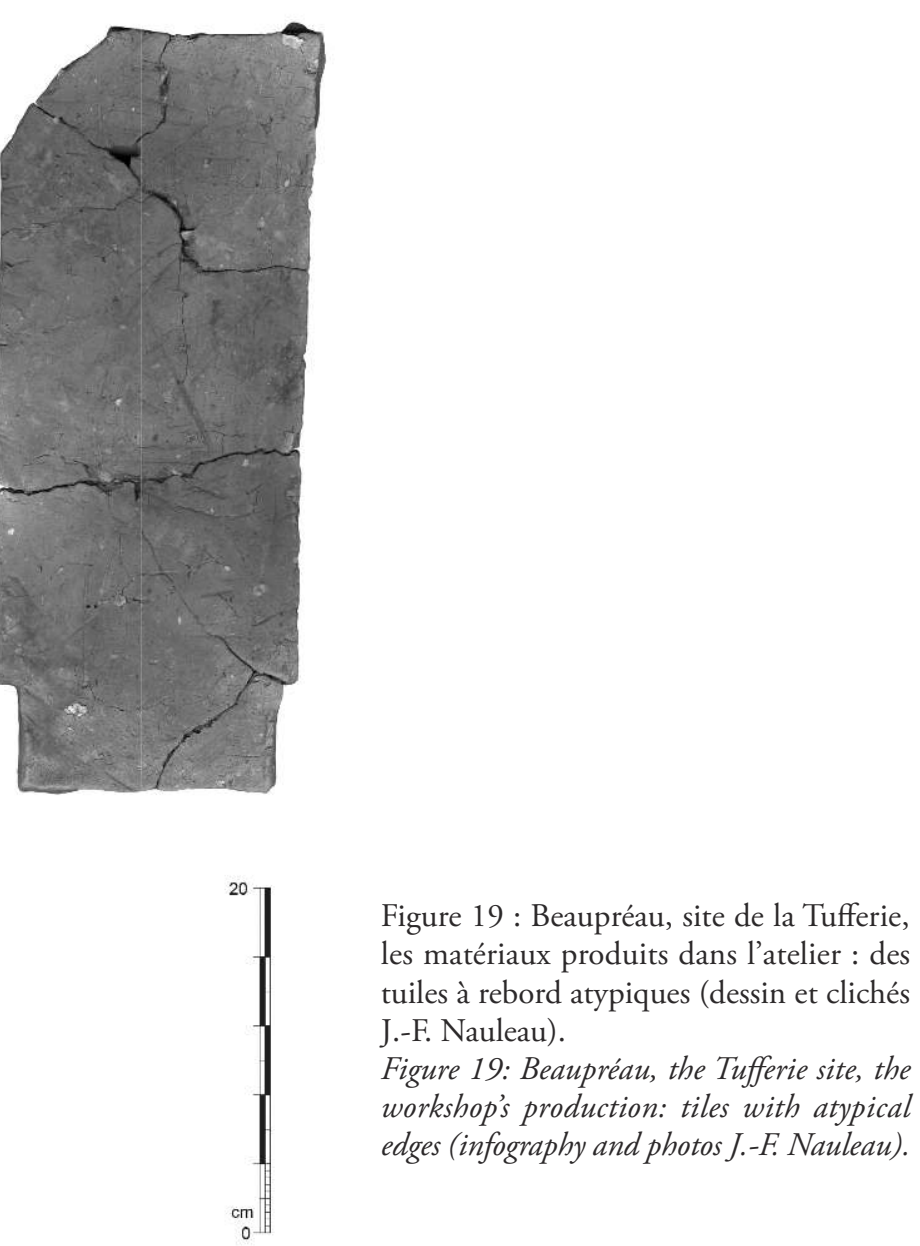

l'autre quatre. Ils sont de même nature que ceux présents sur un récipient modelé très grossier (fig. 15, lot 29) découvert à proximité, dans la fosse F.229.1 (cf. \$3. Le mobilier céramique).

L'estampille est un " cartouche " ovoïde (fig. 20), d'environ $45 \mathrm{~mm}$ de long pour $25 \mathrm{~mm}$ de haut, contenant en relief un quadrupède stylisé (loup ou chien), à queue en panache (se développant au-dessus du corps) et à gueule ouverte. Aucun des cartouches découverts n'est réellement complet, mais la mise en parallèle des différents restes a permis de constater qu'il s'agissait bien d'un seul et même motif et d'en proposer une restitution. La brique Tc 1202 en porte trois, tandis que l'on en dénombre deux sur l'élément Tc 1200 et également deux sur Tc 1201.

Les deux fragments Tc 1200 et 1201 possèdent un rebord curviligne qui évoque la morphologie des briques pour colonne en demi ou en quart-de-rond : ici, les diamètres restitués dans cette configuration sont estimés aux alentours de $500 \mathrm{~mm}$.

Compte tenu de ces caractéristiques, il est difficile de bien cerner la nature de ces briques et leur fonction. 


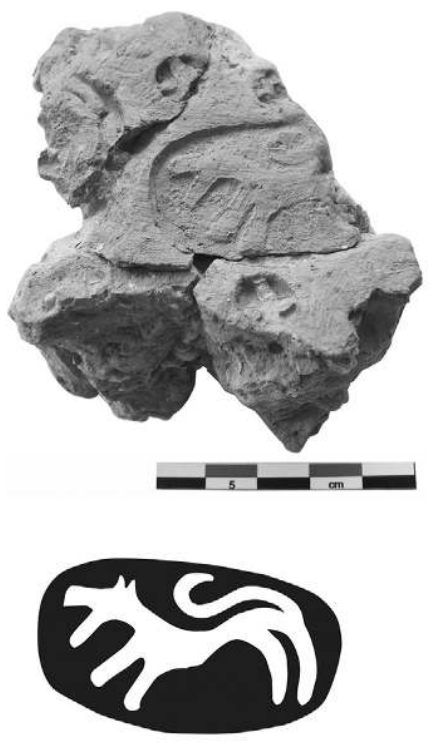

Figure 20 : (Voir planche couleur XXVI) Beaupréau, site de la Tufferie, les décors sur briques, l'individu Tc 1202 et la restitution du cartouche à partir des différentes marques découvertes (cliché et dessin J.-F. Nauleau).

Figure 20: (See colour plate XXVI) Beaupréau, the Tufferie site, decorated bricks, the object Tc 1202 and a restitution of the stamp from the different marks discovered on site. (photo and infography J.-F. Nauleau).
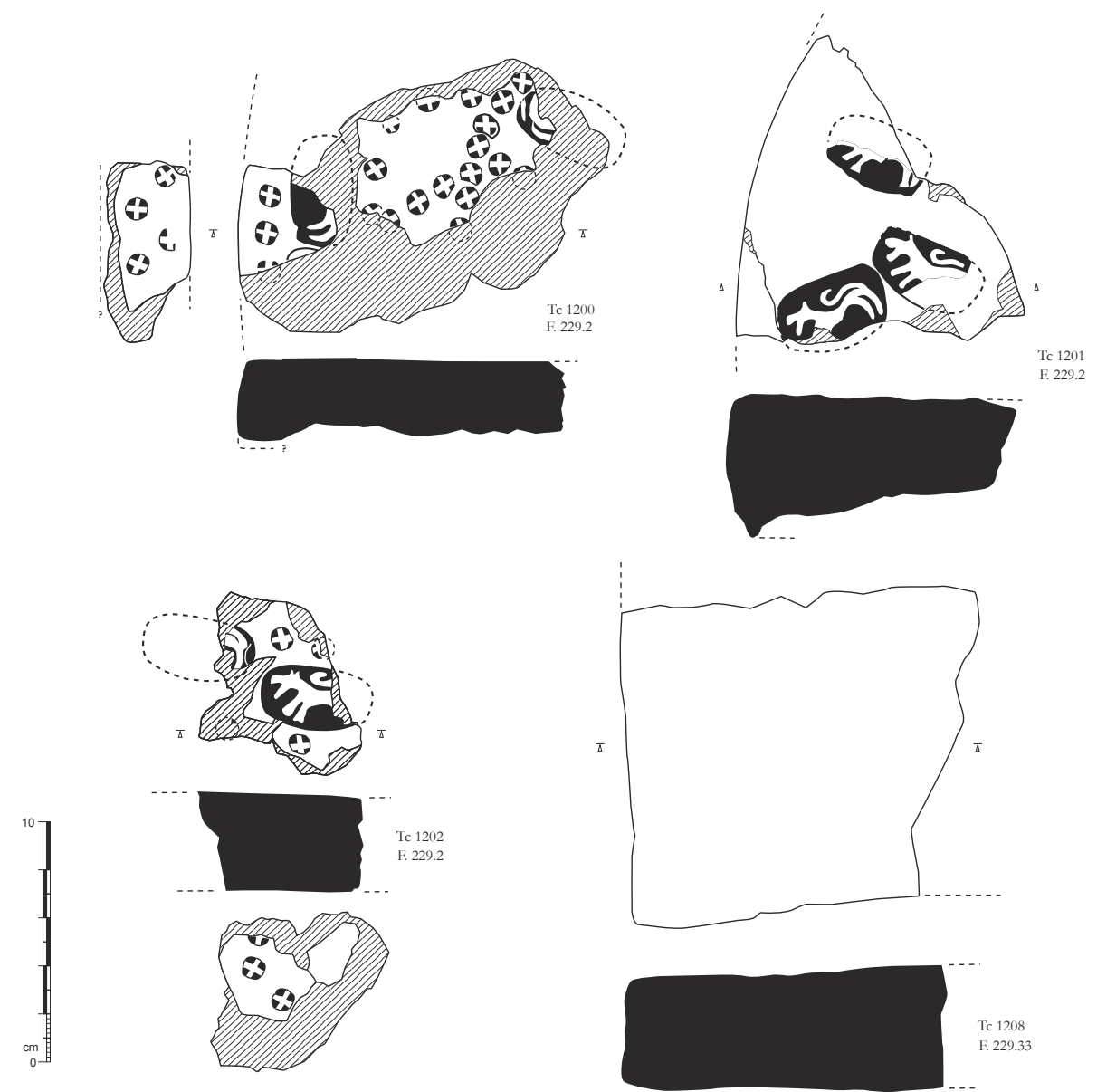

Figure 21 : Beaupréau, site de la Tufferie, les briques décorées à poinçons et cartouches estampés (dessin J.-F. Nauleau).

Figure 21: Beaupréau, the Tufferie site, stamp decorated bricks and the stamps (infography J.-F. Nauleau).
Le format général évoque celui des briques mises en œuvre pour l'édification de colonnes enduites. Mais les décors relevés sur les faces de pose contredisent cette hypothèse, et par ailleurs ces briques spécifiques ne sont plus connues après l'époque romaine.

Globalement, les pâtes utilisées sont grossières et la qualité de façonnage de ces éléments est très médiocre, ce qui est contradictoire avec le caractère exceptionnel des décorations qu'elles portent. (Les mêmes observations peuvent être faites pour le gros récipient non tourné découvert dans la structure F.229.1 qui porte des poinçons de même type et qui a été très probablement produit dans l'atelier $[\mathrm{cf}$. $\$ 3$. Le mobilier céramique]).

Sur la brique Tc 1200, à l'exception de la tranche et de la zone proche du rebord, les poinçons se superposent à plusieurs reprises et sont appliqués avec des pressions très variables, sans que l'on puisse déceler une quelconque organisation.
On ne peut écarter l'hypothèse d'un décor fortuit résultant soit d'un jeu d'enfant soit d'un travail préparatoire sur un support secondaire, permettant de tester les poinçons et les estampilles et leur agencement au sein d'un décor. Mais, dans ce cas, on comprend mal pourquoi ces décors ont été portés sur des briques à rebords curvilignes, si singulières, et surtout pourquoi le processus de production est allé jusqu’à son terme, c'est-à-dire jusqu'à la cuisson?

Une autre hypothèse est à considérer, celle d'éléments architecturaux ornementaux. Dans le domaine religieux, l'alternance de cercles renfermant des animaux et des motifs végétaux ou cruciformes se rencontre régulièrement. Ce type de combinaison est présent sur des tissus décoratifs, des vêtements, des peintures murales, des objets d'orfèvrerie, etc.

La transposition d'éléments décoratifs en pierre vers la terre cuite semble avérée pour la période, mais reconnaissons que ces décors sont très atypiques et différents de ceux 
connus à cette époque sur les plaques de chancel, les plaques d'autel, ou les décors d'ambon ${ }^{14}$.

On peut également proposer une destination profane pour ce matériau décoratif; le décor de la demeure médiévale est encore largement méconnu. Le motif du cartouche est proche de ceux de l'héraldique ou des carreaux de sol historiés. Dans les deux cas, le loup ou le chien sont des motifs récurrents. Cependant dans le cas présent, le cartouche représente une figure isolée et évoque d'une certaine façon les sceaux destinés à identifier un individu ou une famille. Ils portaient fréquemment, dès le $\mathrm{XI}^{\mathrm{e}}$ siècle des figures emblématiques de type animaux, plantes ou objets, dont quelques grandes familles faisaient déjà usage. Elles sont ensuite associées à d'autres signes en un assemblage codifié, à partir du milieu du XII ${ }^{\mathrm{e}}$ siècle, pour former les armoiries (Pastoureau, 2004, p. 239-247).

\section{Les " tuyaux " de canalisation}

Plusieurs éléments de ce type (fig. 22 et 23) ont été découverts dans la citerne F.229.33 encadrant l'interruption du fossé d'enclos.

Il s'agit de tuyaux très grossiers dans leur façonnage et le type de pâte employé. Aucun élément n'est intact, les trois fragments sont longs de 260, 290 et $310 \mathrm{~mm}$. Une valeur initiale d'environ $350 \mathrm{~mm}$ est envisagée. Le diamètre moyen

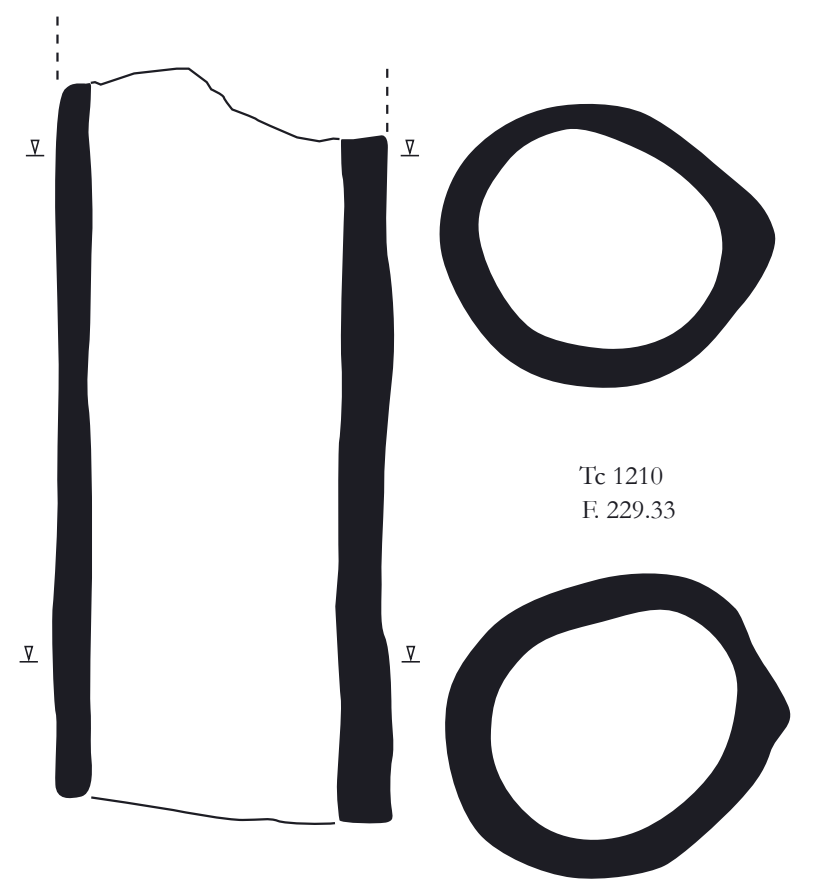

14. Merci à Christian Sapin (directeur de recherche au CNRS, centre d'études médiévales, UMR 6298 ARTeHIS- université de Bourgogne) et Christian Davy (chercheur au service de l'Inventaire de la région des Pays de la Loire) pour leur concours concernant ces décors. se situe aux alentours de $120 \mathrm{~mm}$, mais avec des valeurs très variables sur un même individu. L'épaisseur est également très fluctuante et oscille entre 15 et $25 \mathrm{~mm}$. Le façonnage est très grossier avec un bourrelet très proéminent, résultant de la jonction des deux extrémités de la plaque d'argile. Les pâtes sont très hétérogènes avec une part non plastique importante. La cuisson semble médiocre.

Rappelons (cf. $\$ 2$. L'enclos annulaire) qu’ils étaient probablement en place dans la structure F.229.33, permettant le transit de l'eau au travers du parement. Leur usage limité au site même pourrait expliquer leur très médiocre qualité.

\section{Les argiles employées au sein de l'atelier (fig. 24)}

Un échantillon représentatif de matériaux a été découpé afin de réaliser des observations concernant la texture et la nature des pâtes employées.

L'ensemble des observations concourt à montrer que les différents matériaux ont été façonnés avec la même préparation argileuse. Sa fraction plastique présente une structure très légèrement marbrée, indiquant un mélange incomplet d'argiles de couleurs différentes. La fraction non plastique, elle, est assez abondante et est principalement composée de quartz plus ou moins émoussés, dont la taille moyenne se situe entre 1 et $2 \mathrm{~mm}$. Cependant, certains

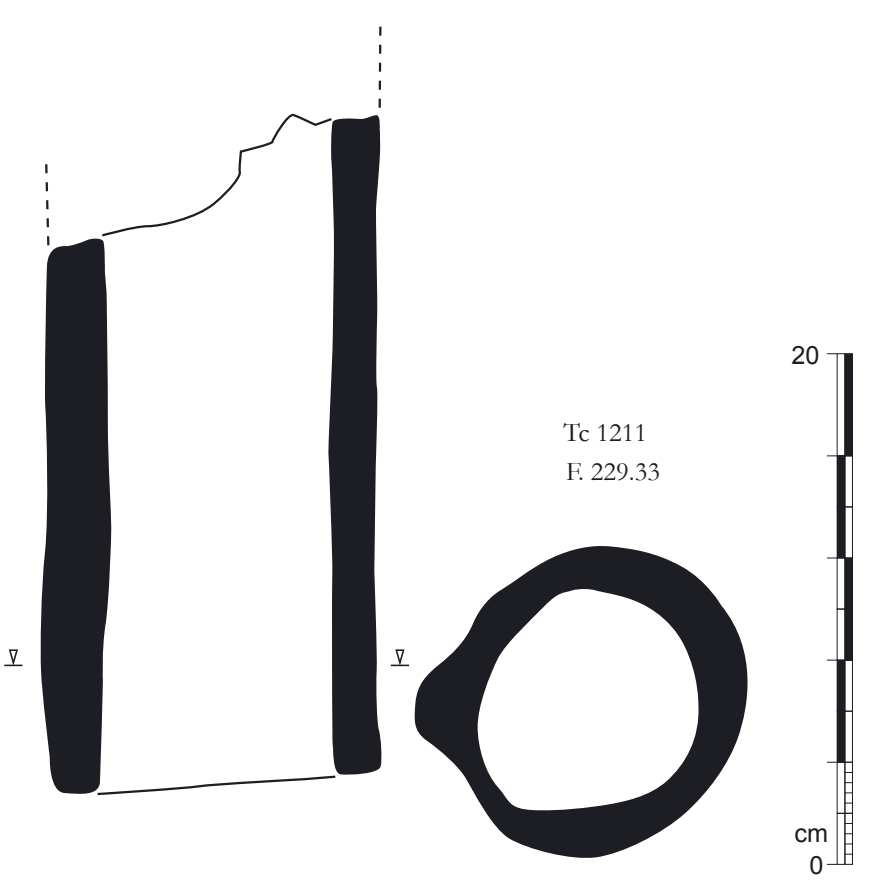

Figure 22 : Beaupréau, site de la Tufferie, les tuyaux de canalisation (dessin J.-F. Nauleau).

Figure 22: Beaupréau, the Tufferie site, the canalisation pipes (infography J.-F. Nauleau). 


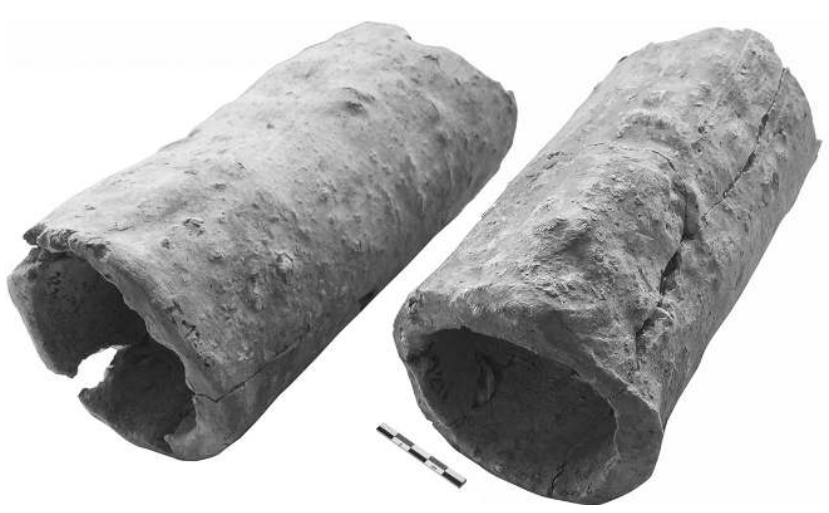

Figure 23 : (Voir planche couleur XXVI) Beaupréau, site de la Tufferie, vue de deux exemplaires de tuyaux de canalisation (mire de $5 \mathrm{~cm}$; cliché J.-F. Nauleau).

Figure 23: (See colour plate XXVI) Beaupréau, the Tufferie site, photo of two examples of drain pipes (scale is $5 \mathrm{~cm}$ long; photo J.-F. Nauleau).

éléments atteignent 7 à $8 \mathrm{~mm}$. La nature même des éléments quartzeux est variable. Certains sont sains, d'autres nettement cariés. L'hétérogénéité manifeste de cette fraction quartzeuse montre qu'il ne s'agit en aucun cas d'un apport volontaire dans le but d'augmenter la part " dégraissante ", mais bien d'une présence originelle dans ces argiles altéritiques. D'autres éléments appartenant à la fraction non plastique sont identifiables. Il s'agit d'une part de fragments de grès à ciment ferrugineux dont la taille varie de 1 à environ $8 \mathrm{~mm}$, et d'autre part de fragments de micaschiste assez peu abondants mais qui peuvent être de grande taille, jusqu'à $10 \mathrm{~mm}$. Mentionnons enfin quelques nodules d'oxyde ou d'hydroxyde de fer.

Un tamisage effectué sur une partie de la motte d'argile découverte dans la structure profonde F.229.2, ainsi que sur un prélèvement d'argile du substrat a fourni les mêmes éléments siliceux, à savoir des quartz cariés non roulés, fragments de grès fins et grès conglomératiques à ciment ferrugineux. Les données granulométriques sont également concordantes; il y a bien corrélation entre les pâtes employées pour les matériaux d'une part, et les argiles composant la motte et le substrat local d'autre part.

Les argiles locales résultent de l'altération du feldspath, composant majeur des micaschistes; seuls ont été préservés une partie des micas (biotite et muscovite) et le quartz. L'argile exploitée est donc une argile qualifiée de maigre, car peu plastique, et riche en micas ce qui la rend sensible au "feuilletage ". En cela les argiles altéritiques ont des caractéristiques bien différentes des argiles rencontrées dans les bassins sédimentaires mésozoïques (bassins Parisien et Aquitain), où elles sont en général nettement plus homogènes, car triées et granoclassées. Globalement, ces dernières
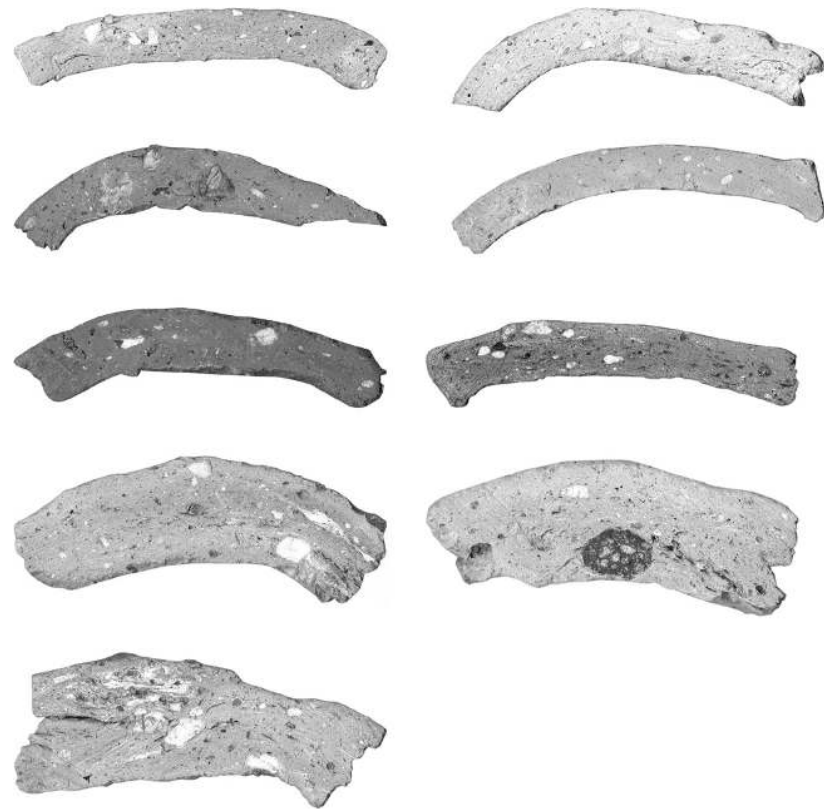

Figure 24 : (Voir planche couleur XXVII) Beaupréau, site de la Tufferie, échantillons représentatifs des types de pâtes rencontrés au sein de l'atelier.

Figure 24: (See colour plate XXVII) Beaupréau, the Tufferie site, representative samples of paste types from the workshop

sont plus plastiques et préférées pour un façonnage d'éléments plus fins, tels les carreaux de sol.

\section{Les terres cuites provenant de la structure du (ou des) four(s)}

Dans cette catégorie est rangée la trentaine de restes en terre cuite qui n’appartient pas à la famille des matériaux produits dans l'atelier. Il s'agit de fragments dont la morphologie est très variable, mais la plupart ont en commun de présenter une ou plusieurs surfaces concaves (fig. 25). Nombre d'entre eux ont aussi conservé des traces d'empreintes de doigts laissées pendant le façonnage. Ces restes sont de taille variée, de 5 à $15 \mathrm{~cm}$ avec des épaisseurs très diverses. L'un de ces fragments, le plus gros, montre aussi sur ses flancs des négatifs d'empreinte de tuiles creuses.

Quelques individus présentent des traces de sur-cuisson manifeste. La pâte utilisée semble la même que celle employée pour les matériaux produits eux-mêmes. C'est une argile hétérogène à tendance marbrée avec d'assez rares gros dégraissants siliceux; les couleurs vont du beige blanchâtre au rouge ocre.

Ces restes proviennent principalement des structures d'extraction F.363.1 et F.363.3 situées en dehors de l'enclos. La structure F.230.2 a également livré quelques gros éléments. 


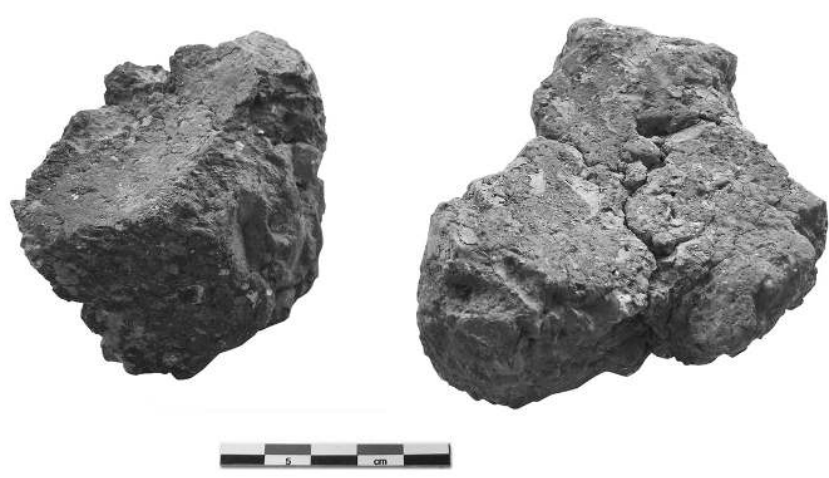

Figure 25 : (Voir planche couleur XXVII) Beaupréau, site de la Tufferie, éléments constitutifs d'un four (sole, paroi ou autre), issus de la structure F.363.3 (cliché J.-F. Nauleau).

Figure 25: (See colour plate XXVII) Beaupréau, the Tufferie site, construction elements from a furnace (floor, walls or other) from the feature F.363.3 (photo J.-F. Nauleau).

Compte tenu des caractéristiques présentées ici (traces de sur-cuisson, morphologie), il semble avéré que ces éléments peuvent être rattachés à une structure de cuisson.

Aucun four n'a malheureusement été observé directement dans l'atelier. Seuls des indices indirects permettent de penser qu'il(s) est (sont) situé(s) à proximité immédiate des vestiges reconnus, entre l'enclos et la tranchée $363^{15}$.

Les grandes quantités de fragments de parois de four ont été récoltées dans les niveaux supérieurs des comblements des fosses d'extraction en association avec des blocs de pierre : ceci suggère qu'il s'agit probablement de niveaux de démolition provenant des substructures des fours, piégés dans les fosses encore partiellement ouvertes. Ces restes peuvent être liés à l'abandon définitif de l'atelier ou à des phases de réfection des fours dont on sait combien ils doivent être entretenus régulièrement ${ }^{16}$.

La question de la nature et de la morphologie de ces fours reste entièrement posée. Un assez grand nombre a été rencontré sur des ateliers modernes. Il s'agit de structures quadrangulaires à tirage vertical. La chambre de chauffe, très souvent excavée, est constituée de deux couloirs séparés par un muret sur lequel viennent s'appuyer les voutains supportant la sole à claire-voie. Le tout est précédé d'un alandier généralement trapézoïdal. Le laboratoire est clos de murs munis d'une ouverture latérale. La nature du couvrement est inconnue, mais il est très probable que dans la plupart

15. La présence d'un réseau électrique aérien n'a pas permis d'effectuer les tranchées d'investigation souhaitées dans ce secteur (fig. 4).

16. La répétition des chocs thermiques occasionnés par les cycles de cuisson (aux alentours de 900-1000 ${ }^{\circ} \mathrm{C}$ ) détruit rapidement les maçonneries, voûtes et soles. Le caractère saisonnier de l'activité (arrêt hivernal) conjugué au fait que les fours ne sont pas couverts est un autre facteur aggravant leur fragilité. des cas, seuls des matériaux posés directement sur la charge en assurent la fonction.

Il est difficile de comprendre la place des fragments de terre cuite décrits ici dans le four. Les surfaces concaves évoquent des amorces de carneaux dans une sole perforée, mais la grande fragmentation des restes ne permet pas de valider l'hypothèse. Le plus gros fragment, qui présente des empreintes de tuiles, évoque quant à lui une paroi de four qui aurait été constituée d'argiles et de matériaux de rebuts.

Les découvertes de fours de tuilier sont relativement nombreuses à partir des XIV $\mathrm{X}^{\mathrm{e}} \mathrm{XV}^{\mathrm{e}}$ siècles : Soirans-Fouffrans (Côted'Or; Charlier, 1994), Paris (Dufaÿ, 1998), Genvry (Oise; Desachy, 1992), abbaye de Vauclair (Aisne; Source, 1975), Grisolles (Aisne; Galmiche et al., 2014), Gournay (Indre; Joly, Bouillon, 2012). En revanche, pour des périodes plus anciennes, on sait très peu de choses, et dans la région aucun atelier médiéval n'est connu. Il semble exclu qu'il puisse s'agir de fours en meule dont l'apparition semble plus tardive et, qui plus est, pour des régions plus septentrionales sur le territoire français (Thuillier, 2010; Peirs, 1979).

En définitive, on sait assez peu de choses sur les fours de l'atelier de la Tufferie. Ils devaient probablement être en partie excavés, et sont peut-être installés dans des fosses ayant servi à l'extraction, comme par exemple F.363.2/3.

Il est à noter que la totalité des fours étudiés jusqu’à présent, que ce soit en Normandie, Picardie ou Midi-Toulousain, ont des maçonneries constituées de tuiles plates ou de briques ${ }^{17}$, matériaux propres à cet usage car présentant des faces de pose. Or, dans le cas présent, les briques sont très minoritaires et les tuiles plates absentes ${ }^{18}$, tandis que les tuiles creuses, matériaux semble-t-il majoritairement produits dans l'atelier, ne peuvent pas être employées aisément. Les blocs de roche disponibles localement et rencontrés dans les comblements de structure sont également très impropres à la construction; ils ne sont pas affectés d'un réseau de diaclases et sont donc dépourvus de surfaces de pose planes. Toutes ces données convergent et laissent penser que l'argile devait être fortement impliquée dans la construction des fours.

\section{5. ÉLÉMENTS DE DATATION}

En premier lieu, notons que les structures médiévales présentent une cohérence d'ensemble qui se manifeste par l'absence de recoupement stratigraphique et par des orientations concordantes. C'est le cas par exemple du bâtiment probable F.229.1 et de la cave F.229.2. Ces indications ont

17. C'est le cas du remarquable four de Lignou-de-Briouze dans l'Orne (Dufournier, Flambard-Héricher, 1992).

18. L'aire de diffusion des tuiles plates est localisée approximativement sur le territoire du département de la Sarthe. 
évidemment une valeur relative, mais donnent malgré tout un indice d'occupation plutôt brève.

\section{Éléments issus de l'étude du mobilier céramique et des matériaux de construction}

La datation fournie par le mobilier céramique tourné est cohérente pour l'ensemble du lot, même si elle s'appuie sur un NMI très restreint. L'étude de la morphologie des bandeaux donne une fourchette située entre la seconde moitié du XII ${ }^{\mathrm{e}}$ et la première moitié du XIII ${ }^{\mathrm{e}}$ siècle (cf. $\$ 3$. Le mobilier céramique).

Le type de matériaux produits donne également quelques indications chronologiques. On peut en effet s'appuyer sur un travail de recensement en cours (Nauleau, à paraître) qui montre que les matériaux en terre cuite sont rares sur les sites de consommation avant le début du XIII ${ }^{\text {e }}$ siècle (cf. $\$$ 6. La nature de la production). Les tuiles creuses à crochet, par exemple, sont connues sur une trentaine de sites en Pays de la Loire et seules les églises du Loir sont datées, par des considérations architecturales, de la seconde moitié du $\mathrm{XII}^{\mathrm{e}}$ siècle. La plupart des autres sites montrent une diffusion au cours des $\mathrm{XIII}^{\mathrm{e}}$ et XIV ${ }^{\mathrm{e}}$ siècles.

\section{Datation 14C}

Une datation $14 \mathrm{C}$ a été effectuée sur des charbons de bois provenant de l'US 3 de la structure profonde F.229.2. Rappelons qu'il est probable que ces charbons de bois proviennent d'un assemblage de pièces de bois de type étagère, plancher, escalier ou autre élément de ce type. La datation obtenue est $870 \pm 30 \mathrm{BP}$, soit 1170 apr. J.-C. Les intervalles obtenus à deux sigma (95\% de probabilité) sont 1050 1090, 1120-1140, 1150-1220 apr. J.-C. À un seul sigma (68\% de probabilité), le seul intervalle retenu est 1160 1220 apr. J.-C ${ }^{19}$.

La datation à deux sigma est parfaitement conforme à la fourchette chronologique large fournie par l'étude du mobilier céramique. Mais plusieurs indices permettent de proposer une date limitée à la seule calibration à un sigma. C'est tout d'abord l'étude céramique elle-même qui propose une hypothèse plus serrée, limitée au seul XIII ${ }^{e}$ siècle, et c'est par ailleurs la connaissance (même imparfaite) de l'histoire de ces matériaux en terre cuite dans la région (cf. supra) qui autorise à retenir, comme hypothèse principale de datation, la fourchette 1160-1220 apr. J.-C.

19. Datation ${ }^{14} \mathrm{C}: 1160-1220$ à 1 sigma, 1050-1090, 1120-1140, 1150-1220 à 2 sigma (Beta Analytic Radiocarbon Dating Laboratory; Beta-360232).

\section{Caractérisation et mise EN PERSPECTIVE DE L'ATELIER DE TUILIER}

\section{Le site et ses marqueurs fonctionnels : activité artisanale stricte ou occupation mixte ?}

Au regard de la nature des vestiges, l'hypothèse d'une occupation mixte, c'est-à-dire conjuguant atelier et habitat peut être proposée. En effet, régionalement, plusieurs sites d'habitat contemporains ou légèrement plus tardifs sont structurés autour d'un enclos circulaire, ovoïde ou annulaire de même nature que celui-ci. C'est le cas des sites récents fouillés à Saint-Corneille (Sarthe; Guérin, 2013), et à Soulgé-sur-Ouette (Mayenne; Hervé, 2014), ou encore des sites de Tiercé (Maine-et-Loire; Guérin, Pétorin, 2006), et Vivy (Maine-et-Loire; Thooris, 2012). Sur ces différentes entités, les vestiges de bâtiments implantés au cœur de l'enclos ne sont guère plus denses ou plus nombreux que dans le cas présent. Par ailleurs, on remarque également le peu d'aménagements externes à l'enclos; les creusements ponctuels - fosse et trou de poteau - et les fossés structurants l'espace environnant sont rares.

Lexistence de structures excavées profondes en contexte d'habitat, si elles restent rares, sont avérées dans la région. Dans les Deux-Sèvres, le site de la Vallée de Faye (Bolle, 2012) a révélé l'existence d'un vaste souterrain ramifié placé sous un bâtiment en partie maçonné et situé au cœur d'un enclos annulaire; le site est occupé à partir de la fin du $\mathrm{x}^{\mathrm{e}}$ jusqu'au début du XII ${ }^{e}$ siècle. En Vendée, le site de Champ de Lise à Sainte-Hermine (Le Roux, 2011) a lui aussi montré une association entre un habitat et un souterrain pour un site occupé du $\mathrm{X}^{\mathrm{e}}$ jusqu'à la charnière des $\mathrm{XII}^{\mathrm{e}}$-XIII ${ }^{\mathrm{e}}$ siècles.

Par ailleurs, on sait que, en ce qui concerne les productions potières, dans la plupart des cas, des bâtiments d'habitat sont rencontrés en association avec les bâtiments techniques de tournage et de séchage, même si, en général, les indices matériels permettant une discrimination fonctionnelle restent rares. C'est le cas, par exemple, à Fyé en Sarthe pour un site potier des $\mathrm{XI}^{\mathrm{e}}-\mathrm{XII}^{\mathrm{e}}$ siècles ou encore pour l'atelier B. de Fontenay à Chartres-de-Bretagne en Ille-et-Vilaine (Fichet de Clairefontaine, Dufournier, 2006, p. 270-272 ${ }^{20}$ ).

Il apparait aussi clairement que l'artisanat tuilier et potier est presque toujours pratiqué en complément d'une activité agricole aussi bien au Moyen Âge (Fichet de Clairefontaine, Beuchet, 1996, p. 33) qu'aux époques moderne et contem-

20. En revanche, à Trémentines dans le Maine-et-Loire, le site de production de la Frétellière n'a pas révélé de structures domestiques associées aux différents fours de potiers qui ont produit entre le $\mathrm{vI}^{\mathrm{e}}$ et le milieu du $\mathrm{x}^{\mathrm{e}}$ siècle (Valais, 2012b). 
poraine ${ }^{21}$. Les deux activités sont complémentaires sur bien des points : l'exploitation des terres dans le cadre agricole permet l'extraction des argiles et la récolte du bois, tandis que les animaux de trait facilitent le transport et le foulage des terres et la livraison des matériaux produits (Audouin, 2002, p. 23).

En Bretagne, des sites à enclos annulaires et à activités mixtes sont connus; celui de la Ville d'Ahaut à Meillac (Illeet-Vilaine) est lié à un atelier d'exploitation du minerai de fer tandis que celui du Gué de Plélan à Plélan-le-Grand (Illeet-Vilaine) semble relever du même cas, avec présence d'une plate-forme servant d'assise à des bas-fourneaux de la fin du XIII ${ }^{\mathrm{e}}$ ou du début du XIv siècle (Brand'Honneur, 2001).

Tous ces éléments renvoient l'image d'un site d'habitat dont les occupants ont pu, à certaines périodes et de façon saisonnière, pratiquer un artisanat de la terre cuite. Ce qui n'exclut pas que certaines des structures présentes, telle la cave, soient intégralement dédiées à l'activité de l'atelier. En effet, sa morphologie évoque davantage un cellier de stockage qu'un souterrain à développement horizontal, tels qu'ils sont rencontrés dans les habitats décrits précédemment. La découverte de la motte d'argile est à cet égard révélatrice de son usage.

\section{La nature de la production}

En s'appuyant sur les restes de matériaux découverts dans le périmètre de l'atelier, on peut esquisser le profil de la production. Si les tuiles sont effectivement largement dominantes, ce sont les tuiles creuses sans crochet qui sont de loin les plus abondantes, seuls trois fragments de crochets ayant été mis au jour. Quant au "dérivé " de tegula, s'il est typologiquement très atypique et riche d'informations sur son origine culturelle, il n'a été collecté qu'en restes très réduits numériquement.

La brique est avérée dans l'atelier, mais les restes sont peu nombreux et on ne peut exclure un usage strictement interne (comme dans le cas des tuyaux de canalisation), dédié au seul four.

Les briques décorées sont remarquables et constituent un lot important régionalement. Leur destination n'est pour l'heure pas connue; l'hypothèse principale reste celle d'éléments de décors à usage interne.

Les tuyaux de canalisation, très grossièrement façonnés, semblent avoir été produits pour un usage propre au site

21. Jusqu'au milieu du $\mathrm{xx}^{\mathrm{e}}$ siècle dans les petits ateliers non industrialisés, l'activité ne s'est pratiquée que du milieu du printemps à la fin septembre. C'est l'impossibilité d'assurer correctement le séchage des matériaux l'hiver (crainte du gel principalement) qui contraint cette saisonnalité. (aménagement de la citerne). En revanche, aucun carreau de sol n’a été découvert.

Pour mettre en perspective ces données, on peut s'appuyer sur le travail de recensement en cours, des matériaux de construction en terre cuite médiévaux dans la région (Nauleau, à paraître). Celui-ci dresse un bilan de nos connaissances à partir d'un corpus d'une soixantaine de sites d'usage sur lesquels ces matériaux ont été mis en œuvre.

Même si de nombreux points restent à approfondir, compte tenu du peu d'intérêt porté à ces matériaux jusqu'à présent, les grandes lignes de ce paysage de la terre cuite au cours des $\mathrm{XII}^{\mathrm{e}}$-XIII ${ }^{\mathrm{e}}$ siècles semblent se dessiner. La tuile apparaît (ou réapparaît) à la toute fin $\mathrm{du} \mathrm{XII}^{\mathrm{e}}$ ou au début du XIII ${ }^{\mathrm{e}}$ siècle sous la forme de tuiles creuses à crochet sur la quasi-totalité du territoire, à l'exception de la partie nordouest de la région. Mais il faut attendre la seconde moitié $\mathrm{du} \mathrm{XIII}^{\mathrm{e}}$ siècle pour voir s'amorcer une véritable diffusion de cette tuile. Quant à la brique, si elle est présente dès le milieu du XIII ${ }^{\mathrm{e}}$ siècle, c'est bien timidement, en un petit module (environ $21 \times 10 \times 3 \mathrm{~cm})^{22}$ utilisé uniquement pour la cheminée (conduit, âtre, souche...) qui se rapproche déjà du futur format moderne. L'ensemble est accompagné par un nouveau matériau, glaçuré ou brut, le carreau de sol $^{23}$. Généralement, ces matériaux sont façonnés dans des argiles claires (kaolinitiques et alumineuses) très bien cuites.

La juxtaposition des données collectées à l'échelon régional et celles provenant de la tuilerie révèle donc des différences notables. Dans l'atelier, les matériaux produits témoignent d'une culture constructive mixte, associant tradition romaine et nouveauté médiévale. Sur les sites de consommation, le cortège de matériaux appartient clairement à une culture technique du second Moyen Âge.

Apparaissent ici, les contradictions entre un état des connaissances fondé sur un corpus de sites de consommation et les observations réalisées à l'échelle d'un atelier. Ce type de constatation a déjà été fait pour des sites de production romains : des matériaux atypiques découverts dans des ateliers, n'ont jamais été recensés sur les sites de consommation étudiés pourtant nombreux (Nauleau, 2013) ${ }^{24}$.

Ces différences mettent possiblement en lumière le caractère précoce de l'atelier, peut-être actif dès la seconde moitié du XII ${ }^{\mathrm{e}}$ siècle. S'il est résolument situé dans le second Moyen Âge, de par son contexte historique et socio-économique (rôle du commanditaire, cf. $\$ 6$. Le statut de l'atelier et $\$ 6$.

22. Ce format de brique de faible épaisseur sera dénommé « chantignolle » à partir de l'époque moderne.

23. Ces caractéristiques générales semblent largement partagées sur le territoire français (Chapelot, 2004, Chapelot et al., 2009).

24. On peut penser par exemple que les petites séries ou de façon plus générale, les matériaux plus complexes à produire, vont être surreprésentés car sujets à de plus nombreux ratés de production que les matériaux usuels. 
Les commanditaires potentiels et le bâti ancien à partir des sources écrites), sa production est en revanche encore imprégnée d'une culture technique antique ${ }^{25}$ qui va céder sa place sous peu à un nouveau cortège de matériaux. À ce titre, l'atelier de la Tufferie est un jalon régional important dans l'histoire de ces matériaux.

\section{Le statut de l'atelier}

Réfléchir au statut de l'atelier, c'est essayer de comprendre son insertion dans la société médiévale à la charnière des XII ${ }^{\mathrm{e}-}$ $\mathrm{XIII}^{\mathrm{e}}$ siècles. Rien de très facile compte tenu du peu d'éléments éclairant cet aspect à l'issue de l'étude des vestiges et du mobilier.

La présence du «sceau » au quadrupède sur les briques est un élément signifiant, mais comment l'interpréter? Si l'on considère ces briques comme probables éléments de décor, le sceau est à lier au commanditaire de la production. Si on les considère comme briques courantes simplement " décomptées " par l'artisan, il identifie le propriétaire de l'atelier. La première hypothèse est la plus vraisemblable, mais au reste, la question n'a peut-être qu'une valeur secondaire, dans la mesure où il est probable que le propriétaire de l'atelier et le commanditaire de la production ne faisaient qu'un seul individu. En effet, durant cette période précoce de l'histoire de la terre cuite médiévale, la production de matériaux de ce type ne répond pas à la demande d'un marché, mais à des commandes ponctuelles qui vont entraîner des productions épisodiques. Seul un commanditaire appartenant à une élite, qu'elle soit civile ou religieuse, était à même de susciter, au travers d'un projet de construction, la production de matériaux encore rares et de recruter des artisans capables de la réaliser. La tuile et la brique, absentes depuis plusieurs siècles, ne faisaient plus partie des traditions constructives.

La localisation de l'atelier n'apporte que des indications très relatives. En effet, on constate que celui-ci est situé en sommet de plateau dans les zones où la couverture argileuse est la plus épaisse, en dehors des placages éocènes riches en graviers, cailloutis et conglomérats. Cette implantation privilégiée ne semble rien devoir au hasard; l'abondance de la ressource parait être le facteur qui a prévalu. L'isolement de l'atelier n'est que géographique et n'éclaire en rien la nature de ses liens avec les groupes sociaux en place à cette époque.

Il est malaisé de vouloir préciser le statut de l'atelier à partir de ces données fragmentaires. Des études ont été faites pour des périodes légèrement plus tardives sur le territoire allemand aux XIII ${ }^{e}$ et XIV ${ }^{e}$ siècles (Lohrmann, 1986), et dans un grand nombre de cas, il apparaît que les abbayes et les

25. C'est le cas des rares ateliers connus pour la période du premier Moyen Âge, tel celui de Saran (Loiret; Jesset, 2014). ordres monastiques étaient les seuls à pouvoir apporter des investissements suffisants pour lancer la production et la rentabiliser.

En revanche, en Bourgogne, les tuileries sont ducales et répondent aux besoins ponctuels et locaux de la seigneurie (Chapelot, 1986). En Bretagne, l'influence seigneuriale a également été montrée dans le dynamisme de l'activité potière et tuilière (Fichet de Clairefontaine, Beuchet, 1996) au moins à la fin du Moyen Âge.

Mais on ignore quasiment tout de la question pour les périodes hautes (De Boüard, 1986) et singulièrement dans la région où aucun atelier de tuilier n'est connu.

\section{Les commanditaires potentiels et le bâti ancien à partir des sources écrites}

La recherche et l'identification du ou des édifices ayant bénéficié de matériaux en terre cuite dans cette période de la seconde moitié du XII ${ }^{\mathrm{e}}$ ou du début du XIII ${ }^{\mathrm{e}}$ siècle sont délicates, dans la mesure où il est difficile d'estimer l'ampleur de la diffusion autour de l'atelier. Néanmoins, compte tenu de l'absence de marché des matériaux en terre cuite pour la période, il est probable que la diffusion a dû rester locale. C'est pourquoi un recensement sur le territoire communal élargi a été réalisé.

Il est possible, au vu des sources disponibles, de brosser le tableau des commanditaires potentiels à l'échelle de Beaupréau et de ses environs immédiats entre le $\mathrm{XI}^{\mathrm{e}}$ et le $\mathrm{XIII}^{\mathrm{e}}$ siècle, afin de proposer des pistes concernant la destination des matériaux produits dans l'atelier. Trois groupes de membres de l'élite civile ou ecclésiastique peuvent être identifiés.

Le premier est, de façon évidente, la famille seigneuriale belloprataine. Le château de Beaupréau est évidemment une destination privilégiée pour de tels matériaux. Mais on ne sait rien du premier château médiéval, très probablement sur motte, ni de ceux qui ont suivi avant la reconstruction du château actuel vers le milieu du Xvi ${ }^{\mathrm{e}}$ siècle (fig. 26). Cette forteresse, dont le nom l'a finalement emporté sur le toponyme religieux, comme ce fut souvent le cas, s'inscrit dans un ensemble de places fortes destinées à rendre durable la domination angevine dans les Mauges en barrant la route des Poitevins. Plusieurs indices laissent penser que celle de Beaupréau fut bâtie dans les années 1020. Installé sur un éperon formé par le coteau abrupt de l'Èvre au sud et par un modeste affluent au nord-ouest, ce château fut doublé d'une enceinte à l'intérieur de laquelle se développa une agglomération. On sait que c'est un fidèle du comte Foulques

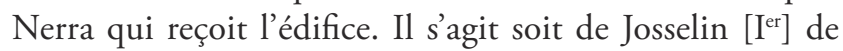
Rennes, soit de son fils Girois [I ${ }^{\mathrm{er}}$ ] (Véron, 2007). Les seigneurs de Beaupréau s'y firent construire une chapelle cas- 


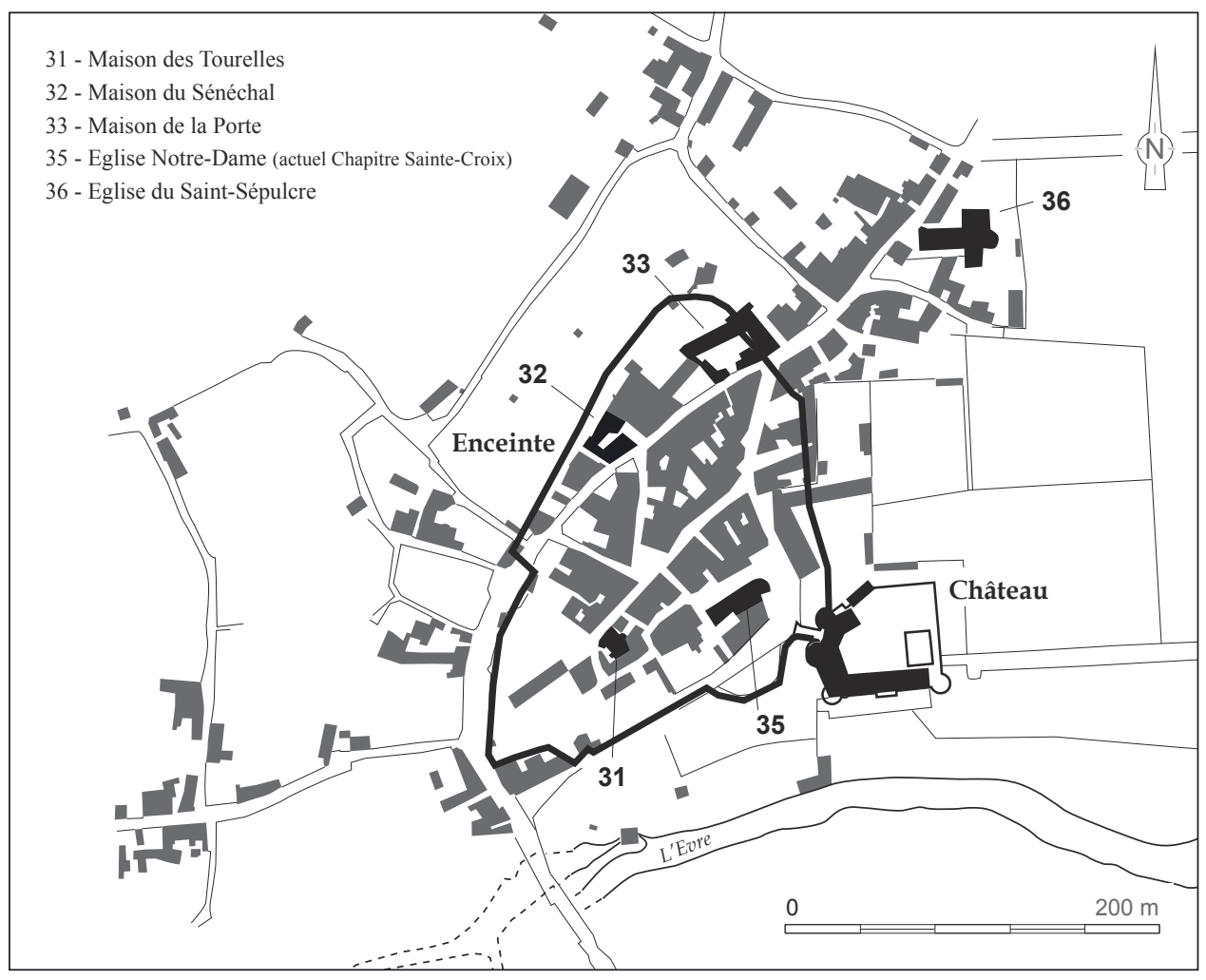

Figure 26 : Le château et l'enceinte de Beaupréau (cadastre ancien, Beaupréau, section E3, 1835, dessin J.-F. Nauleau). Figure 26: The castle and the enclosure at Beaupréau (old land register, section E3, 1835, infography J.-F. Nauleau). trale (" capella " attestée en 1062) dédiée à Notre-Dame qui devint par la suite l'église paroissiale (" ecclesia » en 1100) de la ville close. L'équipement religieux de la forteresse fut même augmenté dès les premières années du XII ${ }^{\mathrm{e}}$ siècle de la chapelle du Saint-Sépulcre, fondée par un prêtre nommé Odilier, qui échut également à l'abbaye Saint-Serge. Le château était déjà peuplé en 1062 quand Girois [II] de Beaupréau autorisa les moines de Saint-Serge à fonder un bourg à Saint-Martin, car l'acte précise qu'ils avaient l'autorisation d'attirer des hommes provenant de n'importe quel lieu à l'exception notable de son château. Même si aucun texte ne l'éclaire vraiment avant 1210 (burgi mei castelli de Bello Pratello), le bourg castral fut probablement assez attractif du fait de la sécurité qu'il procurait en plus de la proximité avec le pouvoir seigneurial. Marchés et foires, attestés dès l'époque du seigneur Orry, au XII ${ }^{\mathrm{e}}$ siècle, en renforçaient probablement l'attrait. Cependant, cette agglomération avec ses faubourgs ne débordait que très peu l'enceinte médiévale jusqu'à la fin du XviII ${ }^{\mathrm{e}}$ siècle (Cussonneau, 2002).

Deuxième source possible, les vassaux directs des seigneurs de Beaupréau ont peut-être été également " clients » de la tuilerie. En effet, si, au XI siècle, ils étaient logés dans le château pour en assurer la défense, ils en sont progressivement sortis, préférant s'installer au milieu de leurs domaines dans des demeures plus agréables, bien que souvent fortifiées, et qui ont elles-mêmes dû évoluer fortement au cours du
Moyen Âge. Ce qui pouvait n'être au départ qu'un édifice en bois sur motte est devenu progressivement un manoir en dur où les matériaux en terre cuite ont pu être utilisés. Le toponyme "Roche-Baraton" (fig. 27, n 26), attesté en 1223 (Véron, 2012), démontre qu'au moment où l'atelier était en activité, le transfert avait déjà eu lieu pour la famille "Baraton" fréquemment mentionnée au $\mathrm{XII}^{\mathrm{e}}$ siècle. Les restes d'un édifice médiéval et d'une chapelle du XvI siècle y étaient encore visibles au XIX ${ }^{e}$ siècle selon C. Port (Port, 1876, p. 277). On connaît en outre, le lieu d'implantation des principaux vassaux du seigneur de Beaupréau attestés du XI ${ }^{e}$ au XIII ${ }^{e}$ siècle. Il s'agit des Hayes-Gasselin à Andrezé (fig. 27, no 7), où le château du Xve siècle est en ruine mais reste encore imposant, et de l'Épinay-Greffier à la Chapelledu-Genêt (fig. 27, no 21) pour ne citer que les plus importants. La liste précise des vassaux est fournie dans l'aveu rendu au duc d'Anjou par le seigneur de Beaupréau Jean de Sainte-Maure, le 22 mars 1416 (Chronique de Beaupréau). Mais pour assurer leur « ligence ", c'est-à-dire leur service de garde, les vassaux devaient disposer d'une maison de ligence au sein de la ville close. Si l'on en croit ce même aveu, ils étaient au moins douze à avoir besoin d'une telle demeure. Les maisons de ligence que l'on peut observer aujourd'hui datent de la fin du Moyen Âge pour les plus anciennes, à l'image de la maison dite des Tourelles qui appartenait au chevalier du Mesnil-Bouteille, mais l'existence de trois 


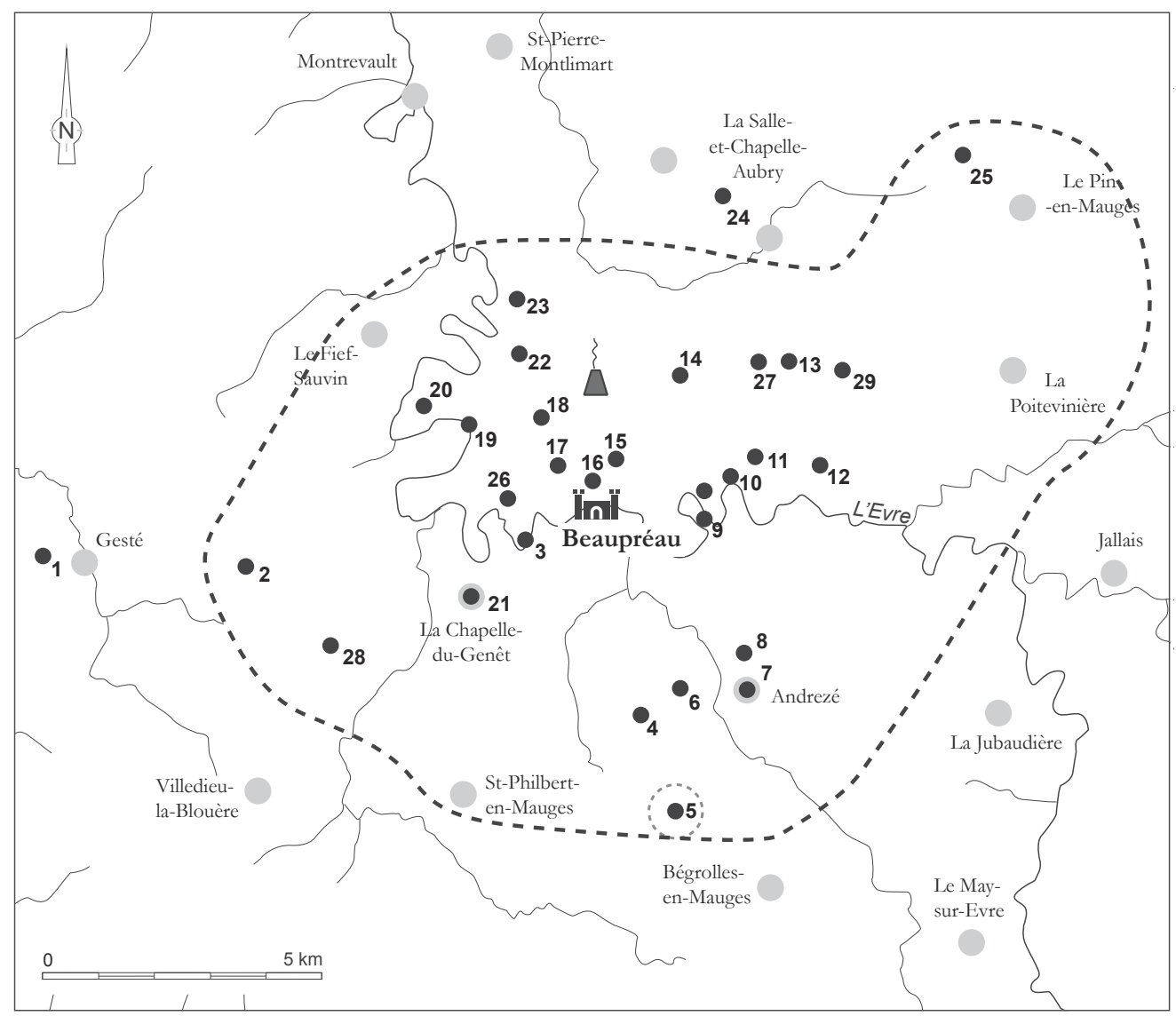

1 - Sauzaie (Salzeia)

2 - Les Aulnaies (Alnetas)

3 - Le Petit Coin (Cuneum)

4 - Les noues (Noas)

5 - La Lande Fleurie (Bois, Landa Floride)

6 - La terre des Landes (Landa)

7 - Andrezé (Andreziacus)

8 - La Guerche (Wirchia)

9 - Coin des Pierres Blanches? (Lapidibus Albis)

10 - Moulin de Pont Roseau (Petroso ou Perosel)

11 - Le Châtaignier (Castaneriis)

12 - La Moncoillère (Marcheillum ou Mercilliacum)

13 - La Bâte (Baata)

14 - La Bretonnière (Britunariam)

15 - Ouche du Pré Archer (Fontis Archerii)

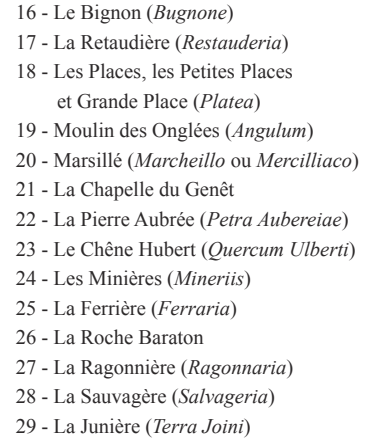

16 - Le Bignon (Bugnone)

17 - La Retaudière (Restauderia)

18 - Les Places, les Petites Places et Grande Place (Platea)

19 - Moulin des Onglées (Angulum)

20 - Marsillé (Marcheillo ou Mercilliaco)

21 - La Chapelle du Genêt

22 - La Pierre Aubrée (Petra Aubereiae)

23 - Le Chêne Hubert (Quercum Ulberti)

24 - Les Minières (Mineriis)

25 - La Ferrière (Ferraria)

26 - La Roche Baraton

27 - La Ragonnière (Ragonnaria)

28 - La Sauvagère (Salvageria)

29 - La Junière (Terra Joini)

Limite approximative

de la seigneurerie de Beaupréau graphy J.-F. Nauleau/T. Veron).

niveaux de caves superposés laisse penser que l'édifice actuel a des fondations plus anciennes (fig. 26, n 31). En tous cas, la généralisation de ces maisons doit coïncider avec le départ des vassaux pour des habitations plus excentrées, aux environs du XII ${ }^{\mathrm{e}}$ siècle. Par ailleurs, certains fidèles sont semblet-il restés à l'intérieur de l'enceinte, à l'exemple du sénéchal (fig. 26, $n^{\circ} 32$ ) et de la famille de la Porte dont la demeure est devenue la maison des enfants de chœur (fig. 26, n 33) au Xvi ${ }^{\mathrm{e}}$ siècle selon la Chronique de Beaupréau. Il est vrai qu'elle se trouvait justement à la porte principale de la ville de Beaupréau.
Enfin, les chapelles " privées » érigées par certains chevaliers bellopratains ont également pu recevoir des matériaux provenant de l'atelier de la Tufferie. Une chapelle SaintNicolas (fig. 28, n 30) est attestée au lieu que l'on appelle "Lescluseau » en 1239, à l'occasion de la fondation d'une chapellenie par le chevalier Pierre Ribot et son neveu Pierre du Vigneau. La Chronique de Beaupréau permet de localiser l'édifice aujourd'hui disparu. Elle mentionne en effet qu'à la fin $\mathrm{du} \mathrm{Xv}^{\mathrm{e}}$ siècle le fief dit du Sablier, planté en vignes, était voisin d'une chapelle Saint-Nicolas, et que ce fief joignait celui du Cluseau, nommé plus tard le Grain d'or. Une avenue qui part du parc du château, entre la ville close et le 


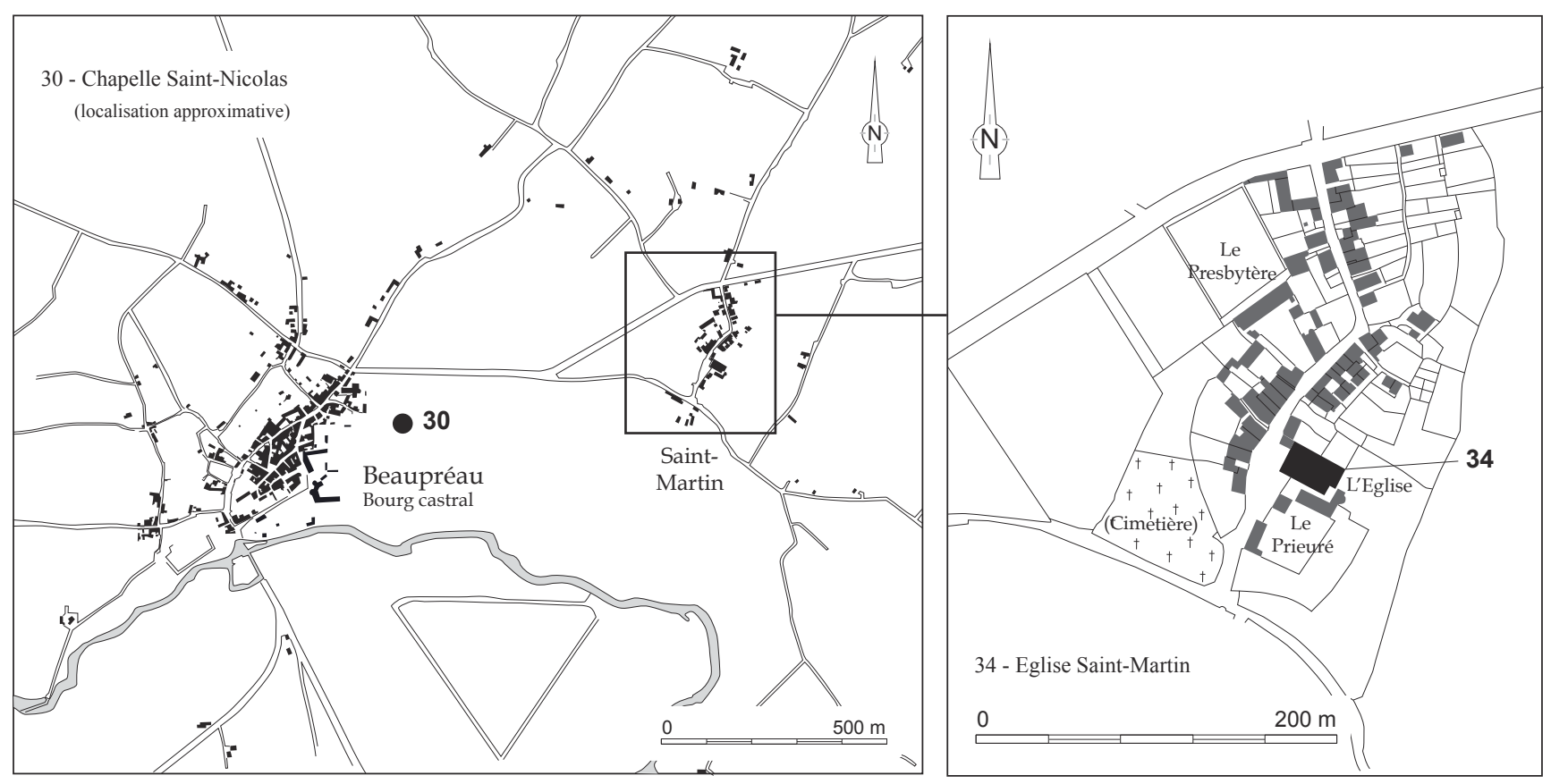

Figure 28 : Le village de Saint-Martin et son prieuré (cadastre ancien, Beaupréau, section E3 et D1, 1835; dessin J.-F. Nauleau). Figure 28: the village of Saint-Martin and its priory (old land register, Beaupréau section E3 and D1, 1835, infography J.-F. Nauleau).

bourg de Saint-Martin, perpétue le souvenir des vignes du "grain d'or ». La Chronique de Beaupréau précise en plus que ces terrains ont été depuis en partie enclavés dans le parc, ce qui circonscrit le périmètre où chercher l'ancienne chapelle Saint-Nicolas de Lescluseau.

Troisième et dernier groupe de commanditaires possibles, les religieux qui disposaient également de nombreux édifices. L'agglomération de Beaupréau est issue de la fusion de deux noyaux urbains. Le premier était situé autour de l'église Saint-Martin, le second étant le bourg castral à l'intérieur de l'enceinte, d'une manière tout à fait classique (Pichot, 2002). Le plus ancien des deux est probablement le premier puisque la dédicace à Saint-Martin est le signe d'une fondation précoce. Cette église (fig. $28, \mathrm{n}^{\circ} 34$ ) était le centre d'une vaste paroisse rurale qui préexistait certainement à l'érection du château. Elle fut donnée aux moines de Saint-Serge par le seigneur Girois [II] de Beaupréau qui les autorisa à fonder un bourg et à le peupler. La création d'un bourg ne signifie toutefois pas que l'église Saint-Martin se trouvait éloignée de toute habitation, mais elle est le signe d'une volonté d'accroître la densité du peuplement. L'acte de fondation du prieuré est intéressant par ailleurs, puisqu'il fait indirectement allusion aux matériaux de construction utilisés à l'occasion de l'implantation des moines. En effet, le seigneur Girois [II] cède aux Bénédictins pour la construction de leur réserve " autant que leur sera nécessaire " dans sa forêt des Landes-Fleuries (fig. 27, no 5). C'est donc le bois qui, selon toute probabilité, fut utilisé par les moines pour ériger leurs bâtiments. Mais l'acte de donation fait référence à un deuxième temps, celui de la dédicace de l'église Saint-Martin en 1062, en présence de l'abbé de Saint-Serge et de l'évêque d'Angers. Il faut peut-être l'interpréter comme l'indication selon laquelle l'église Saint-Martin fut reconstruite à cette époque. Une carte postale du XIx ${ }^{e}$ siècle (fig. 29), complétée par la description qu'en fait C. Port dans son dictionnaire (Port, 1876, p. 259), atteste en effet qu'un édifice de style roman contemporain de la période de création du prieuré fut construit. Cette dernière fut un succès comme le révèle la prospérité du prieuré Saint-Martin qui bénéficia d'un grand nombre de donations attestées par de nombreux actes conservés dans les archives de l'abbaye Saint-Serge. Il est donc plus que vraisemblable que l'implantation humaine en fut favorisée.

En plus des églises paroissiales à Beaupréau (SaintMartin, Notre-Dame et Saint-Sépulcre, fig. 26, nos 35 et 36), à Andrezé (Saint-Pierre), et à La Chapelle-du-Genêt (Notre-Dame), les moines de Saint-Serge possédaient une maison (domus monachorum) attestée avant 1190 (Véron, 2012). On a vu précédemment que le seigneur leur avait donné la possibilité de se fournir en bois dans la forêt de la Lande-Fleurie lors de la fondation du prieuré en 1062, mais cela n'est pas contradictoire avec l'adoption d'une couverture en tuiles. Il en est de même pour le petit édifice cultuel que les moniales de Saint-Sulpice-la-Forêt ont érigé 


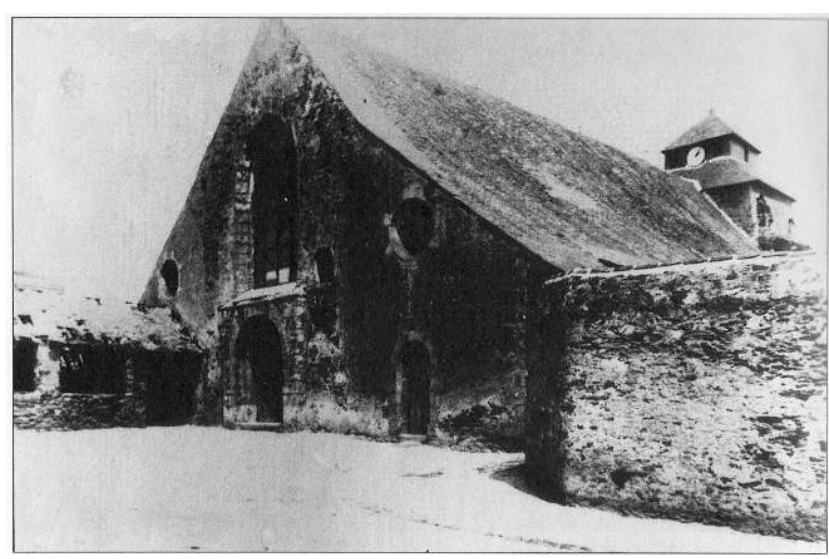

Figure 29 : L'église Saint-Martin dans son état roman (remaniée à l'époque moderne), aujourd'hui démolie (carte postale 1891, coll. privée)

Figure 29: The Romanesque church of Saint-Martin (rebuilt during the modern period), demolished (postcard 1891, private collection).

à la Pierre-Aubrée (fig. 27, $\mathrm{n}^{\circ}$ 22), avec sa maison (domus) et son enclos ou cloître (claustrum). Ce dernier exemple est d'autant plus intéressant que d'une part, on ne se situe qu'à 1,5 kilomètre de la Tufferie, et que d'autre part, la construction a été effectuée entre 1138, date à laquelle les seigneurs de Beaupréau et les moines de Saint-Serge donnent la possibilité aux moniales de fonder leur prieuré, et 1225, lorsque ces dernières sont autorisées à y retirer les sœurs qu'elles remplacent par deux chapelains, soit exactement au moment où fonctionnait l'atelier de la Tufferie.

L'étude des sources écrites n'a pas révélé de mention d'un atelier de tuilier sur le territoire étudié. En revanche, le recensement d'un corpus d'édifices ayant été susceptibles de recevoir les matériaux produits dans la tuilerie peut constituer le point de départ d'un travail de prospection visant à identifier sur les différents sites les témoins d'une telle production.

\section{Conclusion}

L'histoire de l'atelier médiéval de tuilier-briquetier de la Tufferie est relativement bien cernée, au moins dans ses grandes lignes, malgré la nature limitée des investigations archéologiques.

Au vu de nos découvertes, il a produit au tournant des $\mathrm{XII}^{\mathrm{e}}$-XIII ${ }^{\mathrm{e}}$ siècles, et pendant un laps de temps semblant assez bref, des tuiles de différentes natures, quelques briques et des éléments décoratifs, probablement destinés à un ou des édifices disposant d'un statut privilégié.

Concernant l'atelier lui-même, des analogies structurelles avec des sites d'habitat contemporains laissent penser que sa vocation était mixte, atelier de production de terre cuite et site domestique.

Seul un commanditaire appartenant à l'élite civile ou religieuse a pu susciter, au travers d'un projet de construction, la production de matériaux en terre cuite encore rares à cette époque et recruter des artisans capables de mener à bien cette entreprise.

Létude des sources écrites a montré que sur le territoire même de la commune de Beaupréau ou à proximité immédiate, de nombreux édifices contemporains de l'atelier ont pu recevoir des matériaux produits en son sein. Trois "groupes sociaux " ont été identifiés comme étant en position de jouer le rôle de commanditaire : la famille seigneuriale belloprataine elle-même, les vassaux directs qui érigent des demeures en dehors de l'enceinte castrale ainsi que des chapelles privées, et enfin les élites ecclésiastiques qui, au travers des prieurés et autres possessions de l'abbaye SaintSerge d'Angers, jouaient un rôle local important dans la dynamique constructive.

Au travers de l'exemple de l'atelier de Beaupréau, il s'avère que les matériaux en terre cuite médiévaux illustrent bien le renouveau constructif qui s'opère durant les XII ${ }^{e}$ et $\mathrm{XIII}^{\mathrm{e}}$ siècles, y compris sur des territoires ruraux.

Au-delà de ce rôle de marqueur, la présence de terres cuites témoigne de l'adoption de nouveaux matériaux et de nouvelles techniques constructives, illustrant la recrudescence de la circulation des hommes et des idées à cette époque.

\section{Bibliographie}

Audouin M., 2002 - «Le village potier du Fuilet, de la tradition à la modernité ", Les cahiers des Mauges, no 2, p. 21-29.

Bolle A., 2012 - Villiers-en-Plaine (Deux-Sèvres), " La Vallée de Faye ", in Valais A. (dir.), L'habitat rural au Moyen Âge dans le Nord-Ouest de la France, t. 2, Notices, Rennes, PUR, coll. "Archéologie et Culture », p. 405-416.

Brand'Honneur M., 2001 - Manoirs et châteaux dans le comté de Rennes. Habitat à motte et société chevaleresque (XI'-XII siècles), Rennes, PUR.

Снapelot O., 1986 - "Les tuileries ducales en Bourgogne $\left(\mathrm{XIV}^{\mathrm{e}}-\mathrm{XV}^{\mathrm{e}}\right.$ siècles) : l'apport des textes à la connaissance des bâtiments ", dans Terres cuites architecturales au Moyen Âge, Mémoires de la Commission départementale d'Histoire et d'Archéologie du Pas-de-Calais, t. XXII, Arras, p. 23-32.

Chapelot O., 2004 - « La terre cuite architecturale dans le bâtiment médiéval ", dans Bessac J.-C. et al., La construction - Les matériaux durs : pierre et terre cuite, édition augmentée, Paris, Errance, coll. «Archéologiques », p. 149-167. 
Chapelot J., Сhapelot O. et Rieth B. (dir.), 2009 - Terres cuites architecturales médiévales et modernes, Caen, Publications du CRAHM.

Charlier F., 1994 - «Soirans-Fouffrans, la Tuilerie (Côte-d'Or) : un atelier de terre cuite, $\mathrm{XV}^{\mathrm{e}}-\mathrm{XVII}^{\mathrm{e}}$ siècles ", Archéologie médiévale, t. XXIV, p. 301-366.

Chauvin Y., 1997 - Cartulaires de l'abbaye Saint-Serge et SaintBach d'Angers (XI et XII siècles), Angers, Presses de l'université d'Angers, 2 vol.

Cussonneau B., 2002 - La Ville de Beaupréau, Reflets, Patrimoine de Maine-et-Loire, Angers, Conseil général de Maine-et-Loire.

De BoüArd M., 1986 - «Préface ", dans Terres cuites architecturales au Moyen Âge, Mémoires de la commission départementale d'Histoire et d'Archéologie du Pas-de-Calais, t. XXII, Arras, p. 5-6.

Desachy B., 1992 - "Observations archéologiques sur un four de tuilier moderne à Genvry (Oise) ", Revue archéologique de Picardie, ${ }^{\text {os }} 1-2$, p. 143-153.

Dubillot X., 2003 - "Étude du mobilier ", in Guerin F., La Chapellière, La Chaize-le-Vicomte (Vendée), Rapport de fouille archéologique, Cesson-Sévigné, Inrap GO, p. 123-164.

Dubillot X., 2008 - Beaupréau, ZAC Actiparc Centre Manges, tranche 1, Rapport de diagnostic archéologique, CessonSévigné, Inrap GO.

DufaŸ B., 1998 - «La croissance d'une ville : les tuileries parisiennes du faubourg Saint-Honoré ", in VAN Ossel P. (dir.), Les jardins du Carroussel (Paris). De la campagne à la ville : la formation d'un espace urbain, Documents d'archéologie française, $\mathrm{n}^{\circ} 73$, série Archéologie préventive - Grand Louvre, Paris, Maison des sciences de l'homme, p. 261-310.

Dufournier D. et Flambard-Hericher A.-M., 1992 - « Un four de briquetier du XVIII ${ }^{\mathrm{e}}$ siècle à Lignou-de-Briouze (Orne) ", Revue archéologique de l'Ouest, nº 9, p. 179-186.

Duhamel du Monceau H.-L., Fourcroy C.-R. et Gallon J.-G., 1763 - L'art du tuilier et du briquetier, Paris, Académie royale des sciences, vol. XXVI.

Fichet de Clairfontaine F. et Beuchet L., 1996 - «L'artisanat céramique breton au $\mathrm{Xv}^{\mathrm{e}}$ siècle : potiers et tuiliers ", in FICHET de Clairfontaine F. (dir.), Ateliers de potiers médiévaux en Bretagne, Paris, Éd. de la MSH, coll. « Document d'archéologie française; 55 ", p. 30-40.

Fichet de Clairfontaine F. et Dufournier D., 2006 - « La maison du potier du XI ${ }^{\mathrm{e}}$ au XVII ${ }^{\mathrm{e}}$ siècle dans la France du NordOuest ", in Cadre de vie et manière d'habiter (XII'-XVI siècle), Publications du CRAHM, Caen, p. 267-273.

Galmiche T., Blary F., Buccio V. et Desplanque G., avec la coll. de Legros V., 2014 - "Les tuileries médiévale et moderne du prieuré fontevriste du Charme à Grisolles (Aisne) ", Revue archéologique de Picardie, $\mathrm{n}^{\text {os }} 1-2$, p. 209-243.

Goutal M., 1996 - "Tuiles creuses sur fortes pentes en Lorraine ", Bulletin monumental, t. 15, p. 16-17.
GuÉRIn F., 2013 - Saint-Corneille, "La Chapelle », Sarthe, Rapport de fouille archéologique, Cesson-Sévigné, Inrap GO.

Guérin F. et Petorin N., 2006 - Tiercé, Le Chemin des Halles, Les Tardivières, Maine-et-Loire, Rapport de fouille archéologique, Cesson-Sévigné, Inrap GO.

Herve C., 2014 - Soulgé-sur-Ouette (Mayenne), La Corbinière des Attelés, Rapport de fouille archéologique, Guérande, ArchéoLoire.

JEsSET S., 2014 - «La production de terre cuite architecturale durant le haut Moyen Âge à Saran (Loiret) : entre tradition et modernité ", SFECAG, Actes du Congrès de Chartres, Marseille, p. 177-196.

Joly S. et Bouillon J., 2012 - «Un four de terre cuite architecturale de la fin du Moyen Âge ou de l'époque moderne à Gournay (Centre, Indre) ", Revue archéologique du Centre de la France, no 51 , p. 245-269.

Le Guevellou R., 2013 - Beaupréau, Parc d'activités AnjouActiparc Centre Mauges, tranche 2, Maine-et-Loire, Rapport de diagnostic archéologique, Cesson-Sévigné, Inrap GO.

Le Roux F., 2011 - Sainte-Hermine (Vendée), Champ de Lise : une nécropole et un enclos seigneurial de l'époque médiévale dans le Bas-Poitou, Rapport de fouille archéologique, Cesson-Sévigné, Inrap GO.

Lohrmann D., 1986 - "Remarques sur quelques tuileries et briqueteries cisterciennes de l'Allemagne du Nord-Est (XIII ${ }^{\mathrm{e}}$ $\mathrm{XIV}^{\mathrm{e}}$ siècles) ", in Terres cuites architecturales au Moyen Âge, Mémoires de la commission départementale d'Histoire et d'Archéologie du Pas-de-Calais, t. XXII, Arras, p. 17-22.

Morera-Vinçotte I., 2012 - « Premières synthèses sur les productions céramiques de sites de consommation en milieu rural en Pays de la Loire du $\mathrm{v}^{\mathrm{e}}$ au $\mathrm{Xv}^{\mathrm{e}}$ siècle ", in VAlais A. (dir.), L'habitat rural au Moyen Âge dans le Nord-Ouest de la France, t. 1, Synthèses, Rennes, PUR, coll. Archéologie et Culture, p. 177-224.

Nauleau J.-F., 2009 - "Les matériaux de couverture en terre cuite ", in Valais A., Précigné (Sarthe) Manoir du PlessisRoland, Rapport de diagnostic archéologique, Cesson-Sévigné, Inrap GO, p. 33-42.

Nauleau J.-F., 2012 - "Le mobilier de mouture ", in Valais A. (dir.), L'habitat rural au Moyen Âge dans le Nord-Ouest de la France, t. 1, Synthèses, Rennes, PUR, coll. Archéologie et Culture, p. 235-252.

Nauleau J.-F., 2013 - «Les matériaux de construction en terre cuite d'époque romaine dans l'ouest des Pays de la Loire. Premier bilan ", Revue archéologique de l'Ouest, n 30, p. 223259.

Nauleau J.-F., 2013b - "Les matériaux de construction en terre cuite ", in Valais A., Juigné-sur-Sarthe (Sarthe) les Touches, Rapport de fouille archéologique, Cesson-Sévigné, Inrap GO, p. 116-131. 
Nauleau J.-F., à paraître - « Les tuiles et les briques au Moyen Âge en Pays de la Loire : un état de la question ", Revue archéologique de l'Ouest.

NAveAu J., 1984 - «La céramique à "œil de perdrix” et la production de La Hardelière à Laval (Mayenne) ", Archéologie médiévale, XIV, p. 169-219.

Pastoureau M., 2004 - Une histoire symbolique du Moyen Âge occidental, La librairie du XXI ${ }^{\mathrm{e}}$ siècle, Paris, Seuil.

PeIrs G., 1979 - La terre cuite. L'architecture en terre cuite de 1200 à 1940, Liège, Pierre Mardaga éditeur.

Ріснот D., 2002 - Le Village éclaté. Habitat et société dans les campagnes de l'Ouest au Moyen Âge, Rennes, PUR.

PorT C., 1876 - Dictionnaire historique, géographique et biographique du Maine-et-Loire, t. 2.

"Sources », 1975 - «Un four de tuilier médiéval à l'abbaye de Vauclair (Aisne) ", Cahiers archéologiques de Picardie, p. 69-76.

Thooris C., 2012 - "Vivy (Maine-et-Loire), Le Perray ", in VAlais A. (dir.), L'habitat rural au Moyen Âge dans le Nord-Ouest de la France, t. 2, Notices, Rennes, PUR, coll. "Archéologie et Culture ", p. 295-304.
Thuillier F., 2010 - « La cuisson des briques en meule : un procédé artisanal oublié ", Archeologia, no 474, p. 50-58.

Ulisse N., 2008 - Salernes. De la terre à la céramique, Edisud.

Valais A., 2012a - "Typologie des constructions ", in Valais A. (dir.), L'habitat rural au Moyen Âge dans le Nord-Ouest de la France, t. 1, Synthèses, Rennes, PUR, coll. "Archéologie et Culture ", p. 85-98.

Valais A., 2012b - "Trémentines, la Frétellière ", in Valais A. (dir.), L'habitat rural au Moyen Age dans le Nord-Ouest de la France, t. 2, Notices, Rennes, PUR, coll. "Archéologie et Culture ", p. 233-245.

Veron T., 2007 - L'intégration des Mauges à l'Anjou au XI siècle, Limoges, Presses universitaires de Limoges.

VERON T., 2012 - Les seigneuries angevines (XIF-début du XIIT siècle). L'exemple de Beaupréau, mémoire de master 2 sous la direction de Jean-Michel Matz, université d'Angers.

Wyns R., Clément J.-P., Lardeux H., Gruet M., Moguedet G., Biagi R. et Ballèvre M., 1998 - Carte géologique de la France (1/50000), feuille Chemillé (483), Orléans, BRGM. 
Zasummenfassung: Beaupréau (Maine-et-Loire), la Tufferie. Eine mittelalterliche Ziegelwerkstatt im Bereich der Mauges (Maine-et-Loire, Frankreich) - Die mittelalterliche Ziegelwerkstatt von La Tufferie wurde anlässlich einer Baggerprospektion im Bereich von Beaupréau, einer Gemeinde im Naturraum der Mauges (Maine-et-Loire) entdeckt. Die Ziegelei wird durch eine ovale bis ringförmige Einhegung gekennzeichnet, die etwas mehr $20 \mathrm{~m}$ im Durchmesser aufwies. In ihrem Inneren belegen diverse Pfostenlöcher die Existenz von einem oder von mehreren Gebäuden. In diesem Bereich wurde zudem ein mehr als 2,5 m eingetiefter Befund teilweise freigelegt und dokumentiert. In dem möglichen Keller wurde ein Haufen unbearbeiteten Tons entdeckt, bei dem es sich um das Rohmaterial zur Ziegelherstellung gehandelt haben wird. Außerhalb der Einhegung können die nachgewiesenen zahlreichen tiefen Gruben unterschiedlicher Form, die in die tonigen, alterierten Ablagerungen eingetieft worden waren, Materialentnahmegruben darstellen. Die im Rahmen der Prospektion durchgeführten begrenzten Untersuchungen haben es leider nicht gestattet, einen oder mehrere Ziegelöfen nachzuweisen. Trotzdem gestatten es zablreiche Elemente der rotverziegelten Ofenwandung, die in den außerhalb der Einhegung entdeckten Gruben gefunden wurden, die Position des Ziegelofens ungefähr zu lokalisieren. Die nachgewiesenen archäologischen Befunde und ihre Organisation sowie Analogien mit zeitgleichen Siedlungen erlauben es anzunehmen, dass diese Fundstelle eine doppelte Funktion erfüllt haben muss: Ziegeleiwerkstatt und Siedlungsbereich. Die Ziegelei produzierte innerhalb eines relativ kurzen Zeitabschnittes während des 12. und 13. Jahrhunderts n. Chr. Ziegel unterschiedlicher Formen, darunter auch eine abgewandelte Art tegula, die in diesem Kontext ungewöhnlich erscheint, sowie verschiedene Backsteine. Ferner wurden einige bemerkenswerte Dekorelemente aus gebranntem Ton entdeckt, die möglicherweise für ein privilegiertes Bauvorhaben bestimmt waren. Lediglich ein Auftraggeber, der zur zivilen oder religiösen Elite jener Zeit gehörte, wird anlässlich eines Bauvorhabens die Produktion solcher Ziegelelemente, die in jener Epoche sehr selten sind, gewünscht haben. Nur ein derartiger Auftraggeber wird ferner in der Lage gewesen sein, die entsprechenden Handwerker, die sie herstellen konnten, zu rekrutieren. Eine Auswertung der im Kopialbuch des Klosters von Saint-Serge et Saint-Bach überlieferten Dokumente hat gestattet, verschiedene soziale Gruppen zu identifizieren, die die Rolle der möglichen Auftraggeber und Bauherren für ein derartiges Vorhaben übernommen haben könnten. Die Auswertung hat mehrere Bauwerke nachweisen können, die zeitgleich zur vorgestellten Ziegelwerkstatt existiert haben müssen und die eventuell die Bestimmungsorte der in der Werkstatt hergestellten Ziegel waren. Weitere Prospektionen, die an diesen Plätzen durchgeführt werden sollten, gestatten möglicherweise in Zukunft, weitere Funde dieser Materialgruppe zu machen.

Schlüsselwörter : Mittelalter, ringförmige Einhegung, Baumaterial, Formziegel, Werkstatt, Produktion, Ziegelei, Ziegel, Backstein, Dekor, Ziegelstempel. 